Florida International University FIU Digital Commons

$11-14-2017$

\title{
Drug Candidate Discovery: Targeting Bacterial Topoisomerase I Enzymes for Novel Antibiotic Leads
}

Shayna Sandhaus

Florida International University, ssand008@fiu.edu

DOI: $10.25148 /$ etd.FIDC004005

Follow this and additional works at: https:// digitalcommons.fiu.edu/etd

Part of the Biochemistry, Biophysics, and Structural Biology Commons, and the Chemistry Commons

\section{Recommended Citation}

Sandhaus, Shayna, "Drug Candidate Discovery: Targeting Bacterial Topoisomerase I Enzymes for Novel Antibiotic Leads" (2017). FIU Electronic Theses and Dissertations. 3561.

https://digitalcommons.fiu.edu/etd/3561 


\section{FLORIDA INTERNATIONAL UNIVERSITY}

Miami, Florida

DRUG CANDIDATE DISCOVERY: TARGETING BACTERIAL TOPOISOMERASE I ENZYMES FOR NOVEL ANTIBIOTIC LEADS

A dissertation submitted in partial fulfillment of the

requirements for the degree of

DOCTOR OF PHILOSOPHY

in

CHEMISTRY

by

Shayna Sandhaus

2017 
To: Dean Michael R. Heithaus

College of Arts, Sciences, and Education

This dissertation, written by Shayna Sandhaus, and entitled Drug Candidate Discovery: Targeting Bacterial Topoisomerase I Enzymes for Novel Antibiotic Leads, having been approved in respect to style and intellectual content, is referred to you for judgment.

We have read this dissertation and recommend that it be approved.

David Becker

Niclas Engene

Fenfei Leng

Yuan Liu

Yuk-Ching Tse-Dinh, Major Professor

Date of Defense: November 14, 2017

The dissertation of Shayna Sandhaus is approved.

Dean Michael R. Heithaus College of Arts, Sciences, and Education

Andrés G. Gil

Vice President for Research and Economic Development and Dean of the University Graduate School

Florida International University, 2017 


\section{DEDICATION}

I dedicate this dissertation to my family: to my parents, who encouraged me and took care of me (and my children!) throughout my graduate career; to my siblings, who were always sympathetic and willing to help out; to my in-laws, who would fly down from New York the moment I asked; to my children, who always challenged me to be better and to do better; and to my husband, Alex, without whom none of this work would be possible. I love you all beyond words. 


\section{ACKNOWLEDGMENTS}

Science is a collaborative effort. The combined results of several people working together is often much more effective than could be that of an individual scientist working alone.

—John Bardeen, from his second Nobel Prize Banquet speech (10 Dec 1972)

It was not the doing of any one man; it involved the collaboration of scores of scientists from many different lands.

—J. Robert Oppenheimer, New York Times Sunday Magazine (20 Oct 1957)

This work could not have been done without the help of many people, scientists and non-scientists alike. First, I would like to thank my committee members for sticking with me through the years. Their input was invaluable, and I learned so much from all of them. Secondly, I want to thank my lab mates. Everyone working in Dr. Tse-Dinh's lab was helpful to me in some way, be it with help setting up an experiment, starting a cell culture over the weekend, or just having a friendly face to talk to. To our lab manager Arasu: his guidance keeps this whole lab running. Without him, I am sure we would all have been lost. Next, I would like to thank the FIU Research Initiative for Scientific Enhancement (RISE) fellowship for offering me funding in my last year of graduate work. It certainly made my life easier! Dr. Lickliter, Claudia Balzan, and David Felix do amazing work. To our collaborators: Dr. Alvin Holder at Old Dominion University; Dr. Greg Welmaker and Marc Giulianotti from Torrey Pines; and Dr. Prem Chapagain from the physics department, thank you for collaborating. My work is largely collaborative, 
and this research wouldn't exist without them. Last, but certainly far from least, I want to thank my mentor, Dr. Yuk-Ching Tse-Dinh. I consider myself the luckiest graduate student on the planet because of Dr. Tse-Dinh. She is knowledgeable in all areas, she is always available to help, and most of all, she is always understanding. Thank you, Dr. Tse-Dinh. 


\section{ABSTRACT OF THE DISSERTATION \\ DRUG CANDIDATE DISCOVERY: TARGETING BACTERIAL TOPOISOMERASE \\ I ENZYMES FOR NOVEL ANTIBIOTIC LEADS}

by

Shayna Sandhaus

Florida International University, 2017

Miami, Florida

\section{Professor Yuk-Ching Tse-Dinh, Major Professor}

Multi-drug resistance in bacterial pathogens has become a global health crisis. Each year, millions of people worldwide are infected with bacterial strains that are resistant to currently available antibiotics. Diseases such as tuberculosis, pneumonia, and gonorrhea have become increasingly more difficult to treat. It is essential that novel drugs and cellular targets be identified in order to treat this resistance. Bacterial topoisomerase IA is a novel drug target that is essential for cellular growth. As it has never been targeted by existing antibiotics, it is an attractive target. Topoisomerase IA is responsible for relieving torsional strain on DNA by relaxing supercoiled DNA following processes such as replication and transcription. The aim of this study is to find novel compounds that can be developed as leads for antibiotics targeting bacterial type IA topoisomerase. Various approaches were used in order to screen thousands of compounds against bacterial type IA topoisomerases, including mixture-based screening and virtual screening. In the mixture-based screen, scaffold mixtures were tested against the M. tuberculosis topoisomerase I enzyme and subsequently optimized for maximum potency and selectivity. The optimized compounds were effective at inhibiting the enzyme at low 
micromolar concentrations, as well as killing the tuberculosis bacteria. In a virtual screen, libraries with hundreds of thousands of compounds were screened against the E. coli and M. tuberculosis topoisomerase I crystal structures in order to find new classes of drugs. The top hits were effective at inhibiting the enzymes, as well as preventing the growth of M. smegmatis cells in the presence of efflux pump inhibitors. Organometallic complexes containing $\mathrm{Cu}(\mathrm{II})$ or $\mathrm{Co}$ (III) were tested as well against various topoisomerases in order to determine their selectivity. We discovered a poison for human type II topoisomerase that has utility as an anticancer agent, as it killed even very resistant cell lines of breast and colon cancer. The Co(III) complexes were found to inhibit the bacterial topoisomerase I very selectively over other topoisomerases. The various methods of drug discovery utilized here have been successful at identifying new classes of compounds that may be further developed into antibiotic drugs that specifically target bacterial type IA topoisomerases. 


\section{TABLE OF CONTENTS}

CHAPTER

PAGE

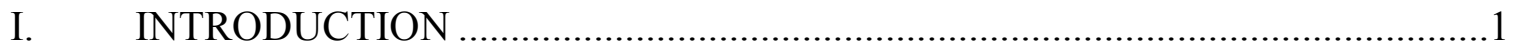

A. ANTIBIOTIC RESISTANCE: THE GLOBAL HEALTH CRISIS...1

B. BACTERIAL TOPOISOMERASES: A SOLUTION .........................

C. BACTERIAL TYPE IA TOPOISOMERASES …….......................10

D. APPROACHES TO DRUG DISCOVERY ....................................16

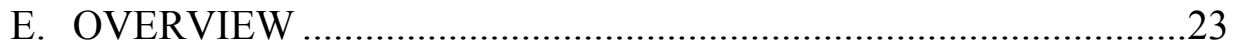

II. CHAPTER 1: USE OF MIXTURE-BASED SCREENING TO TARGET MYCOBACTERIUM TUBERCULOSIS TOPOISOMERASE I.........................25

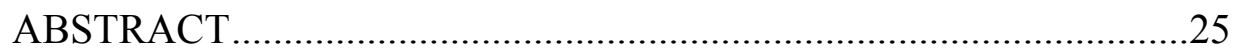

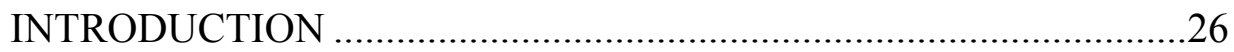

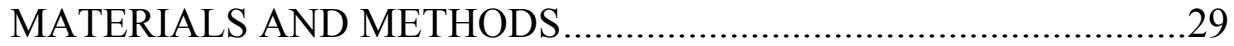

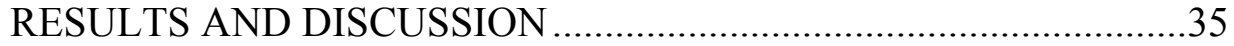

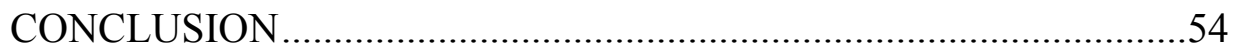

III. CHAPTER 2: DISCOVERY OF NOVEL BACTERIAL TOPOISOMERASE I INHIBITORS BY USE OF IN SILICO AND IN VITRO ASSAYS …….............57

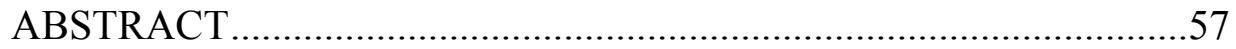

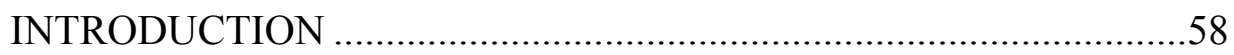

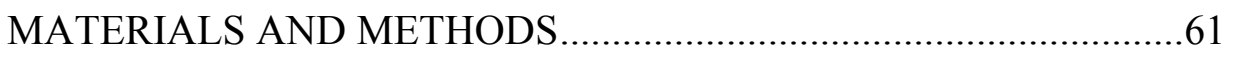

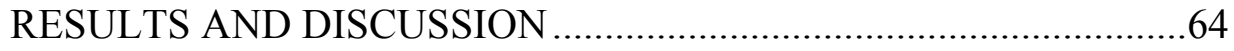

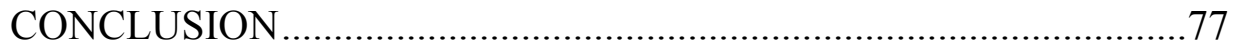

IV. CHAPTER 3: SELECTIVITY OF ORGANOMETALLIC COMPLEXES

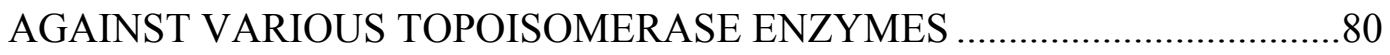

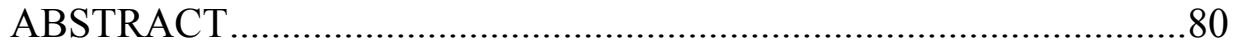

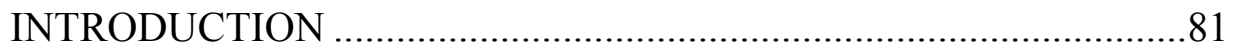

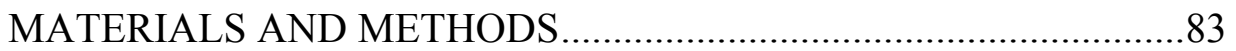

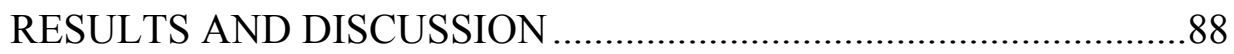

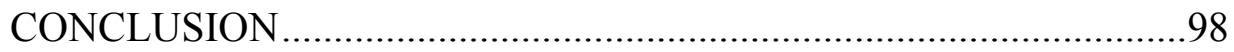

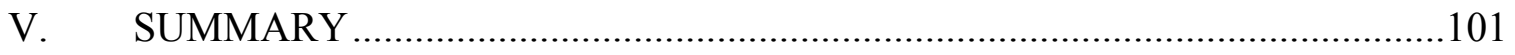

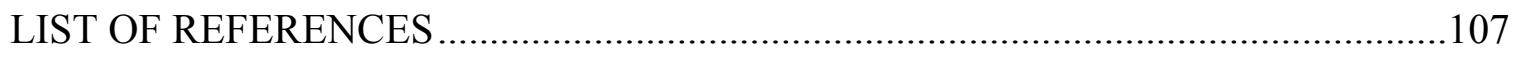

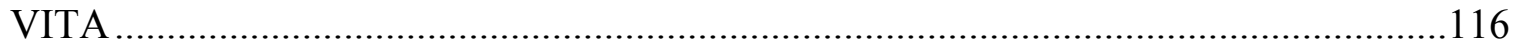




\section{LIST OF TABLES}

TABLE

PAGE

INTRODUCTION

I.1. Types, classes, and subfamilies of topoisomerases 8

CHAPTER 1

1.1. Information on TPI-2471 library: R1, R2, R3 substitutions and $\mathrm{IC}_{50}$ values for

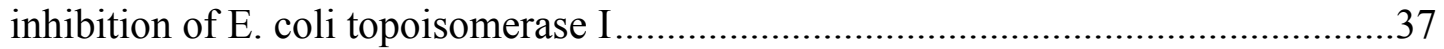

1.2. Antimycobacterial activity of potent MtbTopI inhibitors......................................40

1.3. Effect of MtbTopI overexpression on MICs of select 2471 inhibitors .......................41

1.4. TPIMS hits are selective inhibitors of bacterial topoisomerase I ............................44

1.5. Information on TPI-2580 library: R1, R2, R3 substitutions and $\mathrm{IC}_{50}$ values for inhibition of M. tuberculosis topoisomerase I ......................................................4

1.6. Most potent and selective inhibitors from TPI-2580 library .................................49

1.7. Effect of MtbTopI overexpression on MICs of select 2580 inhibitors ......................50

\section{CHAPTER 2}

2.1. $\mathrm{IC}_{50}$ values of Asinex hit compounds against MtbTopI and HTOPI

2.2. $\mathrm{IC}_{50}$ values of Chembridge hit compounds against MtbTopI, HTOPI, and E. coli

DNA gyrase

2.3. MIC values for antibacterial activity of identified MtbTopI inhibitors against M+ and Mnol strains.

2.4. MIC and $\mathrm{IC}_{50}$ values of top Specs compounds

CHAPTER 3

3.1. MIC and $\mathrm{IC}_{50}$ values of cobalt-thiosemicarbazone complexes 


\section{LIST OF FIGURES}

FIGURE

PAGE

INTRODUCTION

I.1. Timeline of developing antibiotic resistance ....................................................

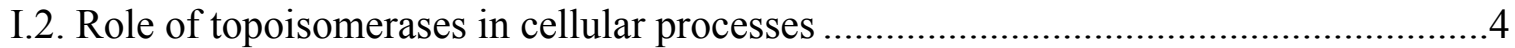

I.3. Mechanism of action of topoisomerase .............................................................. 6

I.4. Bacterial type IA topoisomerase mechanism ...................................................... 11

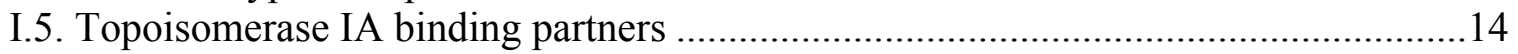

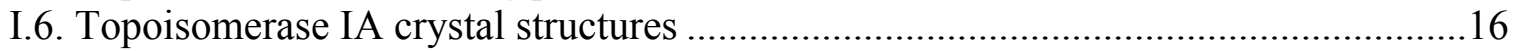

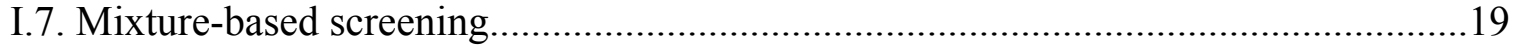

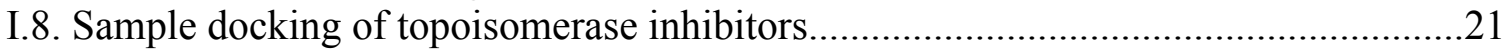

\section{CHAPTER 1}

1.1. TPIMS scaffold 2229 selectively inhibits bacterial type I topoisomerase.

1.2. Effect of MtbTopI overexpression on bactericidal activity of topoisomerase I inhibitors.

1.3. TPIMS hits are selective inhibitors of bacterial topoisomerase I

1.4. Top compounds do not prevent MtbTopI from binding to DNA oligonucleotides ....51

1.5. TPIMS hit compounds prevent MtbTopI from cleaving DNA..... .53

\section{CHAPTER 2}

2.1. Molecular dynamics studies opened the DNA-binding pocket on MtbTopI .65

2.2. Structures of Asinex compounds identified from in silico screening and in vitro MtbTopI assay

2.3. Tertiary amide moiety on Asinex hits interacts with key residues ...........................68

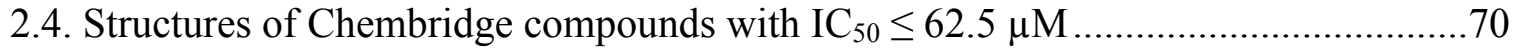

2.5. Selective inhibition of MtbTopI by Chembridge hit compounds .............................72

2.6. Chembridge hits do not prevent MtbTopI from binding to DNA oligonucleotides ...75

2.7. Inhibition of EcTopI relaxation activity by Specs compound 168 ..........................76

2.8. Structures of Specs compounds identified from in silico screening and in vitro MtbTopI assay

\section{CHAPTER 3}

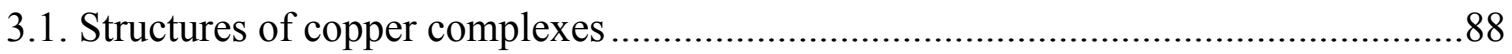

3.2. Inhibition of human topoisomerase II $\alpha$ relaxation activity by copper complexes......89

3.3. Increase in plasmid DNA cleavage by human topoisomerase II $\alpha$ in the presence

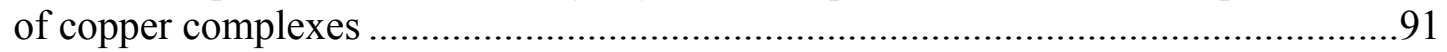

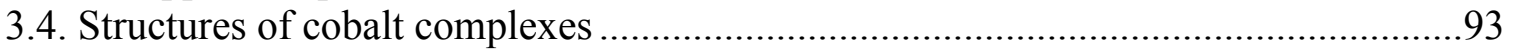

3.5. Cobalt(III) complex can inhibit EcTopI at low concentrations ...............................94

3.6. DNA cleavage by MtbTopI decreases in the presence of cobalt complexes ..............98 


\section{ABBREVIATIONS AND ACRONYMS}

ATP

CADD

DMF

DMSO

DNA

DTT

E. coli

EcTopI

EDTA

HTOPI

HTOPII

$\mathrm{IC}_{50}$

kDNA

LBN

MIC

MtbTopI

MD

MDR-TB

MRSA

M. smegmatis

M. tuberculosis
Adenosine triphosphate

Computer-aided drug discovery

Dimethylformamide

Dimethylsulfoxide

Deoxyribonucleic acid

Dithiothreitol

Escherichia coli

E. coli topoisomerase I

Ethylenediaminetetraacetic acid

Human topoisomerase I

Human topoisomerase II $\alpha$

Half maximal inhibitory concentration

Kinetoplast DNA

Lysogeny broth with sodium chloride

Minimum inhibitory concentration

M. tuberculosis topoisomerase I

Molecular dynamics

Multi-drug resistant tuberculosis

Methicillin-resistant S. aureus

Mycobacterium smegmatis

Mycobacterium tuberculosis 
$\mathrm{OD}_{600}$

PAINS

PY

S. aureus

SDS

TB

TZ

TPIMS

UV
Optical density at $600 \mathrm{~nm}$

Pan-assay interference compounds

Phosphotyrosine

Staphylococcus aureus

Sodium dodecyl sulfate

Tuberculosis

Thioridazine

Torrey Pines Institute for Molecular Studies

Ultraviolet 


\section{INTRODUCTION}

\section{A. ANTIBIOTIC RESISTANCE: THE GLOBAL HEALTH CRISIS}

The emergence of drug-resistant strains of bacterial pathogens is a global problem. According to the World Health Organization, antibiotic resistance is present in every single country around the globe, and its effects can be devastating (World Health Organization, 2016a). Healthcare costs skyrocket when confronted with resistant bacteria, as patients require longer hospital stays, more expensive drugs, and additional tests. More troubling than the fiscal aspect of resistance is that without antibiotics, our way of life would change drastically. Major surgeries would not be possible, as the risk of infection would be too high. Cancer patients, AIDS patients, and other immunocompromised people such as infants and the elderly would be at an increased risk of life-threatening infections (Friedman et al., 2016). Minor, common infections, like urinary tract infections, have become so resistant that there are countries where more than half of all patients do not respond to fluoroquinolone antibiotics, the most widely used treatment (World Health Organization, 2016a). There were 10.4 million new cases of tuberculosis (TB) reported in 2015, and 480,000 new cases of multidrug-resistant tuberculosis (MDRTB). Cases of MDR-TB are resistant to at least two of the most powerful first-line drugs

used for TB treatment, isoniazid and rifampicin. With an estimated death toll of 1.4 million people in 2015, TB remains one of the top ten causes of death globally (World Health Organization, 2016b). In short, in the war against bacterial pathogens, we are losing (Alanis, 2005; Carlet et al., 2012). 
There are many factors that contribute to the rapid evolution of antibiotic resistance. The overuse of antibiotics is a huge factor - a recent report from the Centers for Disease Control and Prevention reported that $30 \%$ of antibiotic prescriptions in ambulatory patients were inappropriate (Fleming-Dutra et al., 2016). Uneducated patients demand antibiotic prescriptions from their doctors without realizing the damage they can potentially cause. Some countries do not even require a prescription to obtain antibiotics, promoting excessive overuse. The abuse of antibiotics has long been warned against, and epidemiological studies have shown a direct correlation between antibiotic consumption and the proliferation of resistant bacteria (Nature Editorial, 2013). Antibiotics wipe out the susceptible bacteria, leaving behind only resistant strains to procreate and thrive (Ventola, 2015). Poor governance and corruption can play a major role in the development of resistance as well (Collignon et al., 2015).

There are solutions being proposed for these social and political factors, including the appointment of antibiotic stewards in hospitals to ensure antibiotics are prescribed responsibly, and global meetings to discuss resistance. In September 2016, global leaders met in the United Nations to discuss antimicrobial resistance. As only the fourth time in the history of the United Nations that a health problem was discussed in the General Assembly, the severity of the problem is highlighted (World Health Organization, 2016c). These are all solutions that fall outside the scope of the present body of work. However, there are other ways of combatting antibiotic resistance, namely, the discovery of novel drugs and drug targets.

Bacteria generally become resistant to drugs by developing a mutation in the drug's cellular target. For example, fluoroquinolones have become less effective since 
their targets, DNA Gyrase and Topoisomerase IV, have become mutated in a way that the drugs can no longer bind to them (Hooper, 2001). Through horizontal gene transfer, bacteria can also share plasmids that confer resistance, as seen with some carbapenem and colistin resistant strains of Escherichia coli (Liu et al., 2016; Poirel et al., 2016). A way to address the issue of resistance is by finding new drugs that target novel enzymes and cellular processes (Clatworthy et al., 2007). If the bacteria have never been exposed to a specific new class of drugs, resistance would take longer to develop. In the past, new drugs were created all the time that were simply slightly modified versions of previous drugs. Antibiotic classes such as penicillin and sulfonamides have been around so long that resistance to similar kinds of drugs is generally swift (Figure I.1), with antibiotic resistant strains emerging rapidly in hospitals (Ventola, 2015). For all of the above reason, the discovery of novel drug targets and novel drug structures is of utmost importance.

Antibiotic deployment

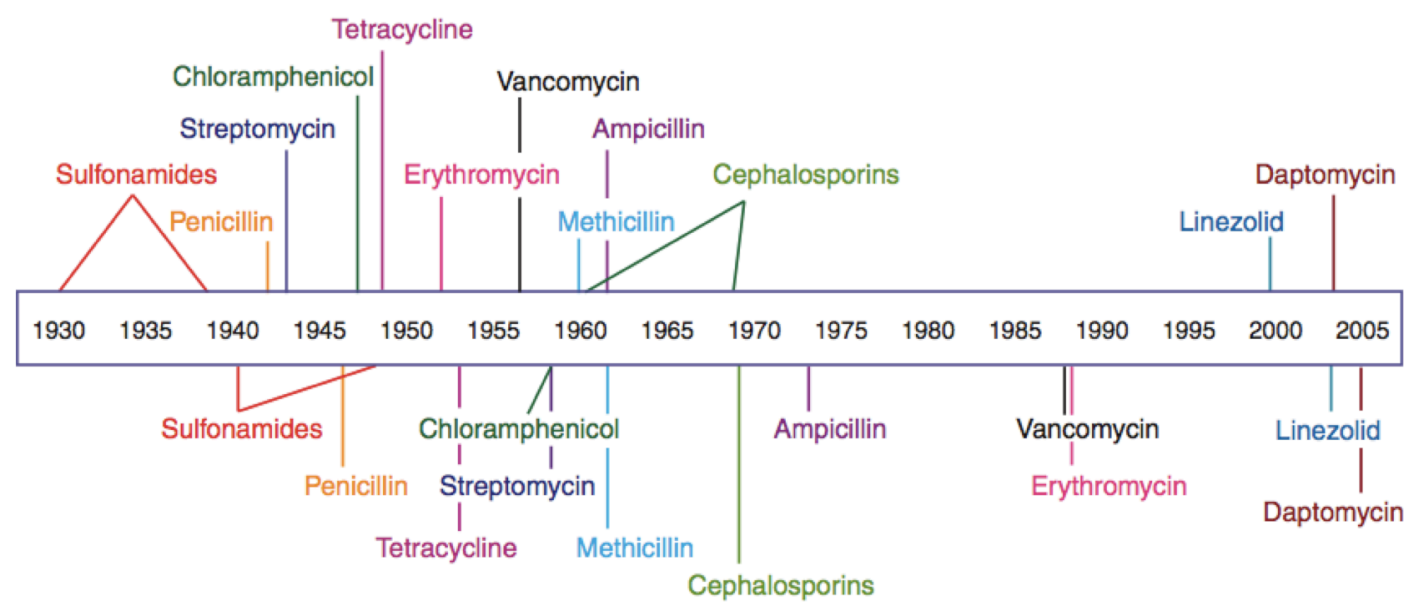

Antibiotic resistance observed

Figure I.1. Timeline of developing antibiotic resistance: Emergence of resistant strains of bacteria on the basis of early reports in literature (Clatworthy et al., 2007). 


\section{B. BACTERIAL TOPOISOMERASES: A SOLUTION}

As mentioned above, antibiotic resistance is a global threat that must be addressed as quickly as possible. The need for novel drugs and drug targets is urgent. One such novel drug target is bacterial topoisomerase I.

Topoisomerases are essential enzymes that are present in all kingdoms of life. They are responsible for resolving all the topological barriers that can arise from the superhelical structure of deoxyribonucleic acid, DNA (Vos et al., 2011; Wang, 2002). During cellular processes such as DNA replication or transcription, the DNA is unwound by the replication or transcription fork in order to separate and expose the bases within (Figure I.2). Such unwinding activity causes much torsional stress on the DNA structure, and the strain can create many problems for the cell. Aside from aiding in relieving the torsional strain during replication and transcription, topoisomerases also help with maintaining the genome integrity, in DNA repair pathways, and in Holliday-junction resolution (Branzei and Foiani, 2010).

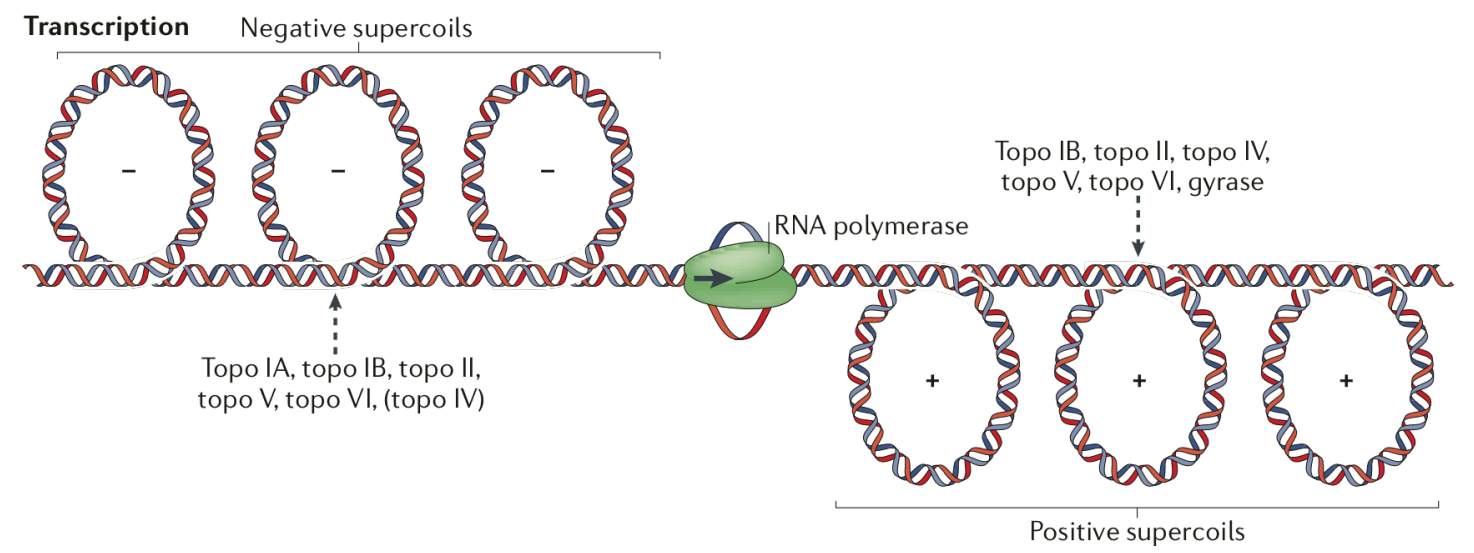

Figure I.2. Role of topoisomerases in cellular processes: Cellular processes such as DNA transcription can cause the formation of positive DNA supercoils ahead of the fork, and negative DNA supercoils behind the transcription complex. Topoisomerases are responsible for relieving the torsional strain caused by supercoiling (Vos et al., 2011). 
All topoisomerases have the same basic mechanism of action. All possess an active-site tyrosine residue that acts as a nucleophile to attack the phosphodiester backbone of DNA (Wang, 1996). The enzyme then becomes covalently linked to the DNA. Type I topoisomerases have one active site to cleave a single strand of DNA, while type II topoisomerases have two active sites on two polypeptides to attack doublestranded DNA. The phosphotyrosine (PY) bond that is formed covalently links the DNA to the enzyme, causing a break on the DNA (Figure I.3). The polarity of the break can either leave a 5' end or 3' end of DNA, depending on the classification of the topoisomerase. The enzyme can then rotate the non-covalently linked strand or pass another DNA strand or duplex through the break, again depending on the type of topoisomerase. The strand or duplex passage causes the linking number of the DNA to change, either winding or unwinding the DNA in order to restore the correct topology (Vos et al., 2011; Wang, 1996; Wang, 2002). Type I enzymes change the linking number by factors of 1, while type II enzymes change the linking number by factors of 2 . The topoisomerase then religates the DNA and the enzyme is released to carry out further reactions if necessary. In this manner, topoisomerases are responsible for maintaining the integrity of the DNA by not allowing it to become tangled, too supercoiled, or too underwound. 
a)

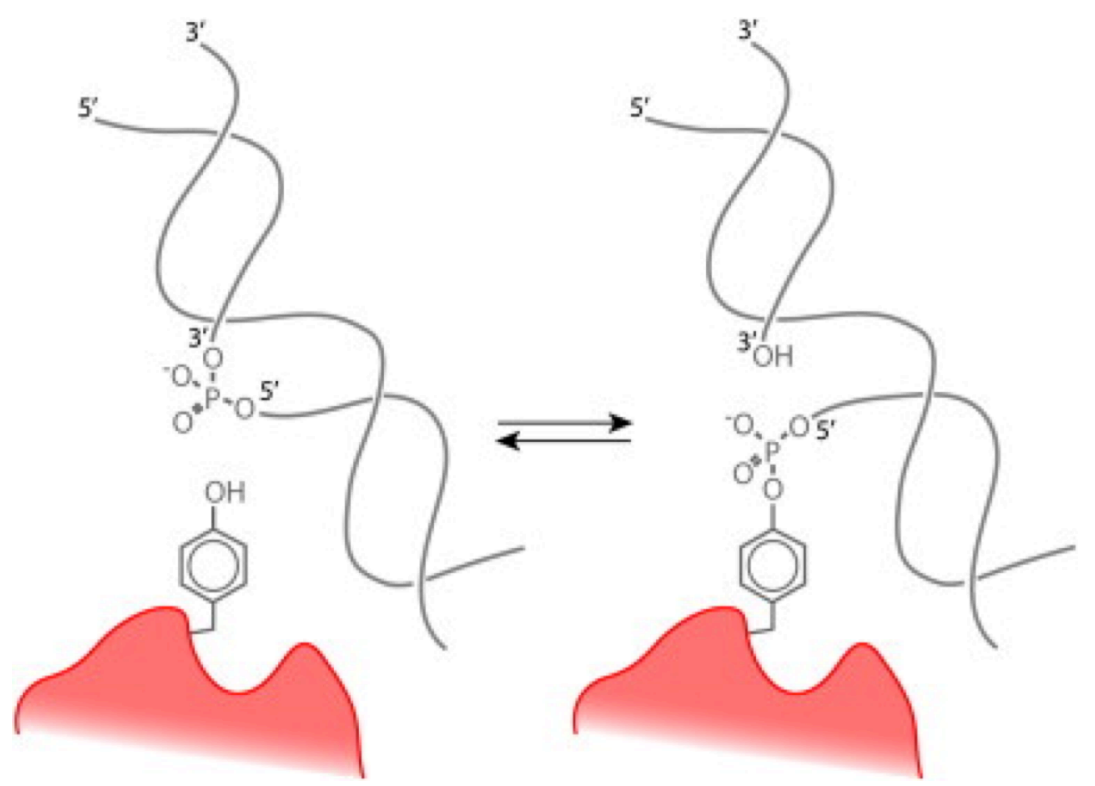

b)

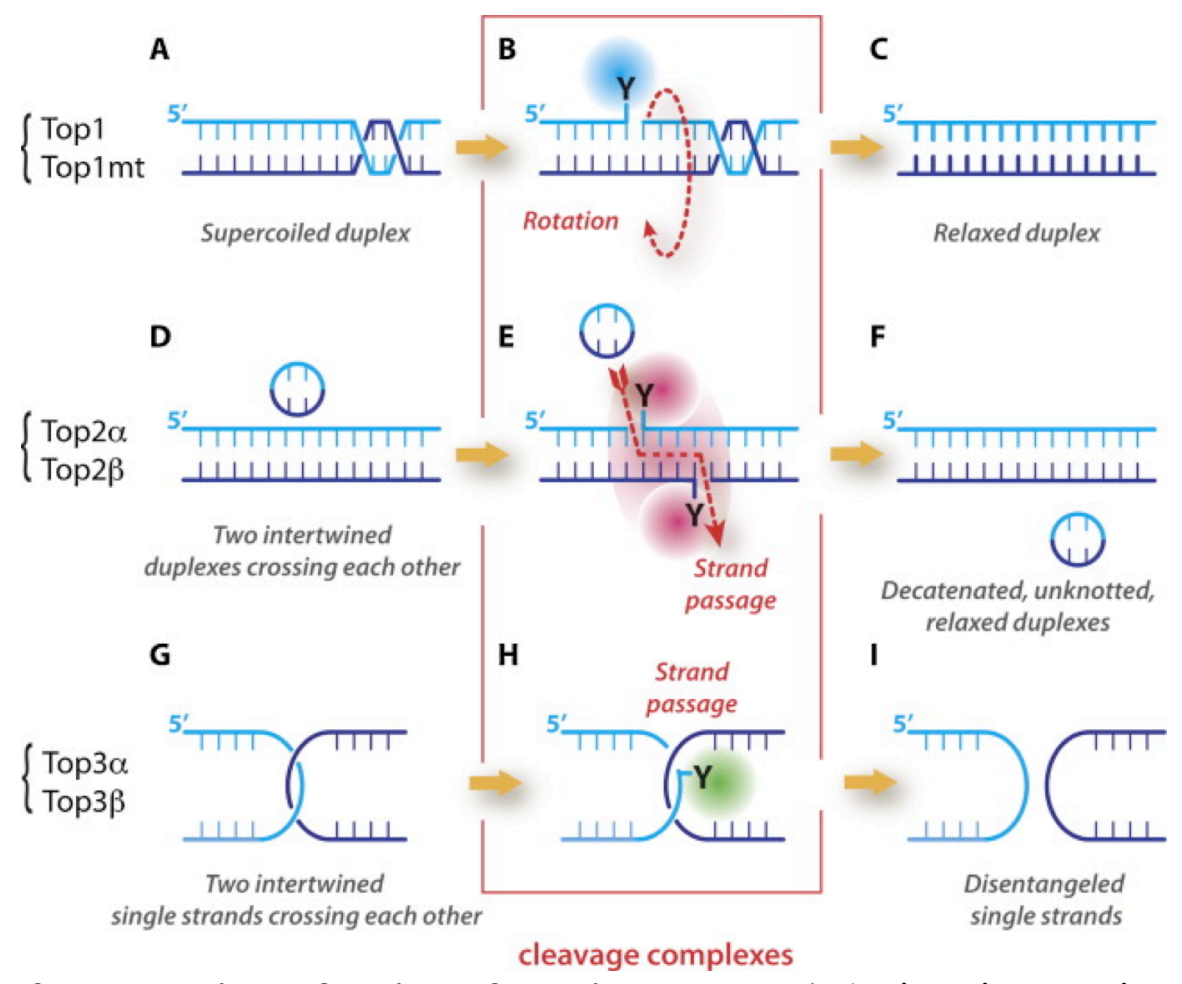

Figure I.3. Mechanism of action of topoisomerase: a) Active-site tyrosine residues attack the phosphodiester backbone of DNA in order to form a covalent DNA-enzyme intermediate. Shown is an example of a type IA mechanism (Viard and de la Tour, 2007). b) Classes of topoisomerases have different modes of untangling DNA, either through rotation of the free strand or passage of a DNA duplex through the break (Pommier et al., 2014). 
As was briefly touched on earlier, topoisomerases can be divided into two basic groups: type I and type II. Type I enzymes cause one single-stranded break on the DNA, while type II enzymes create a double-stranded break (Vos et al., 2011). Their cellular roles are very different as a result of their different mechanisms. Topoisomerases can be further classified by the polarity of their phosphate linkage- 5 ' phosphate links are classified as type IA or IIA, and 3' phosphate links are type IB or IIB (Champoux, 2001). Topoisomerases can be broken down into further categories and subfamilies on the basis of their structures.

Different organisms have various types of topoisomerases (Table I.1). For example, in the model organism Escherichia coli, there are four different types of topoisomerase present: Topoisomerase I and III are both type IA, and DNA Gyrase and topoisomerase IV are both type IIA. While some overlap of their functions is present, it appears that each topoisomerase enzyme has its own specific role in the cell: DNA Gyrase is able to generate negative supercoils on relaxed DNA, while topoisomerase IV is better at decatenating and relaxing negatively supercoiled DNA (Champoux, 2001). The type IA topoisomerases also have distinct roles that are discussed more in depth in following sections. 
Table I.1. Types, classes, and subfamilies of topoisomerases

\begin{tabular}{|c|c|c|c|}
\hline Type & $\begin{array}{l}\text { Polarity } \\
\text { of bond }\end{array}$ & Representative Members & Drugs? \\
\hline IA & 5'-PY & $\begin{array}{l}\text { Bacterial topoisomerases I and III, } \\
\text { Yeast topoisomerase III, } \\
\text { Mammalian topoisomerase III } \alpha \text { and III }\end{array}$ & None \\
\hline IB & 3'-PY & $\begin{array}{l}\text { Eukaryotic topoisomerase I, } \\
\text { Mammalian mitochondrial } \\
\text { topoisomerase I }\end{array}$ & Anticancer \\
\hline IIA & $5^{\prime}-\mathrm{PY}$ & $\begin{array}{c}\text { Bacterial Gyrase and topoisomerase IV, } \\
\text { Yeast topoisomerase II, } \\
\text { Mammalian topoisomerase II } \alpha \text { and II }\end{array}$ & $\begin{array}{c}\text { Anticancer, } \\
\text { antibiotic }\end{array}$ \\
\hline
\end{tabular}

As may be apparent upon review of their mechanism, topoisomerases are extremely important enzymes. Without them, cellular functions would fail. DNA replication and transcription would not be possible, because at a certain point the DNA would be too tightly coiled for the fork to unravel further. Topoisomerases are also interesting because as important as their mechanism is, it also leaves the cell vulnerable for as long as the covalent intermediate lasts. In cases where the topoisomerase becomes trapped on the DNA, there are specific enzymes whose purpose is to excise the enzyme from the DNA and process the $3^{\prime}$ or $5^{\prime}$ end of the DNA. These enzymes are called tyrosyl-DNA-phosphodiesterases, and they come in two types as well: TDP1 is responsible for processing trapped topoisomerase I linked to the 3'-end of DNA, while TDP2 processes trapped topoisomerase II linked to the 5'-end of DNA (Pommier et al., 2014).

Breaks along the DNA can lead to cell growth arrest or even apoptosis, and so the completion of the topoisomerase's work is essential. Any disruption of the activity, be it 
before or after the reaction has begun, can be lethal to the cell (Pommier, 2013). Essentiality is what makes topoisomerases attractive drug targets-disrupting or inhibiting the activity of the enzymes can prove to be lethal to the cells. The lethal effect applies when targeting cancer cells or bacterial cells. Since the discovery of topoisomerases in 1971 (Wang, 1971), there have been a number of anticancer and antibiotic drugs that specifically target topoisomerases.

Among the most famous anticancer drugs targeting topoisomerases are those in the camptothecin family, which target the human type IB topoisomerase (Hsiang et al., 1985), and a variety of drugs such as mAMSA, doxorubicin, and etoposide, which all target the human type IIA topoisomerase (Nitiss, 2009). They are extremely effective anticancer agents, with successful uses against a variety of cancers. In the antibiotic realm, there are drugs that target the type IIA enzymes. One of the most important classes of antibiotics discovered in the past century is the quinolone family. Ciprofloxacin, a second-generation fluoroquinolone, has become one of the most widely used antibiotics (Goossens et al., 2007). The importance of fluoriquinolones has caused bacterial type IIA topoisomerases to be a valuable and popular target for antibiotics.

Unfortunately, as stated earlier, bacterial resistance to antibiotics is a major issue. Fluoroquinolone resistance is not uncommon (Hooper, 2001), and certain kinds of TB are untreatable even with fluoroquinolones as a second-line drug. We can no longer continue to crank out the same slightly-tweaked drug over and over. What is required now is to find novel drug targets for novel drug structures. An essential cellular target is necessary. Bacterial type IA topoisomerase is one such novel target, as there are no clinical drugs available that target this particular enzyme (Pommier et al., 2010). 


\section{BACTERIAL TYPE IA TOPOISOMERASES}

Bacterial type IA topoisomerases seem to perform a variety of functions inside the cell. Their most obvious function is to relax negatively supercoiled DNA (Figure I.4), generally following cellular processes like DNA transcription and replication. During those processes, the DNA is unzipped in order to allow the DNA or RNA polymerase to access the base pairs. The unzipping action can lead to the generation of supercoils that must be resolved. Bacterial type IA topoisomerases relax the negative supercoils generated behind the RNA polymerase (Vos et al., 2011). Some type IA topoisomerases can also perform decatenation reactions. Generally, "relaxases" are referred to as topoisomerase I, while "decatenases" are topoisomerase III, although there are some enzymes that are efficient at both kinds of reactions (Viard and de la Tour, 2007). Type IA topoisomerases are also involved in maintaining genome integrity, as well as Holliday-junction resolution (Wang, 2002). 


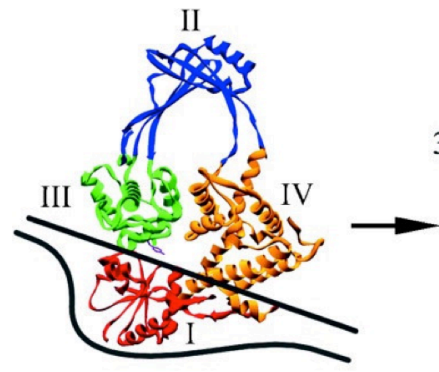

a

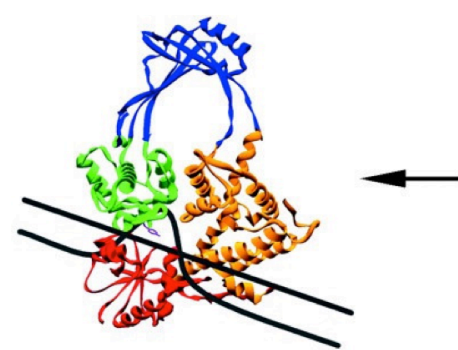

$\mathrm{f}$

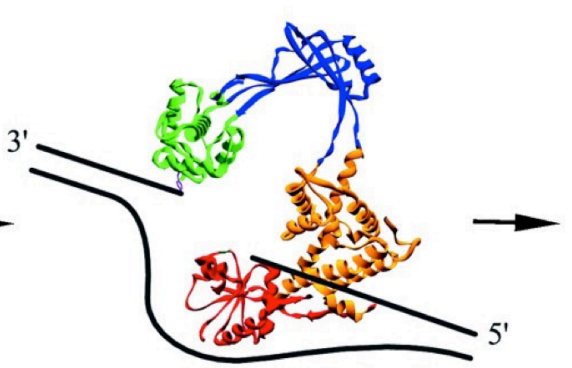

b

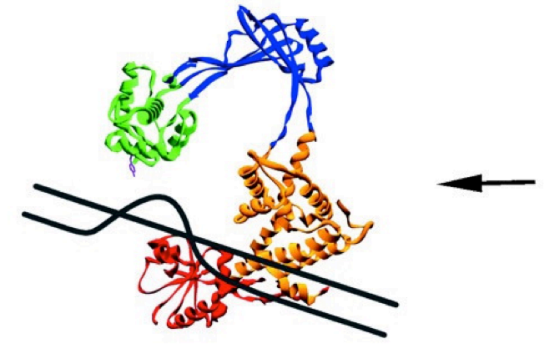

e

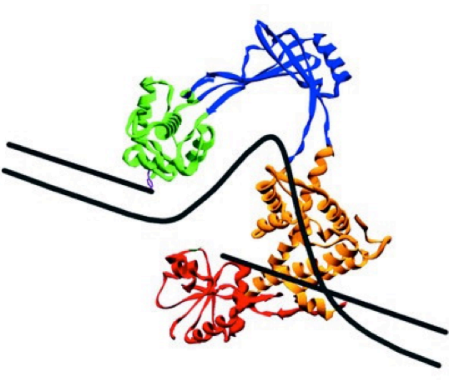

$\mathrm{C}$

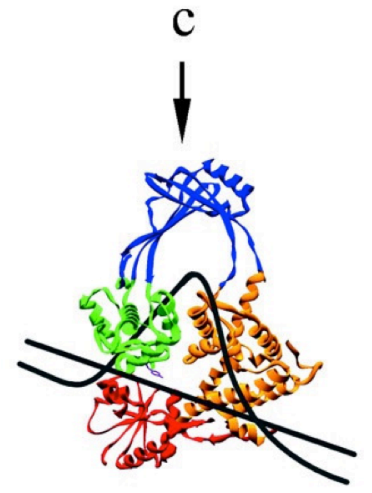

d

Figure I.4. Bacterial type IA topoisomerase mechanism: Upon binding a singlestranded region of DNA, the enzyme cleaves the DNA backbone, passes the other strand through the break, reseals the nick, and then finally releases the DNA (Champoux, 2001).

Structurally, type IA topoisomerases all share similar N-terminal domains with highly variable $\mathrm{C}$-terminal domains. The core $\mathrm{N}$-terminal domain contains the enzyme's active site tyrosine, as well as many conserved motifs necessary for DNA cleavage and religation (Champoux, 2001; Viard and de la Tour, 2007). It has been proposed that the variable C-terminus, in addition to aiding in DNA binding, is responsible for the enzymes' vastly different roles in the cell (Viard and de la Tour, 2007).

The general structure of bacterial type IA topoisomerase N-terminal domains is divided into four subdomains. Domain I is the TOPRIM (topoisomerase-primase) domain — so called because it is present in both type IA and type II topoisomerases, some nucleases, and primases (Aravind et al., 1998). It contains a conserved acidic triad: two 
aspartic acids and one glutamic acid, which have been shown to bind $\mathrm{Mg}^{2+}$ (Zhu and TseDinh, 2000; Zhang et al., 2011). In E. coli topoisomerase I, the divalent ion is necessary for DNA relaxation (Chen and Wang, 1998; Viard and de la Tour, 2007). However, it is not necessary for DNA cutting (Zhu et al., 1997). The religation step then is the step that requires bound $\mathrm{Mg}^{2+}$. The acidic triad, Asp111, Asp113, and Glu115, is located near the active site Tyr319 in EcTopI. The divalent ions may serve to activate the active site tyrosine and stabilize the leaving 3'-OH, and they may also help the protein undergo any conformational changes necessary for strand passage and subsequent religation and release (Zhu et al., 1997). The TOPRIM domain also contains a conserved glutamic acid, E9 in EcTopI, that interacts with the 3' oxygen of the cut phosphate, making it essential for the topoisomerase activity (Zhu et al., 1998; Chen and Wang, 1998).

Domain II is the hinge domain that links domains III and IV. The flexible linkage between domains I, III, and IV allows the enzyme to open and close, like a claw (Figure I.4). Domain III contains the catalytic tyrosine residue that acts as a nucleophile to attack the phosphodiester backbone of DNA. This domain is where the 5'-end of the DNA becomes covalently linked to the enzyme during catalysis. Once the DNA is cleaved, the topoisomerase swings open to allow the uncut strand to pass into the cleft. The strand movement is driven by the superhelical tension, and so bacterial type IA topoisomerases do not require adenosine triphosphate, ATP. Domain IV links domains I and II. It contains a DNA-binding groove that holds the single-stranded DNA while the reaction takes place. It also non-covalently holds the free 3'-end of the DNA after cleavage until it can be religated upon restoring the enzyme to its closed state after the DNA is unwound 
(Viard and de la Tour, 2007). These four domains encompass the N-terminal of the enzyme.

The C-terminal domain, as mentioned earlier, is highly varied from species to species. Escherichia coli topoisomerase I, EcTopI, is one of the best-studied enzymes of all type IA topoisomerases. It contains three tetra-cysteine zinc-binding motifs in its Cterminal domain (Tan et al., 2015). Removal of $\mathrm{Zn}(\mathrm{II})$ or mutations of the cysteines results in the loss of enzyme activity (Tse-Dinh, 1991; Zhu et al., 1995). These zinc ribbon motifs are not present in M. tuberculosis topoisomerase I, MtbTopI (Tan et al., 2016).

The various roles the type IA topoisomerases have in vivo may be attributable to their protein partners that interact with the C-terminal domains (Banda et al., 2016; Viard and de la Tour, 2007). Topoisomerase IA may act to relieve hypernegative supercoiling that is caused by transcription, or it may act to maintain genome integrity (Figure I.5). These differing roles all depend on the protein partners of the individual topoisomerase that will vary from species to species. 


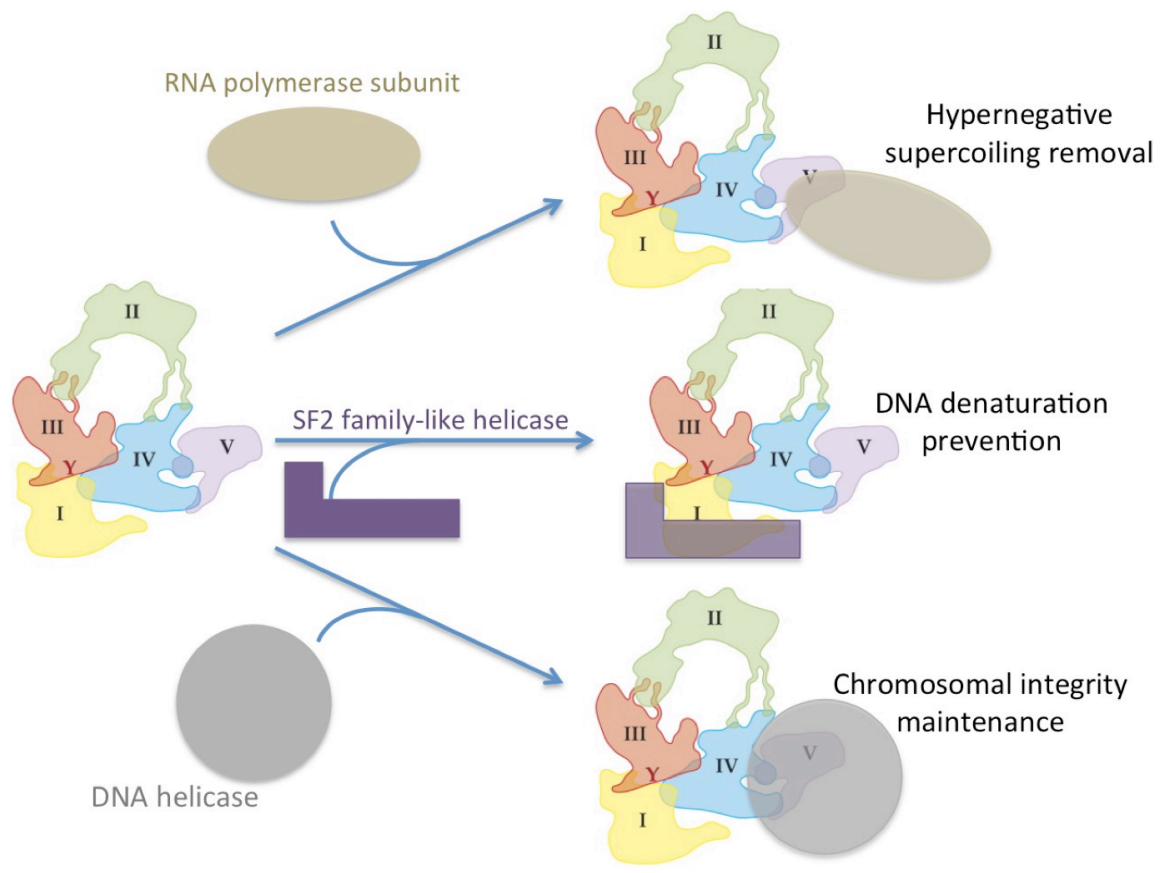

Figure I.5. Topoisomerase IA binding partners: Interactions with various protein partners will affect the in vivo role the topoisomerase assumes (adapted from Viard and de la Tour, 2007).

The significance of these enzymes cannot be overstated. They are attractive as a target for antibiotics because of their importance to the bacterial cell. When a mutant topoisomerase IA that forms a stabilized DNA-enzyme complex was overexpressed in $E$. coli, the DNA was cleaved, but could not then progress to the religation step. With the DNA trapped, an SOS response was triggered in the cells, which eventually led to cell death (Cheng et al., 2005). The cited study proves that should a drug be introduced into the cell that could stabilize the DNA-enzyme complex, it could lead to cell death. A drug that stabilizes the covalent intermediate would be an interfacial inhibitor that interacts with both the DNA and the enzyme (Pommier, 2013; Tse-Dinh, 2015). Stabilization of the covalent complex is called topoisomerase "poisoning", when the enzyme can cleave the DNA, but not religate it. Such an inhibitor would be invaluable in drugging 
topoisomerase IA in E. coli, as the topA-deletion mutant in E. coli is still viable at $37^{\circ} \mathrm{C}$ and $42^{\circ} \mathrm{C}$, so simple catalytic inhibition of the enzyme is not sufficient to kill the bacteria. The topA mutant is not viable at lower temperatures without the EcTopI as a result of excessive negative supercoiling (Stupina and Wang, 2005; Tse-Dinh, 2008). The presence of topoisomerase III in E. coli seems to be the reason knockout mutants were viable, as mutating both the topoisomerase I and topoisomerase III caused the strain to be nonviable (Stupina and Wang, 2005). In cases of stress, it appears that the type III enzyme can take over for the loss of the topoisomerase I.

The redundancy in enzyme function is not present in M. tuberculosis. There is only one copy of the top $A$ gene that encodes for a type IA topoisomerase, and so deletion mutants are not viable unless complimented by a copy top $A$ gene (Ravishankar et al., 2015). Strains with down-regulation of MtbTopI activity were less viable, and unable to infect mice. Since the enzyme is essential in M. tuberculosis, poisoning drugs are not necessary as in E. coli. Simple catalytic inhibition of the enzyme would be sufficient to kill the organism.

As previously stated, there is a necessity for novel drug targets in order to combat antibiotic resistance. Bacterial type IA topoisomerases are an under-utilized antibiotic target that can potentially help solve the problem of multi-drug resistant superbugs. As there are no existing antibiotics that target this enzyme, there would not be resistance up front as we see when the same drug targets are utilized over and over. Of course, the war on bacterial pathogens is more of an arms race, and bacteria may develop resistance to our drugs with new targets. However, with recent pushes for responsible usage of antibiotics, we may limit the resistance outcome. The current body of work is mainly 
concerned with discovering inhibitors of E. coli topoisomerase I and M. tuberculosis topoisomerase I (Figure I.6) (Tan et al., 2015; Tan et al., 2016).
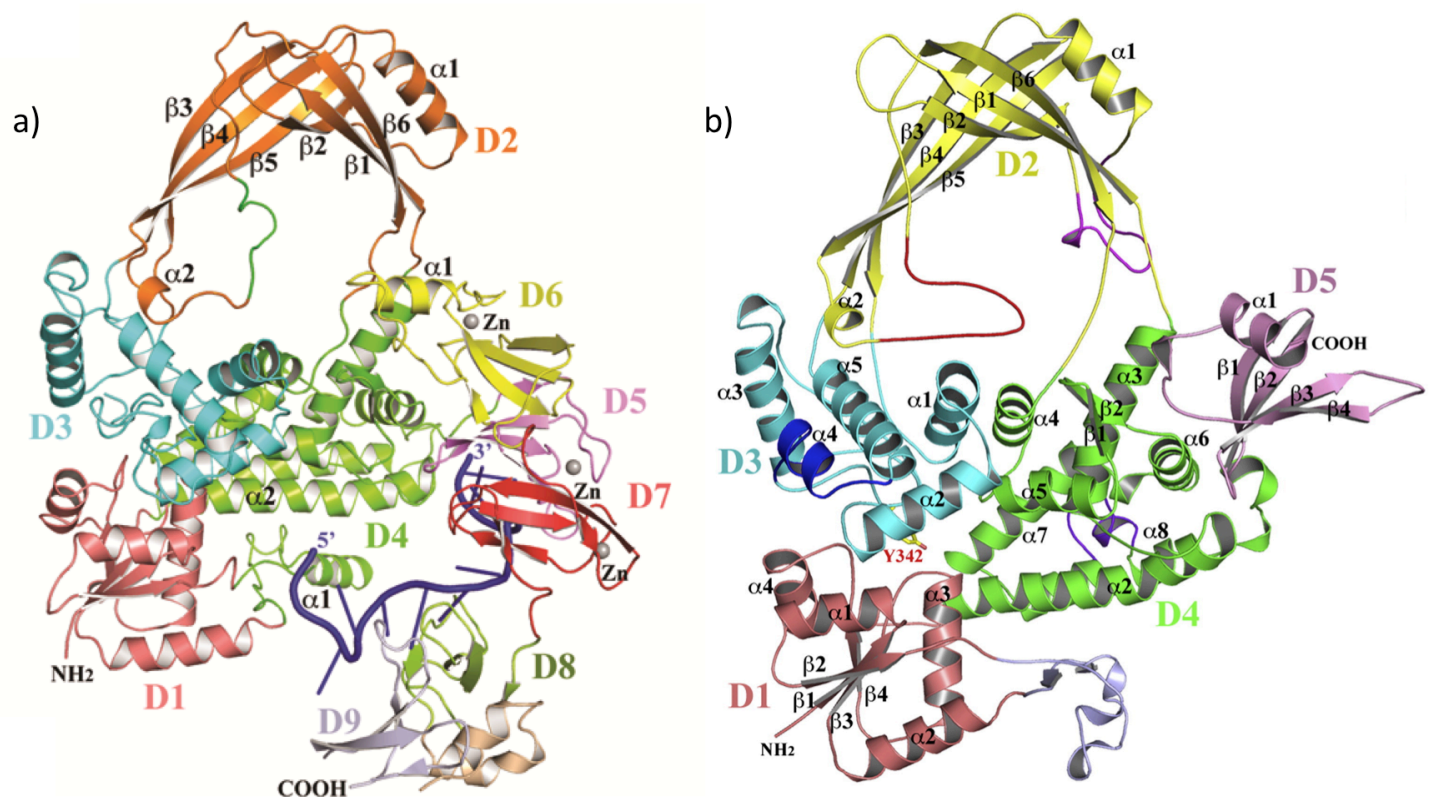

Figure I.6. Topoisomerase IA crystal structures: Resolved crystal structures of a) E. coli topoisomerase I bound to single strand of DNA (PDB 3PX7) (Tan et al., 2015), and b) M. tuberculosis topoisomerase I (PDB 5D5H) (Tan et al., 2016).

\section{APPROACHES TO DRUG DISCOVERY}

Drug discovery is a massive field. There are many varied approaches to discovering novel drug structures, and all have been successful to some extent. Each mode of drug discovery has a logical theory behind it, and many advocates for its advantages. A very common mode of drug discovery, high-throughput screening of compound libraries with up to a million or more compounds, relies on the idea that if one screens enough compounds they will eventually encounter a hit. High-throughput screens 
are generally fluorescence-based assays carried out in plates with hundreds or thousands of compounds at once. The libraries that are used are curated in many fashions; some libraries are made to resemble natural products, others are made to cover a large chemical diversity (Brown and Wright, 2016). There has been a general trend in recent years to return to natural product-like drugs, but they have the disadvantage of being generally complex and difficult to synthetically alter to generate analogues. Some high-throughput assays are designed to specifically test compounds against a validated drug target, others are testing the compounds' ability to prevent bacterial growth and the cellular target can be determined later (Brown and Wright, 2016; Humnabadkar et al., 2015). There are techniques that screen libraries virtually against a specified drug target, and others that use high-throughput assays to screen molecular fragments in order to build potent new drugs (Bowling et al., 2016; Drwal and Griffith, 2013). Whatever the technique that is applied, one thing remains constant: drug discovery is a long and difficult process. The difficulty and sheer magnitude of techniques is the reason the current body of work utilizes multiple drug discovery techniques - to broaden the chances of finding a novel lead for new antibiotic treatments targeting bacterial topoisomerase I.

The current body of work is divided into three distinct projects. The first chapter of my research focuses on a mixture-based screening that was done in collaboration with the Torrey Pines Institute for Molecular Studies (TPIMS). The second chapter involves the use of virtual docking studies. The third and final chapter, done in collaboration with Dr. Alvin Holder at Old Dominion University, discusses the selectivity of various organometallic complexes against different topoisomerases. All of these distinct projects 
had the same aim: to discover novel inhibitors of bacterial topoisomerase I for new antibiotic treatments.

\section{Mixture-based Drug Discovery}

The first chapter utilizes a technique known as mixture-based screening in order to find novel inhibitors of bacterial topoisomerase IA. The general idea behind mixturebased screening is that one can screen a single sample-a sample that contains a mixture of hundreds of thousands of individual compounds. Each of the individual compounds within the mixture share a distinct feature; they will have a common scaffold, or backbone, with varying R-groups emerging from the scaffold (Houghten et al., 2008; Pinilla et al., 2003). The scaffold mixture can then be screened against the desired end effect-enzyme inhibition, bacterial growth inhibition, the ability to bind an opioid receptor, etc. In the case of the present research, the scaffolds were tested for selective inhibition of bacterial type IA topoisomerases.

If a scaffold shows promise, it can then be split into smaller mixtures. Each mixture will now contain fewer individual compounds, and each will share a specific Rgroup (Figure I.7). By thus separating the mixtures, one can positionally scan the library and determine which functionalities are responsible for the desired end effect (Pinilla et al., 1992). In the final deconvolution step, individual compounds are synthesized to combine the best functionalities in the best positions to achieve the most potent end effect. 


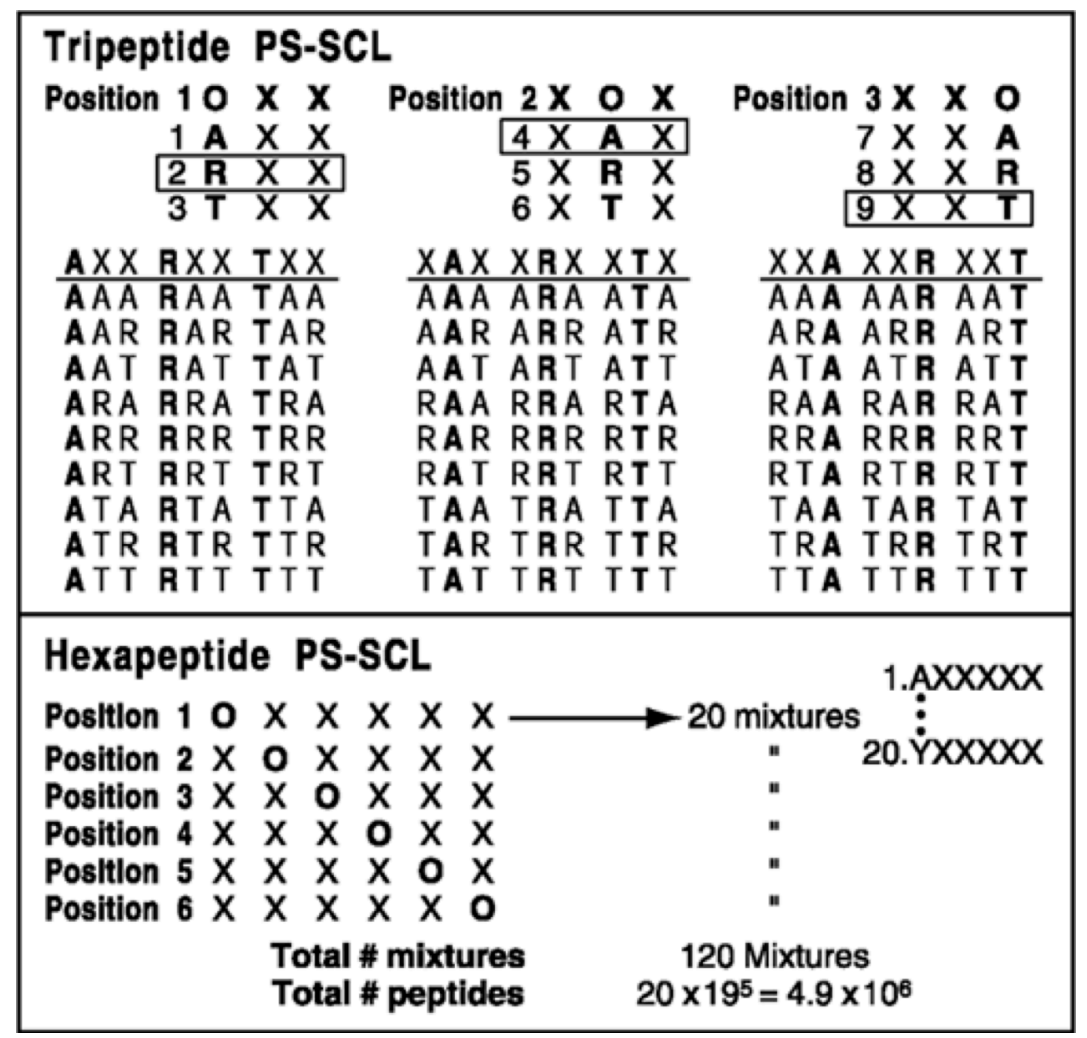

Figure I.7. Mixture-based screening: Sample synthesis of a tripeptide mixture (top) and hexapeptide mixture (bottom) for mixture-based screens (Pinilla et al., 2003).

The mixture-based screening technique has the advantage over traditional highthroughput screening because it uses far less material. With a high-throughput assay, hundreds of thousands of compounds must be synthesized, purified, and then tested in the lab. With a mixture-based approach, millions of compounds can be tested using less material and labor than would be needed if they were screened individually (Houghten et al., 2008). Mixture-based screening is also advantageous to researchers whose assays are not easily adapted to the high-throughput format - gel-based assays, for example, are difficult to adapt to a high-throughput format, as they are very labor intensive. 
In the present study in chapter 1, scaffold mixtures were screened against bacterial type IA topoisomerases and various bacterial strains in order to create potent and selective inhibitors that would be good antibacterial candidates for further study.

\section{Virtual Docking}

The second chapter of the present research utilizes a virtual screening approach to find novel inhibitors of bacterial topoisomerase IA. Virtual screening technique is generally used in a target-based approach, meaning the structure of the cellular target must be known in order to screen compound libraries against it. In the current case, the crystal structure of the cellular target is used to virtually dock a library of compounds. In the event that no crystal structure is available, a homology model can be used as well (Godbole et al., 2014a). One can also use a combination of target-based and ligand-based approaches, where the structure of the target and the compound are taken into account. Combination efforts allow for specificity to the intended target, and also use existing known drug structures as a framework for synthesizing novel structures that are more likely to be active (Drwal and Griffith, 2013; Drwal et al., 2014).

There are many programs that were made specifically to dock small molecules on protein structures, including GOLD, DOCK, and AutoDock, among others (Cross et al., 2009). Generally, the first step is to determine where on the target you wish to attempt to dock the compounds. It may be in the active site of the enzyme, or in an allosteric site that may affect the enzyme's activity in other ways. Once the site on the enzyme is chosen, the library of compounds can be virtually screened for their ability to bind in the specified site on the protein (Figure I.8). Analysis of compounds' binding ability is 
highly complex, as molecules can contort and bend as a result of their flexible bonds. The degree of flexibility can be specified in the program as well.
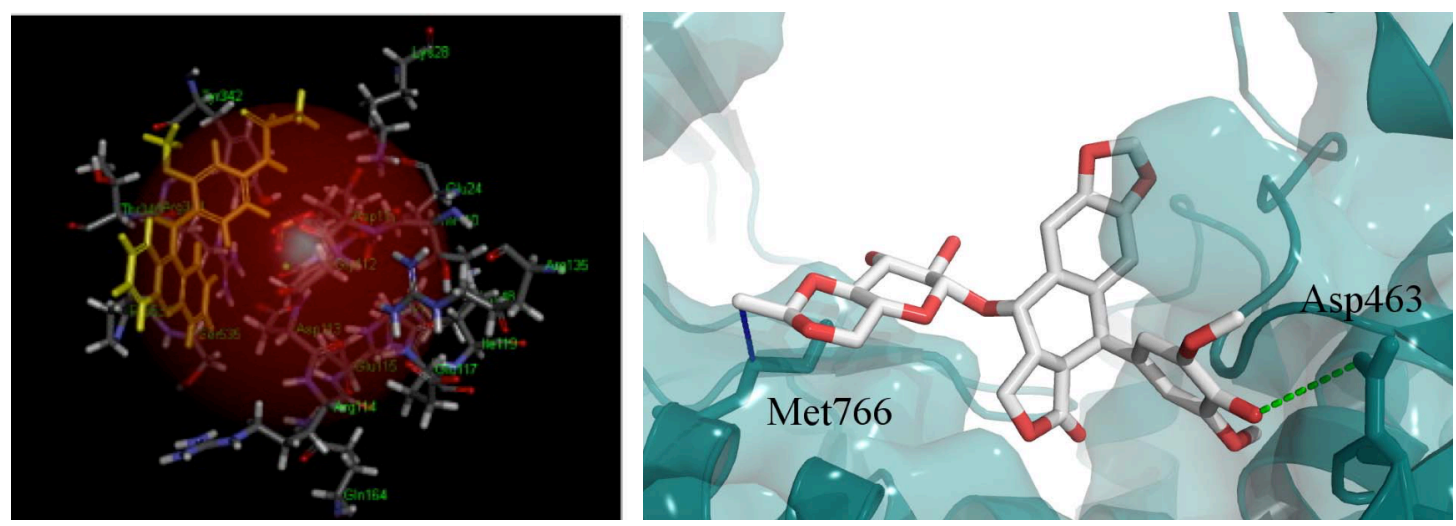

Figure I.8. Sample docking of topoisomerase inhibitors: (left panel) Amsacrine (mAMSA in yellow) was docked on a homology model of MbTopI in the TOPRIM domain near $\mathrm{Mg}^{2+}$ binding site. $\mathrm{Mg}^{2+}$ is shown in red (Godbole et al., 2014). (right panel) Etoposide was docked on the crystal structure of human topoisomerase II $\alpha$. The protein surface is shown in cyan. Two interacting residues are shown as sticks (Drwal et al., 2014).

Once the compounds have been screened against the desired site on the protein, they are scored for their binding ability. Electrostatic and van der Waals interactions are considered. The scoring step is generally very difficult for the reason that the computer may be unable to tell a good hit from an unreasonable one. Some ligand poses may be highly unlikely to occur in nature because they contort the molecules in improbable ways, but to the computer, it is considered a high scorer. Care must be taken at the scoring step to ensure accurate results (Bajorath et al., 2004).

For the current research, the crystal structures for EcTopI and MtbTopI were used in various screens against small molecule libraries. In one screen carried out by Dr. Renate Griffith at the University of New South Wales, compounds were docked into the $\mathrm{Mg}^{2+}$-binding site in E. coli topoisomerase I, crystal structure 3PX7 (Zhang et al., 2011). 
In the other screen done in collaboration with Dr. Prem Chapagain at Florida International University, compounds were docked into the DNA-binding site of $M$. tuberculosis topoisomerase I, crystal structure 5D5H (Tan et al., 2016). The goal of the present study was to find novel molecular structures that could act as a gateway into an untapped class of antibiotic candidates.

\section{Screening of Organometallic Complexes}

Organometallic complexes have been used as anticancer and antimicrobial agents for a long time. Cisplatin, a platinum-based drug, is widely used to treat many cancers despite its side effects and high rates of resistance (Wong and Giandomenico, 1999). As a result of cisplatin's increasingly limited utility, there has been an interest in finding new non-platinum organometallic drugs for anticancer and antimicrobial purposes (Ott and Gust, 2007). There have been reports of ruthenium complexes that are potent antimicrobials (Li et al., 2015), and there are new copper complexes that act as anticancer agents (Duff et al., 2012). For many of these copper complexes, their mechanism of action is believed to be inhibition of the type II topoisomerase in human cells (Das et al., 2014; Galal et al., 2010; Tabassum et al., 2014a; Tabassum et al., 2014b; Zeglis et al., 2011). The human type II $\alpha$ topoisomerase is a popular anticancer target because it is overexpressed in the rapidly growing cancer cells (Jarvinen and Liu, 2006; Nitiss, 2009).

In the interest of expanding the research concerning organometallics as therapeutic agents, novel complexes synthesized in the lab of Dr. Alvin Holder were tested against various topoisomerases in order to determine selectivity and potency. Copper complexes were chosen for their history of targeting topoisomerases-it was of 
great interest to find new poison topoisomerase inhibitors. And since ruthenium and other metals have been studied and found to be effective antimicrobials, cobalt complexes were tested as well to determine if there was another transition metal that could be exploited for antimicrobial use.

\section{E. OVERVIEW}

Antibiotic resistance is a problem that must be addressed. New drugs and drug target are needed desperately to combat the multidrug-resistant pathogens. Bacterial topoisomerase I is an attractive and novel drug target for antibiotics, as it is essential for cellular growth. In this dissertation project, novel inhibitors of bacterial topoisomerase I were discovered and studied in order to advance the field of antibiotics research. In chapter 1, mixture-based drug discovery was used to find inhibitors of Mycobacterium tuberculosis topoisomerase I (MtbTopI). A new class of polyamine inhibitors was found to target the enzyme specifically in M. smegmatis and M. tuberculosis. The compounds were able to prevent bacterial growth as well, with MIC values increasing with the overexpression of the topoisomerase I. These compounds were found to prevent DNA cleavage, thus inhibiting the overall activity of the enzyme. In chapter 2, virtual docking studies were used to find novel inhibitors of bacterial topoisomerase I. A new structural motif was found to help increase the compounds' docking scores and allow the compounds to inhibit the enzyme in vitro as well. The presence of an efflux pump inhibitor had a synergistic effect with the compounds and enabled them to prevent bacterial growth. The compounds containing the common motif were found to inhibit the enzyme activity at a step following DNA binding. In chapter 3, organometallic 
complexes containing $\mathrm{Cu}(\mathrm{II})$ and $\mathrm{Co}(\mathrm{III})$ were tested for selective topoisomerase I inhibition. The $\mathrm{Cu}(\mathrm{II})$ complexes were found to be potent poisons of human topoisomerase II $\alpha$, with potential as anticancer agents. The $\operatorname{Co}(\mathrm{III})$ complexes with thiosemicarbazone ligands were found to inhibit bacterial topoisomerase I selectively over other topoisomerases, including the human enzymes. The most potent complex acted as a catalytic inhibitor. Overall, many varied approaches were used to discover novel inhibitors of bacterial topoisomerase I, leading to several interesting and promising potential antibiotic drugs. 


\title{
II. CHAPTER 1:
}

\section{USE OF MIXTURE-BASED SCREENING TO TARGET MYCOBACTERIUM TUBERCULOSIS TOPOISOMERASE I}

\begin{abstract}
Mixture-based screening has been shown to be an effective method for drug discovery. In the present study, mixture-based combinatorial libraries were screened against Mycobacterium tuberculosis topoisomerase I in order to find novel inhibitors of the enzyme. Mycobacterium tuberculosis topoisomerase I, MtbTopI, has been validated as a novel drug target that is essential in the pathogenesis of tuberculosis, a disease that is among the top ten causes of death worldwide. The screen began with a polyamine scaffold library that was determined to have selective inhibition of the bacterial enzyme. Using positional-scanning deconvolution, selective inhibitors were identified that were both inhibitory toward the topoisomerase I and also bactericidal against Mycobacterium smegmatis and tuberculosis. The compounds were able to inhibit the topoisomerase at low- $\mu \mathrm{M}$ concentrations, and the MIC values for $M$. smegmatis growth inhibition increased upon overexpression of the topoisomerase-indicating the importance of the enzyme in the inhibitors' cellular mode of action. The top hits all exhibit the same mechanism of inhibiting the enzyme; they do not prevent the topoisomerase from binding DNA, but rather they prevent the DNA from being cleaved. These compounds are a promising new class of antimycobacterials that can be further optimized for potentially treating tuberculosis and other non-tubercular mycobacterial infections.
\end{abstract}




\section{INTRODUCTION}

The need for novel antitubercular drugs is urgent. Tuberculosis is one of the top ten leading causes of death from an infectious disease worldwide, with 1.8 million deaths per year, and the number one killer of people who are HIV-positive (World Health Organization, 2016b). The emergence of multidrug-resistant TB (roughly $20 \%$ of new cases in 2015) and even extensively drug-resistant TB is a major cause for concern.

Topoisomerase IA is a novel drug target because it has never yet been targeted by antibiotics used clinically (Tse-Dinh, 2008). Topoisomerases are ubiquitous and essential for cellular survival. They are responsible for maintaining the correct level of DNA supercoiling in the cell, and care for all topological problems that arise from the doublehelical shape of DNA (Wang, 1996). Topoisomerases all share a common mechanism of action - the enzymes use their active site tyrosine residue to attack the phosphodiester backbone of the DNA. The enzyme is covalently linked to the DNA as the second free strand or DNA duplex is passed through the break. The DNA is then religated and released from the enzyme (Vos et al., 2011).

Type IA topoisomerases are responsible for changing the DNA linking number by factors of one. They cleave a single strand of DNA. In bacteria, topoisomerase IA is responsible for relaxing supercoiled DNA (Champoux, 2001). These enzymes, as mentioned above, are essential for bacterial growth. In Mycobacterium tuberculosis, the pathogen responsible for causing tuberculosis, topoisomerase I is especially valuable because there is no other type IA topoisomerase present in the cell (Ravishankar et al., 2015). Therefore, there is no enzyme that can pick up the slack should the topoisomerase 
I activity be compromised. The essentiality of the enzyme makes topoisomerase I a very attractive target in tuberculosis research.

Mixture-based screening is a technique that has been successfully used in the past to discover potent new classes of drugs (Pinilla et al., 1992), including novel inhibitors of tyrosine recombinases and Holliday junction resolving enzymes (Rideout et al., 2011). The Torrey Pines Institute for Molecular Studies (TPIMS) synthesizes scaffold mixtures that each contains hundreds of thousands of individual compounds, all with a common backbone structure. A scaffold mixture is then screened against the desired drug target, in the present case, bacterial topoisomerase I.

Out of the 50 scaffold mixtures screened, scaffold mixture TPI-2229 was found to inhibit bacterial topoisomerase I activity selectively over other topoisomerases, including DNA gyrase (Figure 1.1) (Sandhaus et al., 2016a). The scaffold was then broken down into 216 smaller mixtures in the process called positional scanning. Positional scanning ensures that each mixture contains many individual compounds with one R-group in common, while the other R-groups are varied (Houghten et al., 2008). The positional scanning procedure allows for identifying certain functional groups in set positions that provide the most potent target inhibition. Scaffold TPI-2229 contains three variable Rgroups along a polyamine backbone. The R-groups are generally modified amino acid side chains. After testing all 216 mixtures against MtbTopI and various bacterial strains, the R-groups that allowed for the most potent inhibition of the enzyme and bacterial growth were selected.

The results from the positional scan were then used to synthesize 80 individual compounds with combinations of R-groups that were shown to increase inhibitory 
activity. These compounds were tested for inhibition of E. coli and M. tuberculosis topoisomerase I. Several of them were able to prevent the growth of M. smegmatis and M. tuberculosis as well. In four of these compounds, the MIC values were increased when topoisomerase I was overexpressed in M. smegmatis. The shift in MIC indicates that topoisomerase I plays an important role in these compounds' cellular mechanism of action.

a)

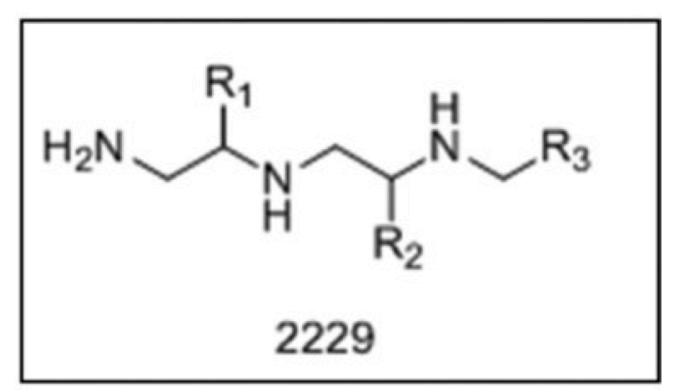

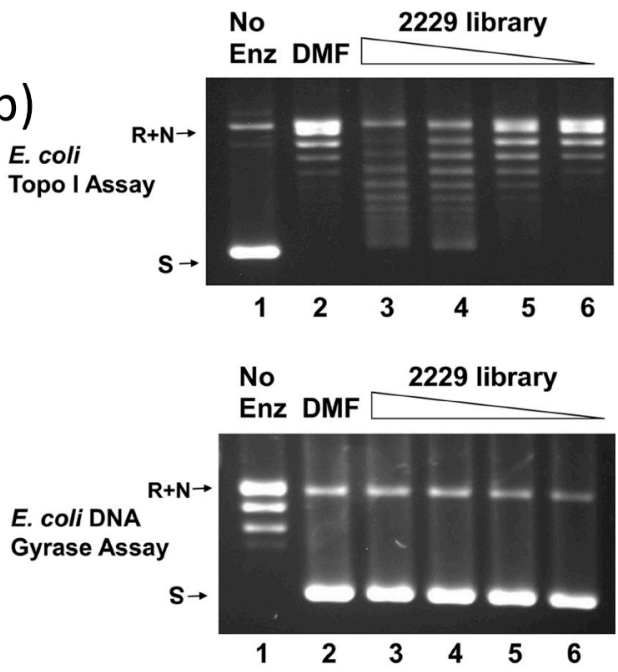

Figure 1.1. TPIMS scaffold 2229 selectively inhibits bacterial type I topoiosmerase: The backbone structure of scaffold TPI-2229 (a) can selectively inhibit bacterial topoisomerase I enzymes over other types of topoisomerases, including DNA gyrase (b) (Sandhaus et al., 2016a).

Following the identification of the four inhibitors that can target topoisomerase I in vivo, 36 new compounds were synthesized. The data from all the previous screens were used to build these in order to increase potency. From the new compounds, two were particularly promising, with $\mathrm{IC}_{50}$ values that were lower than seen in the previous set. The most potent compound had an $\mathrm{IC}_{50}=0.73 \mu \mathrm{M}$, and was extremely selective 
toward the bacterial topoisomerase I. The overall progression of mixture-based screening was highly successful, beginning with a mixture with weak enzyme inhibition and ending with multiple individual compounds with $\mathrm{IC}_{50}$ values below $10 \mu \mathrm{M}$.

\section{MATERIALS AND METHODS}

\section{Bacterial topoisomerase I relaxation inhibition assay}

The relaxation activity of bacterial topoisomerase I, including EcTopI and MtbTopI, was assayed by the use of agarose gel electrophoresis. One percent agarose gels were prepared by dissolving $3 \mathrm{~g}$ agarose in $300 \mathrm{~mL} \mathrm{1x}$ TAE buffer (Tris-acetateEDTA). Recombinant EcTopI and MtbTopI purified in our lab were used for these experiments (Zhu and Tse-Dinh, 1999). The enzymes were first diluted 1:10 in a dilution buffer containing $100 \mathrm{mM} \mathrm{KCl}, 20 \mathrm{mM} \mathrm{KH}_{2} \mathrm{PO}_{4}$ (pH 7.4), 50\% glycerol, 1 mM EDTA, $0.1 \%$ gelatin, and $1 \mathrm{mM}$ dithiothreitol (DTT). The diluted enzyme was then added to a reaction buffer containing $10 \mathrm{mM}$ Tris $(\mathrm{pH} 8.0), 50 \mathrm{mM} \mathrm{NaCl}, 0.1 \mathrm{mg} / \mathrm{mL}$ gelatin, and $0.5 \mathrm{mM} \mathrm{MgCl} 2$ for a final enzyme concentration of $10 \mathrm{ng} /$ reaction. The enzyme mixture was then divided into $10 \mu \mathrm{L}$ aliquots before the addition of $0.5-1 \mu \mathrm{L}$ of the desired compound dissolved in 5\% dimethylformamide (DMF), or the solvent alone for controls. $9 \mu \mathrm{L}$ of the same reaction buffer containing $160 \mathrm{ng}$ of supercoiled $\mathrm{pBAD} / \mathrm{Thio}$ plasmid DNA purified by cesium chloride gradient was added to the enzyme mixture. The samples were then incubated for 30 minutes at $37^{\circ} \mathrm{C}$ before being terminated by the addition of $4 \mu \mathrm{L}$ of $50 \%$ glycerol, $50 \mathrm{mM}$ EDTA, and $0.5 \%$ (v/v) bromophenol blue. The samples were then loaded into a $1 \%$ agarose gel and run at $25 \mathrm{~V}$ overnight. Upon 
completion, the gels were stained in ethidium bromide and photographed under UV light (Cheng et al., 2013).

\section{DNA gyrase supercoiling inhibition assay}

Supercoiling activity of DNA gyrase was assayed by agarose gel electrophoresis as well. The gyrase was obtained from New England BioLabs or was purified in our lab. $2 \mathrm{U}$ of the enzyme was added to a reaction buffer provided by the manufacturer $(35 \mathrm{mM}$ Tris-HCl, $24 \mathrm{mM} \mathrm{KCl,} 4$ mM MgCl 2,2 mM DTT, 1.75 mM ATP, 5 mM spermidine, 0.1 $\mathrm{mg} / \mathrm{mL}$ BSA, and $6.5 \%$ glycerol) and divided into $10 \mu \mathrm{L}$ aliquots. $0.5-1 \mu \mathrm{L}$ of the compounds dissolved in 5\% DMF or the solvent alone were added to the enzyme mixture. $300 \mathrm{ng}$ of relaxed covalently closed circular DNA provided by the manufacturer was then added for a final volume of $20 \mu \mathrm{L}$. The samples were incubated for 30 minutes at $37^{\circ} \mathrm{C}$ before termination by the addition of $4 \mu \mathrm{L}$ of a buffer containing $5 \%$ SDS, $0.25 \%$ bromophenol blue, and 25\% glycerol. The samples were then loaded into a $1 \%$ agarose gel and run at $25 \mathrm{~V}$ overnight before being stained in ethidium bromide and photographed under UV light (Cheng et al., 2013).

\section{Human topoisomerase I relaxation inhibition assay}

Human topoisomerase I (HTOPI) relaxation activity was assayed via gel electrophoresis. Purified human topoisomerase I was purchased from TopoGen. The reactions contained $0.5 \mathrm{U}$ of the enzyme suspended in a buffer containing $10 \mathrm{mM}$ Tris ( $\mathrm{pH}$ 8.0), $150 \mathrm{mM} \mathrm{NaCl}, 0.1 \%$ BSA, $0.1 \mathrm{mM}$ spermidine, and 5\% glycerol. The compounds were then added to the enzyme at the indicated concentrations before the 
addition of $160 \mathrm{ng}$ of supercoiled $\mathrm{pBAD} /$ Thio plasmid DNA suspended in the same buffer. The final reaction volume was $20 \mu \mathrm{L}$. After the samples were incubated for 30 minutes at $37^{\circ} \mathrm{C}$, they were terminated by the addition of a buffer containing $5 \%$ SDS, $0.25 \%$ bromophenol blue, and $25 \%$ glycerol. They were then analyzed on a $1 \%$ agarose gel (Cheng et al., 2013).

\section{Human topoisomerase II $\alpha$ decatenation inhibition assay}

The decatenation activity of human topoisomerase II $\alpha$ (HTOPII $\alpha$ ) was assayed via electrophoresis in an agarose gel containing $0.5 \mu \mathrm{g} / \mathrm{mL}$ ethidium bromide. The enzyme was obtained from TopoGen. The compounds were added to $180 \mathrm{ng}$ of kinetoplast DNA (kDNA) before adding $2 \mathrm{U}$ of the enzyme suspended in an ATP-containing buffer supplied by the manufacturer for a final volume of $20 \mu \mathrm{L}$. The samples were incubated for 15 minutes at $37^{\circ} \mathrm{C}$. The reactions were then terminated by the addition of a buffer containing 5\% sarkosyl, $0.25 \%$ bromophenol blue, and $25 \%$ glycerol. The samples were loaded into a $1 \%$ agarose gel containing $0.5 \mu \mathrm{g} / \mathrm{mL}$ ethidium bromide, and were run in $1 \mathrm{x}$ TAE buffer containing $0.5 \mu \mathrm{g} / \mathrm{mL}$ ethidium bromide as well. The gels were then photographed under UV light (Sandhaus et al., 2016a).

\section{Bacterial strains and overexpression plasmids}

Previously, the $M$. tuberculosis topA gene that encodes topoisomerase I (MtbTopI) was inserted into a pKW08-Lx plasmid under the control of a tetracyclineinducible promoter by Dr. Thirunnavukarasu Annamalai. The resulting plasmid, pKW$\mathrm{M}+$, expresses MtbTopI. A control vector without the gene, $\mathrm{pKW}$-nol, was constructed as 
well. Both plasmids were electroporated separately into the wild-type M. smegmatis strain, $\mathrm{mc}^{2} 155$. The resulting strains, $\mathrm{M}+$ and Mnol, were used for growth inhibition assays, to indicate whether overexpression of MtbTopI affected the antibacterial activity (Sandhaus et al., 2016a).

\section{M. smegmatis growth inhibition and loss of viability}

The antibacterial properties of the compounds were determined with growth assays and cell viability assays. Mycobacterim smegmatis was used as a non-pathogenic model system for Mycobacterium tuberculosis (Shiloh and DiGiuseppe Champion, 2010). Cultures that were grown from streaked LBN/agar plates were used to start cultures in Middlebrook $7 \mathrm{H} 9$ medium supplemented with $0.2 \%$ glycerol, $0.05 \%$ Tween 80, and 10\% ADN (albumin, dextrose, sodium chloride) for 1 day. The overexpression strains contained $50 \mu \mathrm{g} / \mathrm{mL}$ hygromycin B as well. The cultures were then diluted 1:100, 1:200, and 1:500 in the same medium without $\mathrm{ADN}$ and grown overnight until the $\mathrm{OD}_{600}$ was between 0.6 and 0.7 (exponential growth phase). The cells were then adjusted to $\mathrm{OD}_{600}=0.5$ and diluted further $1: 10.50 \mu \mathrm{L}$ of these diluted cells were added to clearbottom 96-well plates containing $50 \mu \mathrm{L}$ of the compounds serially diluted in the same medium. The plates were grown at $37^{\circ} \mathrm{C}$ with shaking for 48 hours. Absorbance readings were taken every $\sim 4$ hours until the cells had grown to saturation $\left(\mathrm{OD}_{600}=1.5\right)$. The MIC values are recorded as the minimum concentration of compound that prevented increased absorbance readings over time.

To determine whether the compounds that prevented growth were bactericidal or bacteriostatic, the cells from the MIC assays with compound concentrations above the 
MIC were diluted and spread on LB plates and allowed to grow at $37^{\circ} \mathrm{C}$ for 3 days. The viable colonies were counted and divided by the number of viable cells pre-treatment for a ratio of loss of viability.

\section{Inhibition of M. smegmatis biofilm formation}

The ability of the most potent antibacterial compound to prevent M. smegmatis bacterial biofilm formation was assayed in the following manner: the cells were grown in Middlebrook $7 \mathrm{H} 9$ medium supplemented with $0.2 \%$ glycerol, $0.05 \%$ Tween 80 , and $10 \%$ ADN (albumin, dextrose, sodium chloride) overnight until they reached saturation. The cells were then spun down and the pellet was resuspended in LBN medium. The cells were then adjusted to $\mathrm{OD}_{600}=0.002$ and added in $100 \mu \mathrm{L}$ volumes to a Costar 2797 96-

well plate (polyvinyl chloride). The plate was incubated at $37^{\circ} \mathrm{C}$ for 18 hours before the addition of $1 \mu \mathrm{L}$ of the compound at $100 \mathrm{x}$ concentrations. The plate was incubated further for 24 hours. After 24 hours, the wells were emptied of the cell cultures. The plate was washed in deionized water and allowed to dry for 5 minutes. Then, $125 \mu \mathrm{L}$ of $0.1 \%$ crystal violet was added to the wells. After 15 minutes, the crystal violet was removed and the plate was washed again in deionized water. The plate was dried again, and then $200 \mu \mathrm{L}$ of $30 \%$ acetic acid was added. After 15 minutes, $125 \mu \mathrm{L}$ of the acetic acid was transferred to a Nunc flat-bottomed 96-well plate and the absorbance was read at $600 \mathrm{~nm}$.

\section{MtbTopI-DNA binding gel shift assay}

The compounds' ability to prevent the topoisomerase from binding DNA was assayed via gel shift. The enzyme was added to a buffer containing $20 \mathrm{mM}$ Tris, 100 
$\mu \mathrm{g} / \mathrm{mL}$ BSA, $18 \%$ glycerol, and $0.5 \mathrm{mM}$ EDTA such that the final amount was ranging from 0.1 pmole $(10 \mathrm{ng})$ to 1 pmole (100 $\mathrm{ng})$. The compound was then added to the enzyme before 0.5 pmole of the labeled oligonucleotide STS-32 was added. The 32 base $\begin{array}{llll}\text { oligonucleotide } & \text { substrate } & \text { STS-32 } & \text { 5'- }\end{array}$ CAGTGAGCGAGCTTCCGCT $\downarrow$ TGACATCCCAATA-3' with an MtbTopI cleavage site (indicated by arrow) was labeled at the 5 '-end with $\gamma-{ }^{32} \mathrm{P}$-ATP and T4 polynucleotide kinase (Tan et al., 2016). The samples were incubated at $37^{\circ} \mathrm{C}$ for 5 minutes, and then left on ice for another 5 minutes. After the addition of gel shift loading buffer, the samples were loaded and run at $100 \mathrm{~V}$ at $4^{\circ} \mathrm{C}$ for 5 hours in $0.5 \mathrm{x}$ TBE buffer (Tris-boric acidEDTA). Once completed, the gels were dried at $80^{\circ} \mathrm{C}$ for 2 hours before Phosphor-Image analysis.

\section{MtbTopI ${ }^{32}{ }^{32}$-DNA cleavage inhibition assay}

The ability of the compounds to prevent DNA cleavage was assayed in the following manner. 0.5 pmole of the labeled STS-32 oligonucleotide was added $10 \mathrm{mM}$ Tris. The compounds were added to the oligonucleotide. Finally, the enzyme was added such that the final amount was ranging from 0.1 pmole $(10 \mathrm{ng})$ to 1 pmole $(100 \mathrm{ng})$. The samples were incubated for 30 minutes at $37^{\circ} \mathrm{C}$. The reactions were stopped by the addition of an equal volume of sequencing gel loading buffer. The samples were then boiled at $95^{\circ} \mathrm{C}$ for 5 minutes before being loaded into a $15 \%$ urea sequencing gel. The samples were run in $1 \mathrm{x}$ TBE buffer at $200-300 \mathrm{~V}$ for $4-5$ hours. The results were analyzed by Phosphor-Image analysis. 


\section{Ethidium bromide MtbTopI-DNA cleavage inhibition assay}

The cleavage inhibition was also assayed in ethidium bromide gels. The enzyme was added to a reaction buffer containing $10 \mathrm{mM}$ Tris (pH 8.0), $50 \mathrm{mM} \mathrm{NaCl}$, and 0.1 $\mathrm{mg} / \mathrm{mL}$ gelatin for a final enzyme concentration of $50 \mathrm{ng} /$ reaction. The enzyme mixture was then divided into $10 \mu \mathrm{L}$ aliquots before the addition of $0.5-1 \mu \mathrm{L}$ of the desired compound dissolved in 5\% dimethylformamide (DMF), or the solvent alone for controls. $160 \mathrm{ng}$ of supercoiled $\mathrm{pBAD} /$ Thio plasmid DNA purified by cesium chloride gradient was added to the enzyme mixture. The samples were then incubated for 30 minutes at $37^{\circ} \mathrm{C}$ before the addition of $2.5 \mu \mathrm{L}$ of $10 \% \mathrm{SDS}$ and $0.625 \mu \mathrm{L}$ of $20 \mathrm{mg} / \mathrm{mL}$ proteinase $\mathrm{K}$. The samples were further incubated for 1 hour. The samples were then loaded into a $1 \%$ agarose gel containing $0.5 \mu \mathrm{g} / \mathrm{mL}$ ethidium bromide and run at $25 \mathrm{~V}$ overnight. Upon completion, the gels were photographed under UV light.

\section{RESULTS AND DISCUSSION}

\section{Positional scan of scaffold TPI-2229 yields selective inhibitor of bacterial topoisomerase I}

Previously, scaffold TPI-2229 was found to be a selective inhibitor of bacterial topoisomerase I at $100 \mu \mathrm{g} / \mathrm{mL}$. The enzyme inhibition was not caused by non-specific interactions of the positively charged polyamine backbone, as the activity of DNA gyrase was not inhibited. Scaffold TPI-2229 was then split into 216 sample mixtures in a positional-scanning library. Each mixture contained one R-group that was held constant, while the other two R-groups were varied. Using the positional-scanning technique, the R-group position and identity could be linked with activity. The mixtures were screened 
against EcTopI for relaxation inhibition, and the effects of different R1, R2, and R3 substitutions on the $\mathrm{IC}_{50}$ values were analyzed. There were several structure-activity relationships (SAR) trends that were apparent, such as large aromatic groups or positively charged functional groups in the $\mathrm{R} 1$ position producing mixtures with $\mathrm{IC}_{50}$ values against EcTopI in the low-micromolar range, among others. Aliphatic substitutions in the R1 positions had $\mathrm{IC}_{50}$ values higher than $100 \mu \mathrm{M}$. These data from the positional-scanning library was used to direct the synthesis of individual compounds. The SAR data were used to include R-groups that would most likely be active, and other R-groups were selected to generate diversity in the TPI-2471 library.

\section{Potency and selectivity for bacterial topoisomerase I by individual compounds in TPI-2471 library}

The 80 individual compounds in the TPI-2471 library were tested against EcTopI and displayed $\mathrm{IC}_{50}$ values ranging from $1.25 \mu \mathrm{M}$ to greater than $160 \mu \mathrm{M}$ (Table 1.1). All of the compounds with $\mathrm{IC}_{50}$ values less than $20 \mu \mathrm{M}$ contained a naphthyl group at the $\mathrm{R} 3$ position. Other substitutions at the $\mathrm{R} 3$ position yielded $\mathrm{IC}_{50}$ values greater than $20 \mu \mathrm{M}$. The results indicate the importance of the naphthyl group in the R3 position. Although the compounds were able to inhibit EcTopI at low concentrations, they did not display strong antibacterial activity against various strains of E.coli. They did, however, inhibit M. tuberculosis topoisomerase I at concentrations similar to those seen against EcTopI. They were therefore all tested for antibacterial activity against M. smegmatis, and 14 compounds showed growth inhibition $\leq 50 \mu \mathrm{M}$ (Table 1.2). The most potent compound, 2471-80, was also able to prevent biofilm formation of M. smegmatis cells. 
Table 1.1. Information on TPI-2471 library: $\mathrm{R} 1, \mathrm{R} 2, \mathrm{R} 3$ substitutions and $\mathrm{IC}_{50}$ values for inhibition of $E$. coli topoisomerase I

\begin{tabular}{|c|c|c|c|c|}
\hline $\begin{array}{c}\text { Compound } \\
\text { Number }\end{array}$ & $\mathbf{R} 1$ & $\mathbf{R 2}$ & $\mathbf{R 3}$ & $\begin{array}{c}\text { EcTopI } \\
\text { Relaxation } \\
\text { Inhibition } \\
\left(\mathrm{IC}_{50}, \boldsymbol{\mu M}\right)\end{array}$ \\
\hline $2471-1$ & S-4-(methylamino)butyl) & S-4-(methylamino)butyl) & 2-(3-bromo-phenyl)-ethyl & 160 \\
\hline $2471-2$ & S-4-(methylamino)butyl) & S-4-(methylamino)butyl) & 2-(3,4-dihydroxy-phenyl)-ethyl & 120 \\
\hline $2471-3$ & S-4-(methylamino)butyl) & S-4-(methylamino)butyl) & 1-naphthylmethyl & 2.5 \\
\hline $2471-4$ & S-4-(methylamino)butyl) & S-3-guanidinepropyl & 2-(3-bromo-phenyl)-ethyl & 160 \\
\hline $2471-5$ & S-4-(methylamino)butyl) & S-3-guanidinepropyl & 2-(3,4-dihydroxy-phenyl)-ethyl & $>160$ \\
\hline $2471-6$ & S-4-(methylamino)butyl) & S-3-guanidinepropyl & 1-naphthylmethyl & 2.5 \\
\hline $2471-7$ & S-4-(methylamino)butyl) & R-propyl & 2-(3-bromo-phenyl)-ethyl & 160 \\
\hline $2471-8$ & S-4-(methylamino)butyl) & R-propyl & 2-(3,4-dihydroxy-phenyl)-ethyl & $>160$ \\
\hline $2471-9$ & S-4-(methylamino)butyl) & R-propyl & 1-naphthylmethyl & 5 \\
\hline $2471-10$ & S-4-(methylamino)butyl) & S-butyl & 2-(3-bromo-phenyl)-ethyl & 160 \\
\hline $2471-11$ & S-4-(methylamino)butyl) & S-butyl & 2-(3,4-dihydroxy-phenyl)-ethyl & $>160$ \\
\hline $2471-13$ & S-3-aminopropyl & S-4-(methylamino)butyl) & 2-(3-bromo-phenyl)-ethyl & 160 \\
\hline $2471-14$ & S-3-aminopropyl & S-4-(methylamino)butyl) & 2-(3,4-dihydroxy-phenyl)-ethyl & $>160$ \\
\hline $2471-15$ & S-3-aminopropyl & S-4-(methylamino)butyl) & 1-naphthylmethyl & 1.875 \\
\hline $2471-16$ & S-3-aminopropyl & S-3-guanidinepropyl & 2-(3-bromo-phenyl)-ethyl & 40 \\
\hline $2471-17$ & S-3-aminopropyl & S-3-guanidinepropyl & 2-(3,4-dihydroxy-phenyl)-ethyl & $>160$ \\
\hline $2471-18$ & S-3-aminopropyl & S-3-guanidinepropyl & 1-naphthylmethyl & 1.25 \\
\hline 2471-19 & S-3-aminopropyl & R-propyl & 2-(3-bromo-phenyl)-ethyl & 160 \\
\hline $2471-20$ & S-3-aminopropyl & R-propyl & 2-(3,4-dihydroxy-phenyl)-ethyl & $>160$ \\
\hline $2471-21$ & S-3-aminopropyl & R-propyl & 1-naphthylmethyl & 7.5 \\
\hline $2471-22$ & S-3-aminopropyl & S-butyl & 2-(3-bromo-phenyl)-ethyl & 160 \\
\hline $2471-23$ & S-3-aminopropyl & S-butyl & 2-(3,4-dihydroxy-phenyl)-ethyl & $>160$ \\
\hline $2471-24$ & S-3-aminopropyl & S-butyl & 1-naphthylmethyl & 10 \\
\hline
\end{tabular}


Table 1.1. cont.

\begin{tabular}{|c|c|c|c|c|}
\hline $2471-25$ & R-4-(methylamino)butyl & S-4-(methylamino)butyl) & 2-(3-bromo-phenyl)-ethyl & 160 \\
\hline $2471-26$ & R-4-(methylamino)butyl & S-4-(methylamino)butyl) & 2-(3,4-dihydroxy-phenyl)-ethyl & 80 \\
\hline $2471-27$ & R-4-(methylamino)butyl & S-4-(methylamino)butyl) & 1-naphthylmethyl & 1.25 \\
\hline $2471-28$ & R-4-(methylamino)butyl & S-3-guanidinepropyl & 2-(3-bromo-phenyl)-ethyl & 40 \\
\hline $2471-29$ & R-4-(methylamino)butyl & S-3-guanidinepropyl & 2-(3,4-dihydroxy-phenyl)-ethyl & 120 \\
\hline $2471-30$ & R-4-(methylamino)butyl & S-3-guanidinepropyl & 1-naphthylmethyl & 2.5 \\
\hline $2471-31$ & R-4-(methylamino)butyl & R-propyl & 2-(3-bromo-phenyl)-ethyl & 160 \\
\hline $2471-32$ & R-4-(methylamino)butyl & R-propyl & 2-(3,4-dihydroxy-phenyl)-ethyl & $>160$ \\
\hline $2471-33$ & R-4-(methylamino)butyl & R-propyl & 1-naphthylmethyl & 5 \\
\hline $2471-34$ & R-4-(methylamino)butyl & S-butyl & 2-(3-bromo-phenyl)-ethyl & 160 \\
\hline $2471-35$ & R-4-(methylamino)butyl & S-butyl & 2-(3,4-dihydroxy-phenyl)-ethyl & $>160$ \\
\hline $2471-36$ & R-4-(methylamino)butyl & S-butyl & 1-naphthylmethyl & 20 \\
\hline $2471-37$ & S-2-naphthylmethyl & R-butyl & 2-(3,5-Bis(Trifluoromethyl)phenyl)-ethyl & 40 \\
\hline $2471-38$ & S-2-naphthylmethyl & R-butyl & 4-tert-butyl-cyclohexyl & 40 \\
\hline 2471-39 & S-2-naphthylmethyl & R-butyl & 4-cyclohexylbutyl & 40 \\
\hline $2471-40$ & S-2-naphthylmethyl & S-3-(methylamino)propyl & 2-(3,5-Bis(Trifluoromethyl)phenyl)-ethyl & 40 \\
\hline $2471-41$ & S-2-naphthylmethyl & S-3-(methylamino)propyl & 4-tert-butyl-cyclohexyl & 40 \\
\hline $2471-42$ & S-2-naphthylmethyl & S-3-(methylamino)propyl & 4-cyclohexylbutyl & 40 \\
\hline $2471-43$ & S-2-naphthylmethyl & R-3-(methylamino)propyl & 2-(3,5-Bis(Trifluoromethyl)phenyl)-ethyl & 40 \\
\hline $2471-44$ & S-2-naphthylmethyl & R-3-(methylamino)propyl & 4-tert-butyl-cyclohexyl & 40 \\
\hline $2471-45$ & S-2-naphthylmethyl & R-3-(methylamino)propyl & 4-cyclohexylbutyl & 40 \\
\hline $2471-46$ & S-2-naphthylmethyl & S-4-fluorobenzyl & 2-(3,5-Bis(Trifluoromethyl)phenyl)-ethyl & 40 \\
\hline $2471-47$ & S-2-naphthylmethyl & S-4-fluorobenzyl & 4-tert-butyl-cyclohexyl & 40 \\
\hline $2471-48$ & S-2-naphthylmethyl & S-4-fluorobenzyl & 4-cyclohexylbutyl & 40 \\
\hline $2471-49$ & S-cyclohexylmethyl & R-butyl & 2-(3,5-Bis(Trifluoromethyl)phenyl)-ethyl & 40 \\
\hline $2471-50$ & S-cyclohexylmethyl & R-butyl & 4-tert-butyl-cyclohexyl & 160 \\
\hline $2471-51$ & S-cyclohexylmethyl & R-butyl & 4-cyclohexylbutyl & 160 \\
\hline $2471-52$ & S-cyclohexylmethyl & S-3-(methylamino)propyl & 2-(3,5-Bis(Trifluoromethyl)phenyl)-ethyl & 160 \\
\hline $2471-53$ & S-cyclohexylmethyl & S-3-(methylamino)propyl & 4-tert-butyl-cyclohexyl & $>160$ \\
\hline
\end{tabular}


Table 1.1. cont.

\begin{tabular}{|c|c|c|c|c|}
\hline $2471-54$ & S-cyclohexylmethyl & S-3-(methylamino)propyl & 4-cyclohexylbutyl & $>160$ \\
\hline $2471-55$ & S-cyclohexylmethyl & R-3-(methylamino)propyl & 2-(3,5-Bis(Trifluoromethyl)phenyl)-ethyl & 160 \\
\hline $2471-56$ & S-cyclohexylmethyl & R-3-(methylamino)propyl & 4-tert-butyl-cyclohexyl & 160 \\
\hline $2471-57$ & S-cyclohexylmethyl & R-3-(methylamino)propyl & 4-cyclohexylbutyl & 160 \\
\hline $2471-58$ & S-cyclohexylmethyl & S-4-fluorobenzyl & 2-(3,5-Bis(Trifluoromethyl)phenyl)-ethyl & 40 \\
\hline $2471-59$ & S-cyclohexylmethyl & S-4-fluorobenzyl & 4-tert-butyl-cyclohexyl & 40 \\
\hline $2471-60$ & S-cyclohexylmethyl & S-4-fluorobenzyl & 4-cyclohexylbutyl & 40 \\
\hline $2471-61$ & R-cyclohexylmethyl & R-butyl & 2-(3,5-Bis(Trifluoromethyl)phenyl)-ethyl & 40 \\
\hline $2471-62$ & R-cyclohexylmethyl & R-butyl & 4-tert-butyl-cyclohexyl & 160 \\
\hline $2471-63$ & R-cyclohexylmethyl & R-butyl & 4-cyclohexylbutyl & 160 \\
\hline $2471-64$ & R-cyclohexylmethyl & S-3-(methylamino)propyl & 2-(3,5-Bis(Trifluoromethyl)phenyl)-ethyl & 160 \\
\hline $2471-65$ & R-cyclohexylmethyl & S-3-(methylamino)propyl & 4-tert-butyl-cyclohexyl & 160 \\
\hline $2471-66$ & R-cyclohexylmethyl & S-3-(methylamino)propyl & 4-cyclohexylbutyl & 160 \\
\hline $2471-67$ & R-cyclohexylmethyl & R-3-(methylamino)propyl & 2-(3,5-Bis(Trifluoromethyl)phenyl)-ethyl & 160 \\
\hline $2471-68$ & R-cyclohexylmethyl & R-3-(methylamino)propyl & 4-tert-butyl-cyclohexyl & 160 \\
\hline $2471-70$ & R-cyclohexylmethyl & S-4-fluorobenzyl & 2-(3,5-Bis(Trifluoromethyl)phenyl)-ethyl & 40 \\
\hline $2471-71$ & R-cyclohexylmethyl & S-4-fluorobenzyl & 4-tert-butyl-cyclohexyl & 40 \\
\hline $2471-72$ & R-cyclohexylmethyl & S-4-fluorobenzyl & 4-cyclohexylbutyl & 40 \\
\hline $2471-73$ & R-2-(1H-indol-3-yl)ethyl & R-2-(1H-indol-3-yl)ethyl & 2-(3,4-dichloro-phenyl)-ethyl & 40 \\
\hline $2471-74$ & R-2-(1H-indol-3-yl)ethyl & R-2-(1H-indol-3-yl)ethyl & 1-naphthylethyl & 40 \\
\hline $2471-75$ & R-2-(1H-indol-3-yl)ethyl & S-3-(methylamino)propyl & 2-(3,4-dichloro-phenyl)-ethyl & 80 \\
\hline $2471-76$ & R-2-(1H-indol-3-yl)ethyl & S-3-(methylamino)propyl & 1-naphthylethyl & 20 \\
\hline $2471-77$ & S-2-naphthylmethyl & R-2-(1H-indol-3-yl)ethyl & 2-(3,4-dichloro-phenyl)-ethyl & 40 \\
\hline $2471-78$ & S-2-naphthylmethyl & R-2-(1H-indol-3-yl)ethyl & 1-naphthylethyl & 40 \\
\hline $2471-79$ & S-2-naphthylmethyl & S-3-(methylamino)propyl & 2-(3,4-dichloro-phenyl)-ethyl & 30 \\
\hline $2471-80$ & S-2-naphthylmethyl & S-3-(methylamino)propyl & 1-naphthylethyl & 2.5 \\
\hline
\end{tabular}

(Sandhaus et al., 2016a) 
Table 1.2. Antimycobacterial activity of potent MtbTopI inhibitors

\begin{tabular}{|c|c|c|c|}
\hline \multirow[b]{2}{*}{ Compound } & \multicolumn{2}{|c|}{$\begin{array}{l}\mathrm{IC}_{50}(\mu \mathrm{M}) \text { for } \\
\text { topoisomerase I }\end{array}$} & \multirow{2}{*}{$\begin{array}{l}\mathrm{MIC}(\mu \mathrm{M}) \text { for } M \text {. } \\
\text { smegmatis } \mathrm{mc}^{2} 155\end{array}$} \\
\hline & EcTopI & MtbTopI & \\
\hline 2471-18 & 1.25 & 1.25 & 50 \\
\hline $2471-27$ & 1.25 & 1.9 & 25 \\
\hline $2471-15$ & 1.9 & 0.625 & 50 \\
\hline $2471-3$ & 2.5 & 2.5 & 50 \\
\hline $2471-6$ & 2.5 & 1.25 & 25 \\
\hline 2471-30 & 2.5 & 2.5 & 25 \\
\hline $2471-80$ & 2.5 & 5 & 6.25 \\
\hline $2471-9$ & 5 & 5 & 50 \\
\hline $2471-33$ & 5 & 5 & 50 \\
\hline $2471-12$ & 7.5 & 7.5 & 12.5 \\
\hline $2471-21$ & 7.5 & 10 & 50 \\
\hline $2471-24$ & 10 & 7.5 & 25 \\
\hline $2471-36$ & 20 & 15 & 25 \\
\hline $2471-76$ & 20 & 10 & 12.5 \\
\hline
\end{tabular}

(Sandhaus et al., 2016a)

We were interested in how the compounds' antibacterial activity would be affected by the overexpression of the hypothesized target. To determine whether overexpression of the target would have any effect, antibacterial studies were conducted using the $\mathrm{M}+$ and $\mathrm{Mnol}$ strains; the $\mathrm{M}+$ strain expresses MtbTopI at least 6-fold higher than the Mnol strain, even in the absence of the tetracycline inducer (Sandhaus et al., 2016a). Growth inhibition assays showed that four of the compounds of interest, 247112, 2471-24, 2471-36, and 2471-80, displayed increased MIC values in the presence of MtbTopI overexpression, indicating that the topoisomerase I is indeed at least one of the cellular targets (Table 1.3). The MIC values were increased 2- to 4-fold when the topoisomerase was overexpressed. Conversely, the overexpression of MtbTopI did not 
affect the MIC of ciprofloxacin, a fluoroquinolone drug that targets the type II topoisomerase, DNA gyrase, in the cell. The results indicate that overexpression of MtbTopI does not have non-specific effects on the growth inhibition even by drugs with similar cellular targets.

Table 1.3. Effect of MtbTopI overexpression on MICs of select 2471 inhibitors

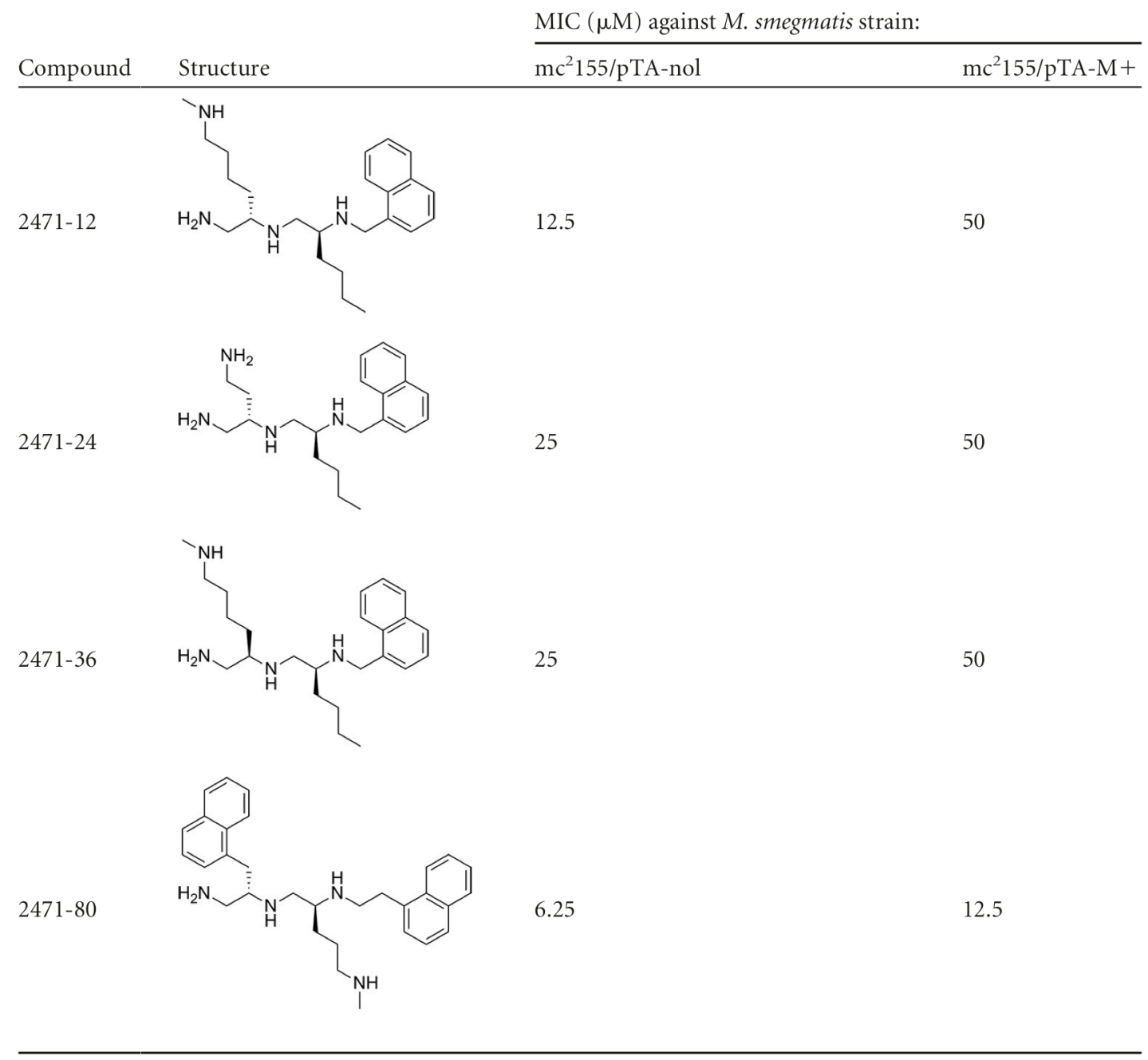

(Sandhaus et al., 2016a)

Counting of viable colonies indicated that these compounds are bactericidal against M. smegmatis. Overexpression of MtbTopI was also able to rescue the cells from death to an extent. The time course cell killing of 2471-12 indicated that the compound 
killed the bacteria rapidly, with no viable colonies detected at 22 hours post-treatment in the Mnol strain. Again, MtbTopI overexpression provided significant protection, and the $\mathrm{M}+$ strain was able to continue growing despite the decrease in viable colonies (Figure

a)

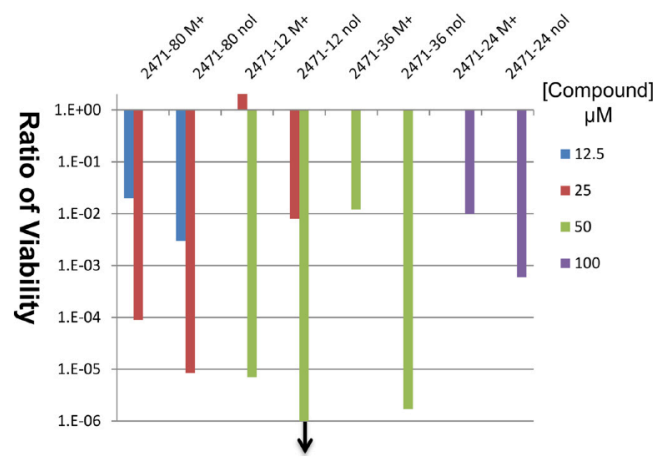

b)

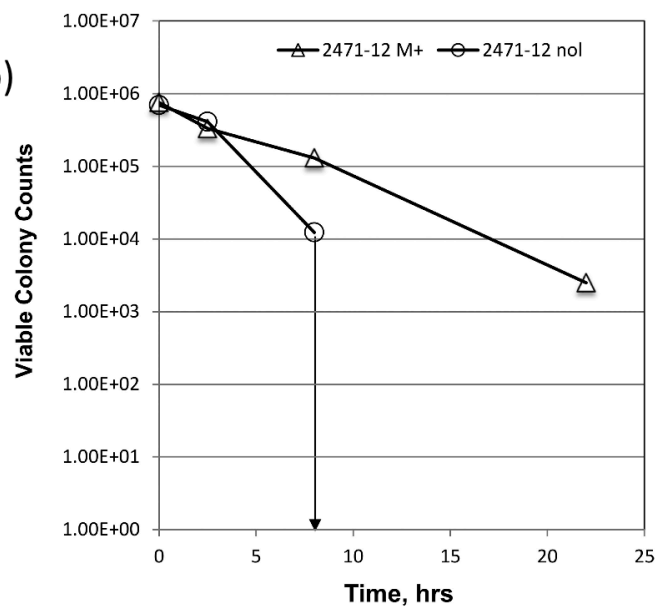

Figure 1.2. Effect of MtbTopI overexpression on bactericidal activity of topoisomerase I inhibitors: The overexpression of MtbTopI in M+ cells was able to reduce the bactericidal effect of TPIMS inhibitors. The downward arrow indicates no viable colonies were detected after 44 hours post-treatment with $50 \mu \mathrm{M}$ 2471-12 (a). Enzyme overexpression was also able to rescue $\mathrm{M}+$ cells from the rapid killing observed in Mnol by 2471-12 at 50 $\mu \mathrm{M}$. The downward arrow indicates no viable colonies were detected at time points later than 8 hours post-treatment (b) (Sandhaus et al., 2016a).

Further studies on M. tuberculosis were performed in the lab of Dr. Kyle Rohde at the University of Central Florida. Dr. Rohde's group confirmed that the cell-killing activity of these four compounds was retained in $M$. tuberculosis, with $\mathrm{IC}_{50}$ values ranging from $3.3 \mu \mathrm{M}$ to $8.4 \mu \mathrm{M}$. The $\mathrm{CC}_{50}$ of the compounds in macrophages ranged from $\sim 40 \mu \mathrm{M}$ to $\sim 100 \mu \mathrm{M}$, with selectivity index values over 10 for three of the compounds ( $\mathrm{SI}=\mathrm{CC}_{50} / \mathrm{IC}_{50}$ ). These studies proved that the compounds were a relatively potent starting point for a hit series. 
The four compounds are also selective in their inhibition of bacterial topoisomerase I-concentrations more than 10-fold higher were required to inhibit the activity of DNA gyrase, human topoisomerase I, and human topoisomerase II $\alpha$ (Figure 1.3, Table 1.4). These results indicate that the mixture-based screening was also successful at discovering selective inhibitors; the polyamine compounds are not promiscuous inhibitors for just any DNA-binding enzyme. 
Table 1.4. TPIMS hits are selective inhibitors of bacterial topoisomerase I

\begin{tabular}{lllll}
\multirow{2}{*}{ Compound } & \multicolumn{2}{l}{$\mathrm{IC}_{50}(\mu \mathrm{M})$ for enzyme: } \\
\cline { 2 - 5 } & M.tuberculosis topoisomerase I & E. coli DNA gyrase & Human topoisomerase I & Human topoisomerase II $\alpha$ \\
\hline $2471-12$ & 7.5 & 160 & 80 & 80 \\
$2471-24$ & 7.5 & $>160$ & $>160$ & 160 \\
$2471-36$ & 15 & $>160$ & $>160$ & $>160$ \\
$2471-80$ & 5 & 160 & 80 & 80 \\
\hline
\end{tabular}

(Sandhaus et al., 2016a). 

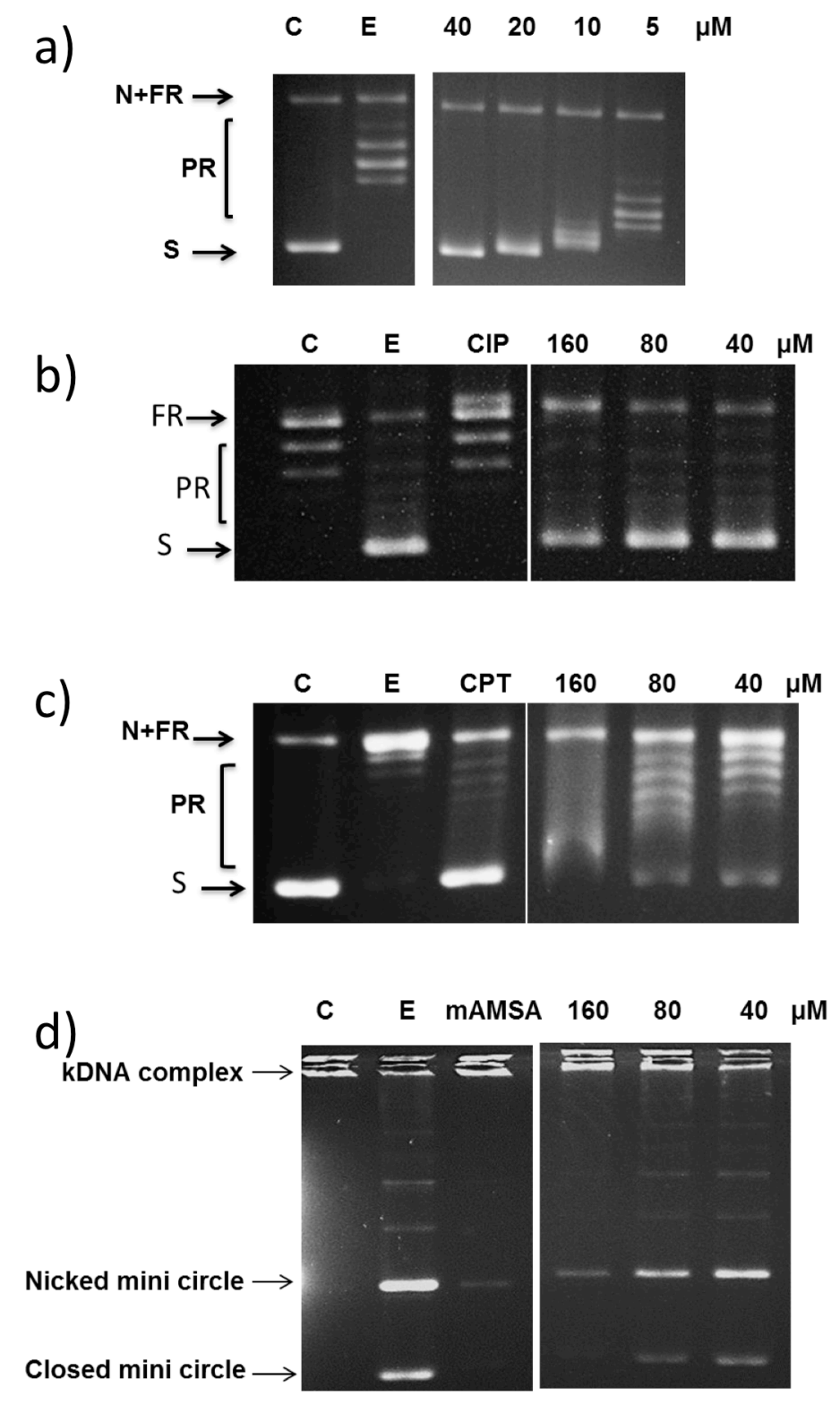

Figure 1.3. TPIMS hits are selective inhibitors of bacterial topoisomerase I: 247180 gel assays shown as example. Inhibition of M.tuberculosis topoisomerase I relaxation activity is strong (a), but inhibition of DNA gyrase (b), human topoisomerase I (c), and human topoisomerase II $\alpha(\mathrm{d})$ is weak. The lanes shown here are from the same gel (Sandhaus et al., 2016a). 


\section{Activity of individual compounds in TPI-2580 library surpasses previous hits}

Following the evaluation of the positional-scanning library and the individual compounds library, another set of individual compounds was synthesized at Torrey Pines. The newest library was intended to further increase the potency of the MtbTopI inhibitors. From the 36 new compounds, a total of eight were very potent inhibitors of bacterial topoisomerase $\mathrm{I}$, with $\mathrm{IC}_{50}$ values below $10 \mu \mathrm{M}$ (Table 1.5). Of the eight, there were five with antibacterial activity below $25 \mu \mathrm{M}$ as well. The most potent by far was $2580-15$, with an $\mathrm{IC}_{50}=0.73 \mu \mathrm{M} .2580-18$ was next most potent, with an $\mathrm{IC}_{50}=3.25 \mu \mathrm{M}$. The compounds are also extremely selective inhibitors, with no inhibition of human topoisomerase I, human topoisomerase II $\alpha$, or DNA gyrase seen up to $100 \mu \mathrm{M}$ (Table 1.6). 
Table 1.5. Information on TPI-2580 library: R1, R2, R3 substitutions and $\mathrm{IC}_{50}$ values for inhibition of $M$. tuberculosis topoisomerase I

\begin{tabular}{|c|c|c|c|c|}
\hline $\begin{array}{c}\text { Compound } \\
\text { Number }\end{array}$ & R1 & $\mathbf{R 2}$ & $\mathbf{R 3}$ & $\begin{array}{l}\text { MtbTopI } \\
\text { Relaxation } \\
\text { Inhibition } \\
\left(\mathrm{IC}_{\mathbf{5 0}}, \boldsymbol{\mu M}\right)\end{array}$ \\
\hline $2580-1$ & R-propyl & R-3-guanidinepropyl & 2-(4-isobutyl-phenyl)-propyl & $>10$ \\
\hline $2580-2$ & R-propyl & R-3-guanidinepropyl & 4-phenylbutyl & $>10$ \\
\hline $2580-3$ & R-propyl & R-3-guanidinepropyl & 1-naphthylethyl & 6.27 \\
\hline $2580-4$ & R-propyl & R-butyl & 2-(4-isobutyl-phenyl)-propyl & $>10$ \\
\hline $2580-5$ & R-propyl & R-butyl & 4-phenylbutyl & $>10$ \\
\hline $2580-6$ & R-propyl & R-butyl & 1-naphthylethyl & $>10$ \\
\hline $2580-7$ & R-propyl & S-3-(methylamino)propyl & 2-(4-isobutyl-phenyl)-propyl & $>10$ \\
\hline $2580-8$ & R-propyl & S-3-(methylamino)propyl & 4-phenylbutyl & $>10$ \\
\hline $2580-9$ & R-propyl & S-3-(methylamino)propyl & 1-naphthylethyl & 10 \\
\hline $2580-10$ & R-propyl & R-2-naphthylmethyl & 2-(4-isobutyl-phenyl)-propyl & $>10$ \\
\hline $2580-11$ & R-propyl & R-2-naphthylmethyl & 4-phenylbutyl & $>10$ \\
\hline $2580-12$ & R-propyl & R-2-naphthylmethyl & 1-naphthylethyl & $>10$ \\
\hline $2580-13$ & R-3-(methylamino)propyl & R-3-guanidinepropyl & 2-(4-isobutyl-phenyl)-propyl & $>10$ \\
\hline $2580-14$ & R-3-(methylamino)propyl & R-3-guanidinepropyl & 4-phenylbutyl & $>10$ \\
\hline $2580-15$ & R-3-(methylamino)propyl & R-3-guanidinepropyl & 1-naphthylethyl & 0.73 \\
\hline $2580-16$ & R-3-(methylamino)propyl & R-butyl & 2-(4-isobutyl-phenyl)-propyl & $>10$ \\
\hline $2580-17$ & R-3-(methylamino)propyl & R-butyl & 4-phenylbutyl & $>10$ \\
\hline $2580-18$ & R-3-(methylamino)propyl & R-butyl & 1-naphthylethyl & 3.25 \\
\hline $2580-19$ & R-3-(methylamino)propyl & S-3-(methylamino)propyl & 2-(4-isobutyl-phenyl)-propyl & $>10$ \\
\hline $2580-20$ & R-3-(methylamino)propyl & S-3-(methylamino)propyl & 4-phenylbutyl & $>10$ \\
\hline $2580-21$ & R-3-(methylamino)propyl & S-3-(methylamino)propyl & 1-naphthylethyl & 10 \\
\hline $2580-22$ & R-3-(methylamino)propyl & R-2-naphthylmethyl & 2-(4-isobutyl-phenyl)-propyl & $>10$ \\
\hline $2580-23$ & R-3-(methylamino)propyl & R-2-naphthylmethyl & 4-phenylbutyl & $>10$ \\
\hline $2580-24$ & R-3-(methylamino)propyl & R-2-naphthylmethyl & 1-naphthylethyl & 8 \\
\hline
\end{tabular}


Table 1.5. cont.

\begin{tabular}{|l|l|c|c|}
\hline $2580-25$ & S-2-naphthylmethyl & R-3-guanidinepropyl & 2-(4-isobutyl-phenyl)-propyl \\
\hline $2580-26$ & S-2-naphthylmethyl & R-3-guanidinepropyl & 4-phenylbutyl \\
\hline $2580-27$ & S-2-naphthylmethyl & R-3-guanidinepropyl & 1-naphthylethyl \\
\hline $2580-28$ & S-2-naphthylmethyl & R-butyl & 2-(4-isobutyl-phenyl)-propyl \\
\hline $2580-29$ & S-2-naphthylmethyl & R-butyl & 4-phenylbutyl \\
\hline $2580-30$ & S-2-naphthylmethyl & R-butyl & 1-naphthylethyl \\
\hline $2580-31$ & S-2-naphthylmethyl & S-3-(methylamino)propyl & 2-(4-isobutyl-phenyl)-propyl \\
\hline $2580-32$ & S-2-naphthylmethyl & S-3-(methylamino)propyl & 4-phenylbutyl \\
\hline $2580-33$ & S-2-naphthylmethyl & S-3-(methylamino)propyl & 1-naphthylethyl \\
\hline $2580-34$ & S-2-naphthylmethyl & R-2-naphthylmethyl & 2-(4-isobutyl-phenyl)-propyl \\
\hline $2580-35$ & S-2-naphthylmethyl & R-2-naphthylmethyl & 4-phenylbutyl \\
\hline $2580-36$ & S-2-naphthylmethyl & R-2-naphthylmethyl & 1-naphthylethyl \\
\hline
\end{tabular}


Table 1.6. Most potent and selective inhibitors from TPI-2580 library

$\mathrm{IC}_{50}(\mu \mathrm{M})$ for enzyme:

\begin{tabular}{lllll} 
Compound & M. tuberculosis topoisomerase I & E. coli DNA gyrase & Human topoisomerase I & Human topoisomerase II $\alpha$ \\
\hline $2580-3$ & 6.3 & $>100$ & $>100$ & $>100$ \\
$2580-15$ & 0.7 & $>100$ & $>100$ & $>100$ \\
$2580-18$ & 3.3 & $>100$ & $>100$ & $>100$ \\
$2580-24$ & 8 & $>85$ & $>85$ & $>85$ \\
$2580-33$ & 8 & $>85$ & $>85$ & $>85$ \\
\hline
\end{tabular}


All of these five compounds displayed increased MIC values (the most effective showed 2- to 4-fold) when MtbTopI was overexpressed in M. smegmatis, confirming the topoisomerase's role as a cellular target (Table 1.7). These compounds are also bactericidal, with complete cell killing activity observed after $\sim 44$ hours of treatment with 2- to 4-fold MIC concentrations.

\section{Table 1.7. Effect of MtbTopI overexpression on MICs of select 2580 inhibitors}

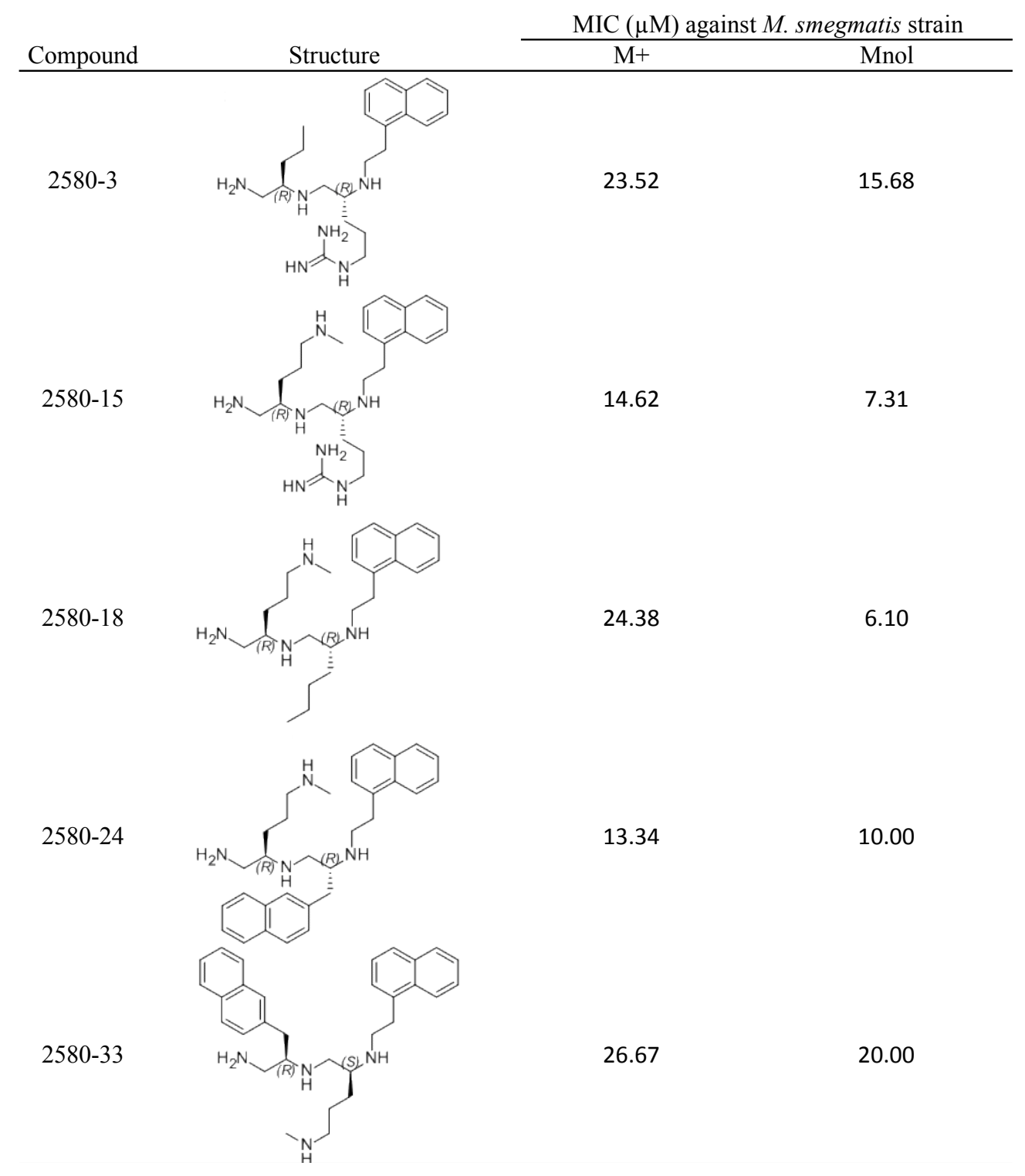




\section{Top compounds act as catalytic inhibitors of bacterial topoisomerase I}

From the two individual compound libraries TPI-2471 and TPI-2580, there are several interesting, potent, and novel inhibitors of bacterial topoisomerase I. The compounds act as catalytic inhibitors in their growth inhibition of $\mathrm{M}+$ and Mnol strainsa poison inhibitor would show lower MIC values for $\mathrm{M}+$, as the increased level of topoisomerase I would offer more targets for poisoning, whereas increased target levels offsets the effect of catalytic inhibitors - and a catalytic mechanism was supported by in vitro studies. Dr. Thirunavukkarasu Annamalai from our lab confirmed that 2471-80 and 2471-12 do not prevent DNA binding with anisotropy assays (Sandhaus et al., 2016a). Gel shift assays indicated the same, and also verified that 2580-15 and 2580-18 do not prevent DNA binding as well (Figure 1.4).

a)

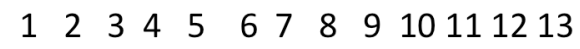

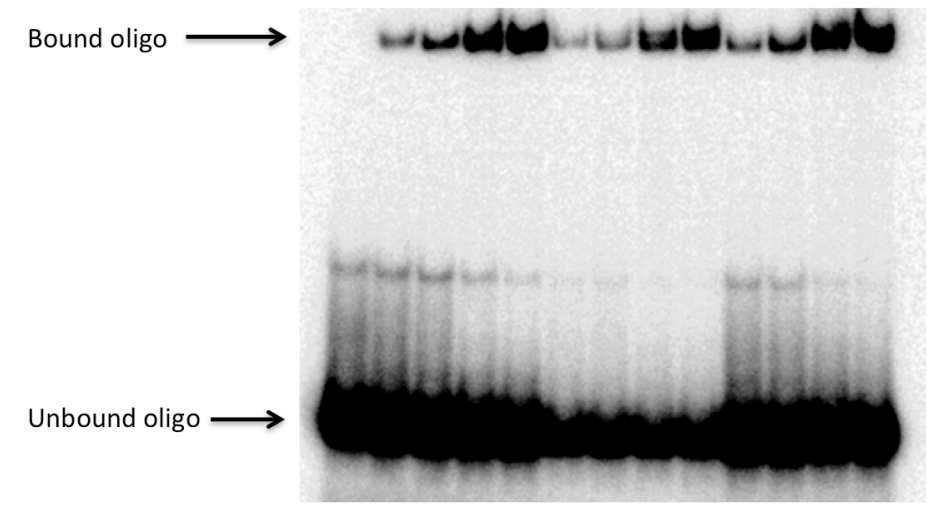

b)
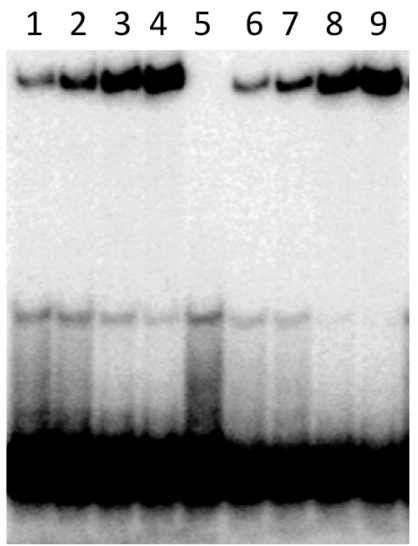

Figure 1.4. Top compounds do not prevent MtbTopI from binding to DNA oligonucleotides: a) Lane 1: STS-32 oligo without enzyme; Lanes 2-5: MtbTopI at 0.1 pmole, 0.2 pmole, 0.5 pmole, and 0.75 pmole; Lanes $6-9$ : MtbTopI at same amounts as mentioned, but in the presence of $20 \mu \mathrm{M}$ 2471-80; Lanes 10 - 13: same enzyme amounts, but in the presence of $10 \mu \mathrm{M}$ 2580-15. b) Lanes $1-4$ : MtbTopI at 0.1 pmole, 0.2 pmole, 0.5 pmole, and 0.75 pmole; Lane 5: STS-32 oligo without enzyme; Lanes 6-9: MtbTopI at same amounts as mentioned, but in the presence of $20 \mu \mathrm{M} 2580-18$. 
Since the compounds do not prevent the enzyme from binding DNA, they must inhibit the activity in another way. Catalytic inhibitors may act by preventing the enzyme from cleaving the DNA, and indeed, that does appear to be the mechanism of inhibition for these compounds. The compounds 2471-12, 2471-80, 2580-15, and 2580-18 were tested in cleavage assays, either with gels containing ethidium bromide, or with radioactive-labeled oligonucleotides. As predicted, the compounds all decreased the amount of DNA cleavage product produced by the topoisomerase. In the ethidium bromide gels, compound 2471-12 was able to prevent approximately $50 \%$ of all DNA cleavage activity at $5 \mu \mathrm{M}$. Compound $2471-80$ prevented over $80 \%$ DNA cleavage at the same concentration. Cleavage inhibition of radioactive-labeled oligonucleotides was also seen, with $20 \mu \mathrm{M} 2580-18$ reducing activity by $\sim 50 \%$. Compound $2580-15$ showed only moderate inhibition of cleavage activity, with an $18 \%$ reduction seen at $10 \mu \mathrm{M}$ of the compound. 
a)

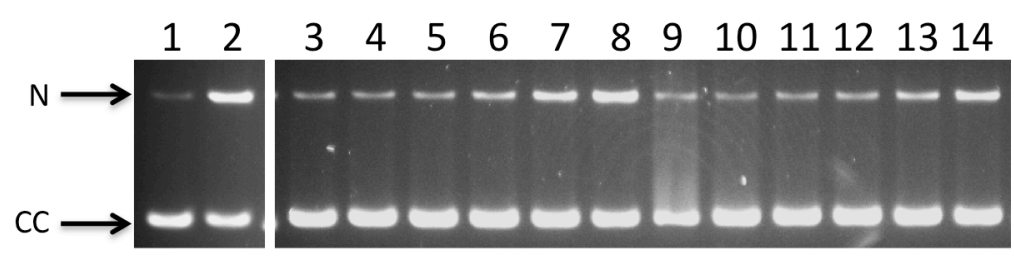

b)

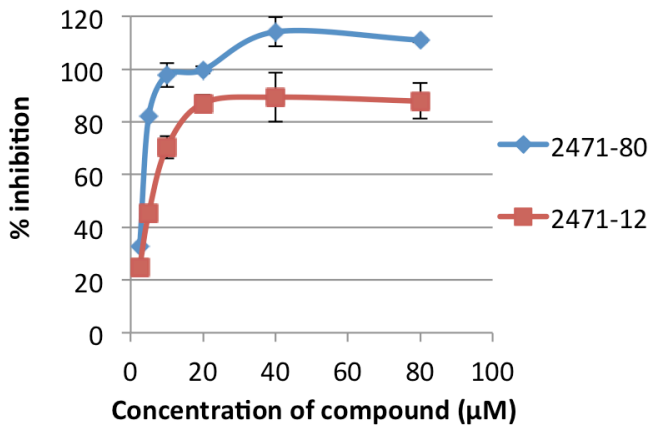

c)

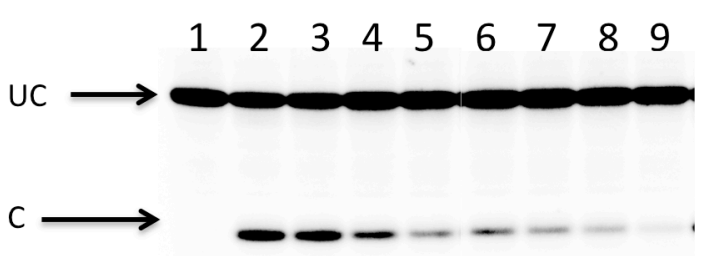

d)

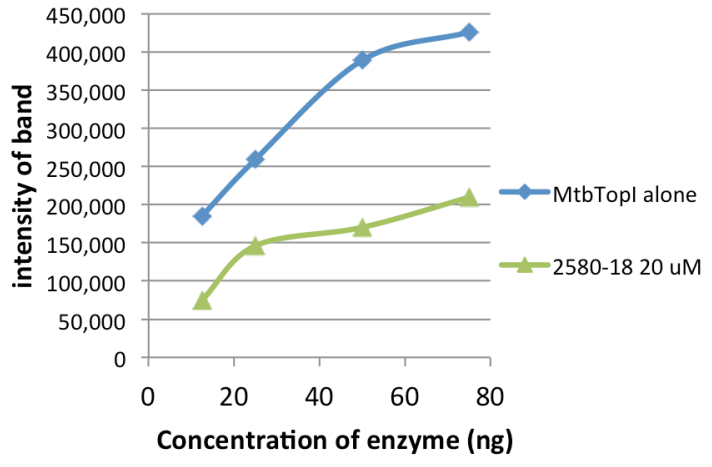

Figure 1.5. TPIMS hit compounds prevent MtbTopI from cleaving DNA: a) Lane 1: Negatively supercoiled pBAD/Thio plasmid DNA; Lane 2: DMF as negative control; Lanes 3 - 8: 80, 40, 20, 10, 5, and $2.5 \mu \mathrm{M} 2471-12$; Lanes 9-14: 80, 40, 20, 10,5 , and $2.5 \mu \mathrm{M}$ 2471-80. Electrophoresis buffer contained $0.5 \mu \mathrm{g} / \mathrm{mL}$ ethidium bromide. The lanes shown here are from the same gel. N: nicked, CC: covalently closed. b) Percent cleavage inhibition by compounds 2471-12 and 2471-80. c) Lane 1: Labeled STS-32 oligo without enzyme; Lanes 2 - 5: MtbTopI at 0.75 pmole, 0.5 pmole, 0.25 pmole, and 0.125 pmole; Lanes 6 - 9: MtbTopI at same amounts as mentioned, but in the presence of $20 \mu \mathrm{M} 2580-18$. UC: uncleaved oligo, C: cleaved oligo. d) Reduction in band signal for oligo cleavage product by compound 2580-18. 


\section{CONCLUSION}

Tuberculosis is a severe threat to global health. With the appearance of multidrug resistant strains, the necessity for novel drugs is more pressing than ever. In the past, there have been antibacterial and anticancer drugs that inhibit type IB and type IIA topoisomerases. Bacterial type IA topoisomerases are a high-value target because clinical antibiotics have never targeted them before. In the current study, different molecular scaffolds not seen before as bacterial topoisomerase I inhibitors were explored. In the original scaffold-ranking library, five polyamine backbones were represented among 50 scaffolds (Sandhaus et al., 2016a). Out of all the scaffolds screened, only TPI-2229 was able to inhibit the relaxation activity of EcTopI at 100 $\mu \mathrm{g} / \mathrm{mL}$. The scaffold was selective as well, with no inhibition of DNA gyrase seen. Positional scanning was able to identify substitutions that are most favorable for inhibition of EcTopI activity. Comparable inhibitory concentrations were observed for MtbTopI. The results presented here demonstrate that varying the substitutions on the polyamine backbone can lead to a new class of bactericidal antimycobacterial agents with topoisomerase I as their cellular target.

Lack of compound uptake by E. coli may be responsible for the deficiency of whole-cell activity observed. The cell wall of Gram-negative bacteria is notoriously difficult to penetrate. Alternatively, the presence of topoisomerase III (an alternate type IA enzyme) in E. coli may be a factor as well. The present study did not discover broad-spectrum antibiotic candidates, or poison inhibitors of bacterial topoisomerase I. Poison inhibitors act not by eliminating topoisomerase activity, but rather by stabilizing the covalent DNA-enzyme intermediate. The poisoning causes the 
topoisomerase to be trapped on the DNA and can be highly effective at causing apoptosis. Topoisomerase poisons would not require that the enzyme activity be essential in order to disrupt cellular growth, while catalytic inhibitors necessarily require their targets be essential. As topoisomerase I is not essential in E. coli, these compounds may be less effective than against $M$. tuberculosis, where topoisomerase I is essential for growth.

Our results have shown that the TPI-2471 and TPI-2580 compound libraries contained extremely effective inhibitors of MtbTopI. The TPI-2471 compounds triggered a rapid cell-killing mechanism involving topoisomerase I, even as they acted as catalytic inhibitors rather than as poisons. The DNA binding and cleavage studies confirmed the results seen in vivo; the compounds were acting to prevent the DNA from being cleaved. As mentioned before, catalytic inhibitors of topoisomerase I can be effective in mycobacteria.

Penetration and retention of individual compounds in bacterial cells is an important determinant of whether an enzyme inhibitor could possess whole-cell activity as well. Lack of penetration or retention may be a reason several of the compounds seen in the two libraries were potent inhibitors of purified MtbTopI, and yet they lacked antimycobacterial growth inhibition activity. There were other compounds that were very effective at preventing mycobacterial growth, and yet they lacked inhibition of MtbTopI. It is possible that other combinations of substitutions along the TPI-2229 scaffold backbone could exert antibacterial activity via an unknown mechanism unrelated to topoisomerase I. In future screens, it may be advisable to use the mycobacterial strains with different levels of topoisomerase I 
expression in cell-based assays alongside the enzyme-based assays. Such a combination would be complementary, as then the scaffolds or compound mixtures that inhibit growth in a manner representative of topoisomerase poisons (i.e., more potent growth inhibition when the target is overexpressed) could be selected and further optimized.

Although we have confirmed that these compounds are acting as catalytic inhibitors of topoisomerase I, we do not know precisely how they are preventing DNA cleavage. Currently, we have sent samples to Dr. Kemin Tan at Argonne National Laboratory in order to potentially obtain a co-crystal of the enzyme bound to the drugs. Such a crystal structure would greatly aid in identifying the specific direct interactions between the enzyme and the compound. Selection of resistant mutants and identification of the causative mutations in the topA gene would further validate MtbTopI as the cellular target. 


\title{
III. CHAPTER 2:
}

\section{DISCOVERY OF NOVEL BACTERIAL TOPOISOMERASE I INHIBITORS BY USE OF IN SILICO DOCKING AND IN VITRO ASSAYS}

\begin{abstract}
Computer-aided drug discovery (CADD) is a popular method of drug discovery. In the present study, virtual screening was performed with Escherichia coli topoisomerase I (EcTopI) and Mycobacterium tuberculosis topoisomerase I (MtbTopI). The crystal structures of these enzymes were used to virtually dock compound libraries and find potential hits. Compounds that were able to virtually bind well on the specified enzyme site were considered hits. Top hits from the virtual screens were tested in the lab to determine potency and specificity. For the screen against MtbTopI, the compounds were docked into the DNA-binding site. The first round yielded several inhibitors of varying degrees of potency. All the top inhibitors shared a common structural motif, and so the motif was used to conduct another virtual screen on MtbTopI. The second screen yielded an even more potent inhibitor, with a lowest $\mathrm{IC}_{50}$ value of $2 \mu \mathrm{M}$. In combination with the known efflux pump inhibitor thioridazine, the compounds were able to prevent bacterial growth, and the strain overexpressing the topoisomerase showed increased MIC values. These inhibitors do not act by preventing DNA binding, and their exact mechanism of inhibition must be studied further. For the screen against EcTopI, compounds were docked into the $\mathrm{Mg}^{2+}$-binding site. Among the top hits that were tested, there were several compounds that showed enzyme inhibition and bacterial growth inhibition.
\end{abstract}


The most potent enzyme inhibitor has an $\mathrm{IC}_{50}$ value between 16 and $30 \mu \mathrm{M}$, and it shows an increase in MIC value when the topoisomerase $\mathrm{I}$ is overexpressed in $M$. smegmatis, indicating the topoisomerase may be a cellular target. The current work demonstrates that in silico screening can be used to discover new classes of bacterial topoisomerase I inhibitors, which may be further optimized for antibiotic purposes.

\section{INTRODUCTION}

The use of computer-aided drug discovery (CADD) has become more popular, and is now very common. There are many clinically approved drugs that were discovered in large part through CADD, including three novel treatments for HIV (Van Drie, 2007). Virtual docking studies can be used to improve existing drugs by changing certain structural aspects to make the compound fit the target's binding site better, and they can also be used to build new classes of drugs. Another common use for virtual studies is to use them as an initial screen, where libraries with hundreds of thousands of individual compounds are docked on the target's crystal structure in order to determine whether they can fit and bind. This kind of in silico docking study can save a lot of time and money, as the amount of compounds that are purchased and physically tested in the laboratory can be reduced tremendously (Sliwoski et al., 2013). A striking validation of virtual screening potential is when separate research groups utilized high-throughput screening and virtual screening, and yet they yielded the same top drug candidate against transforming growth factor- $\beta 1$ receptor kinase (Sawyer et al., 2003; Singh et al., 2003). 
Crystal structures or homology models of the intended drug target are used in virtual docking studies. Crystal structures, however, are static, while proteins are not. Proteins are in constant motion, and so crystal structures can only provide a limited view of the target. Molecular dynamics (MD) studies can be very useful for this reason-movement of the protein can be simulated to reveal new potential binding sites, and then several snapshots of the protein's conformation can be used for virtual docking. Molecular dynamics was invaluable in the discovery of a novel binding trench in HIV integrase, which was then used in the development of raltegravir, a drug used to treat HIV (Schames et al., 2004).

In these studies, bacterial topoisomerase I was the intended drug target. Bacterial topoisomerase I is an essential enzyme in Mycobacterium tuberculosis, and one that can be exploited for antibiotic purposes. One virtual screen was done with the help of Dr. Prem Chapagain from the physics department at Florida International University. In the screen, the crystal structure 5D5H for $M$. tuberculosis topoisomerase I (MtbTopI) was used (Tan et al., 2016). The crystal structure is a truncated form of the protein, missing the last 230 residues at the C-terminal end, which still retains its cutting and rejoining activity of single-stranded DNA. The Elite library from Asinex was used to screen the active site region on the enzyme that is expected to be the DNA binding site. For the screen, Dr. Chapagain carried out molecular dynamics studies to generate 1,000 different poses of the enzyme for docking as well. The compound library was first screened against the original crystal structure, and then the top 1,000 hits from that screen were docked against 1,000 of the MD-generated crystal structure poses. The top hits from the virtual screen were 
purchased and tested in the lab. From among the most potent inhibitors, there was a shared structural motif. A piperidine amide moiety appeared to be aiding the inhibitors in binding to essential amino acids on the protein crystal structure.

The discovery of a common moiety was used to fuel a second round of virtual screens, this time with available Chembridge compounds that contained the motif of interest. Again, the compounds were screened against all 1,000 poses of the enzyme. The top hits were purchased and tested in the lab. From the Chembridge compounds that were purchased, there were several of interest. The most potent compound has an $\mathrm{IC}_{50}$ against MtbTopI of $2 \mu \mathrm{M}$. In the presence of known efflux pump inhibitors, the compound also shows growth inhibition of M. smegmatis that is minimized when the topoisomerase is overexpressed. These results validated virtual screening as a useful tool for discovering novel inhibitors of bacterial topoisomerase I.

In another virtual screen, conducted by Dr. Renate Griffith at the University of New South Wales, the EcTopI crystal structure 3PX7 (Zhang et al., 2011) was used as the intended drug target. In the crystal structure, the protein is bound to a single strand of DNA. Dr. Griffith used the Specs compound library of nearly 200,000 compounds to dock on the EcTopI structure. Specifically, Dr. Griffith docked the compounds into the $\mathrm{Mg}^{2+}$ binding site. The divalent ion is required for the topoisomerase to religate the DNA, and without it, the DNA stays cleaved. A compound that could prevent $\mathrm{Mg}^{2+}$ binding might act as a topoisomerase poison. Although no poison inhibitors were found, there were several compounds of interest that inhibited the EcTopI and were able to prevent M. smegmatis growth, with an increase in MIC when the topoisomerase I is overexpressed. These results further 
confirmed virtual screens as a worthwhile method, and are an interesting start toward using virtual screens as a means of discovering novel topoisomerase I inhibitors for potential antibiotic use.

\section{MATERIALS AND METHODS}

\section{Bacterial topoisomerase I relaxation inhibition assay}

Relaxation inhibition assays for bacterial topoisomerase I were carried out to determine the compounds' ability to prevent enzyme activity. For the Asinex and Chembridge compounds, the assays were carried out in a buffer containing $1 \mathrm{mM}$ EDTA, $20 \mathrm{mM} \mathrm{NaCl}, 40 \mathrm{mM}$ Tris- $\mathrm{HCl}$, and $5 \mathrm{mM} \mathrm{MgCl} 2$ (final concentrations). Briefly, purified bacterial topoisomerase I was added to a buffer as described above in order to achieve $25 \mathrm{ng} /$ reaction mixture. The enzyme mixture was aliquoted into 10 $\mu \mathrm{L}$ before the addition of $0.5 \mu \mathrm{L}$ of the compound of interest at various concentrations dissolved in DMSO. The mixtures were then incubated for 15 minutes at $37^{\circ} \mathrm{C}$ before adding $150 \mathrm{ng}$ of purified $\mathrm{pBAD} /$ Thio plasmid $\mathrm{DNA}$ in the same buffer for a final volume of $20 \mu \mathrm{L}$. The mixtures were further incubated at $37^{\circ} \mathrm{C}$ for 30 minutes to allow for the enzyme's relaxation activity. The reactions were stopped by the addition of $4 \mu \mathrm{L}$ of a buffer containing $5 \%$ SDS, $0.25 \%$ bromophenol blue, and $25 \%$ glycerol. The samples were then run on a $1 \%$ agarose gel overnight at $25 \mathrm{~V}$ before ethidium bromide staining (Godbole et al., 2014b). M. tuberculosis topoisomerase I relaxation inhibition assays for the Specs compounds were carried out as mentioned in chapter 1 . 


\section{DNA gyrase supercoiling inhibition assay}

The supercoiling activity of DNA gyrase was assayed by agarose gel electrophoresis. The gyrase was obtained from New England BioLabs or was purified in our lab. $2 \mathrm{U}$ of the enzyme was added to a reaction buffer provided by the manufacturer (35 mM Tris- $\mathrm{mCl}, 24 \mathrm{mM} \mathrm{KCl,} 4 \mathrm{mM} \mathrm{MgCl} 2,2 \mathrm{mM}$ DTT, $1.75 \mathrm{mM}$ ATP, $5 \mathrm{mM}$ spermidine, $0.1 \mathrm{mg} / \mathrm{mL}$ BSA, and $6.5 \%$ glycerol). $0.5 \mu \mathrm{L}$ of the compounds dissolved in DMSO or the solvent alone were added to the enzyme mixture. $300 \mathrm{ng}$ of relaxed covalently closed plasmid DNA was then added for a final volume of $20 \mu \mathrm{L}$. The reactions were incubated for 30 minutes at $37^{\circ} \mathrm{C}$ before termination by the addition of $4 \mu \mathrm{L}$ of the SDS stop buffer. The samples were then loaded into a $1 \%$ agarose gel and run at $25 \mathrm{~V}$ overnight (Cheng et al., 2013).

\section{Human topoisomerase I relaxation inhibition assay}

The relaxation activity of human topoisomerase I (HTOPI) was assayed via gel electrophoresis. Purified human topoisomerase I, purchased from TopoGen, was added for $0.5 \mathrm{U}$ of the enzyme suspended in a buffer containing $10 \mathrm{mM}$ Tris, $\mathrm{pH} 8.0$, $150 \mathrm{mM} \mathrm{NaCl}, 0.1 \% \mathrm{BSA}, 0.1 \mathrm{mM}$ spermidine, and 5\% glycerol. The compounds were then added to the enzyme at the indicated concentrations before the addition of $160 \mathrm{ng}$ of supercoiled $\mathrm{pBAD} / \mathrm{Thio}$ plasmid DNA. The samples were incubated for 30 minutes at $37^{\circ} \mathrm{C}$ and then they were terminated by the addition of a buffer containing $5 \%$ SDS, $0.25 \%$ bromophenol blue, and $25 \%$ glycerol. They were then run on a $1 \%$ agarose gel before staining with ethidium bromide (Cheng et al., 2013). 


\section{M. smegmatis growth inhibition assay}

The antibacterial properties of the compounds were determined with growth inhibition assays. Cultures were grown in Middlebrook 7H9 medium supplemented with $0.2 \%$ glycerol, $0.05 \%$ Tween 80 , and 10\% ADN (albumin, dextrose, sodium chloride) for 1 day. $50 \mu / \mathrm{mL}$ hygromycin B was added to the overexpression strains as well. The cultures were then diluted 1:100 in the same medium without ADN and grown overnight until the stationary growth phase was reached. The cells were then adjusted to $\mathrm{OD}_{600}=0.1$ and diluted further 1:5. $50 \mu \mathrm{L}$ of diluted cells were added to clear-bottom 96 -well plates containing $50 \mu \mathrm{L}$ of the compounds serially diluted in the same medium. For assays containing known efflux pump inhibitors, the protocol was similar. The efflux pump inhibitors were added by creating 100x stocks and adding 1 $\mu \mathrm{L}$ to each well. Thioridazine was included at $12.5 \mu \mathrm{g} / \mathrm{mL}$. The plates were grown at $37^{\circ} \mathrm{C}$ for 48 hours. Absorbance readings were taken every $\sim 4$ hours until the cells had grown to saturation $\left(\mathrm{OD}_{600}=1.5\right)$. After the cells reached saturation, resazurin was added for a final concentration of $0.002 \%$ in each well. Resazurin is a blue/purple dye that becomes fluorescent pink upon reduction by NADH in the presence of living cells (Prutz, 1994). Fluorescence readings were taken 18 hours later $(E x=540 \mathrm{~nm}$, $\mathrm{Em}=590 \mathrm{~nm})$.

\section{MtbTopI-DNA binding gel shift assay}

The compounds' ability to prevent the topoisomerase from binding DNA was assayed via gel shift as mentioned previously in chapter 1 . The enzyme was added to the buffer $(20 \mathrm{mM}$ Tris, $100 \mu \mathrm{g} / \mathrm{mL}$ BSA, 18\% glycerol, and $0.5 \mathrm{mM}$ EDTA) such 
that the final amount was ranging from $0.1 \mathrm{pmole}(10 \mathrm{ng})$ to 1 pmole $(100 \mathrm{ng})$. The compound was then added to the enzyme before 0.5 pmole of the labeled oligonucleotide STS-32 was added. The samples were incubated at $37^{\circ} \mathrm{C}$ for 5 minutes, and then left on ice for another 5 minutes. After the addition of gel shift loading buffer, the samples were loaded and run. Once completed, the gels were dried before Phosphor-Image analysis.

\section{RESULTS AND DISCUSSION}

\section{Asinex virtual screen}

Two screens were carried out sequentially; the first docked the Asinex Elite library of 104,000 lead-like compounds against the 5D5H crystal structure using AutoDock Vina (Morris et al., 2009). From the first screen, a second round docked the top 1,000 scored compounds against the 1,000 MD-generated protein poses. The MD-generated structures opened the DNA-binding pocket and allowed the compounds to bind much deeper inside the pocket, as opposed to binding closer to the surface on the 5D5H crystal structure (Figure 2.1). The output was used to compile a list of the top binding compounds. All of the hits were scanned using the FAF-Drugs3 program to filter out pan-assay interference compounds (PAINS) (Baell and Walters, 2014; Baell and Holloway, 2010; Lagorce et al., 2008). PAINS compounds tend to interfere with screening because of their non-specific interactions, and give false positive results in most assays. With any potential PAINS compounds removed, the top 82 compounds from the virtual screen were purchased for testing in the lab. 
(a)

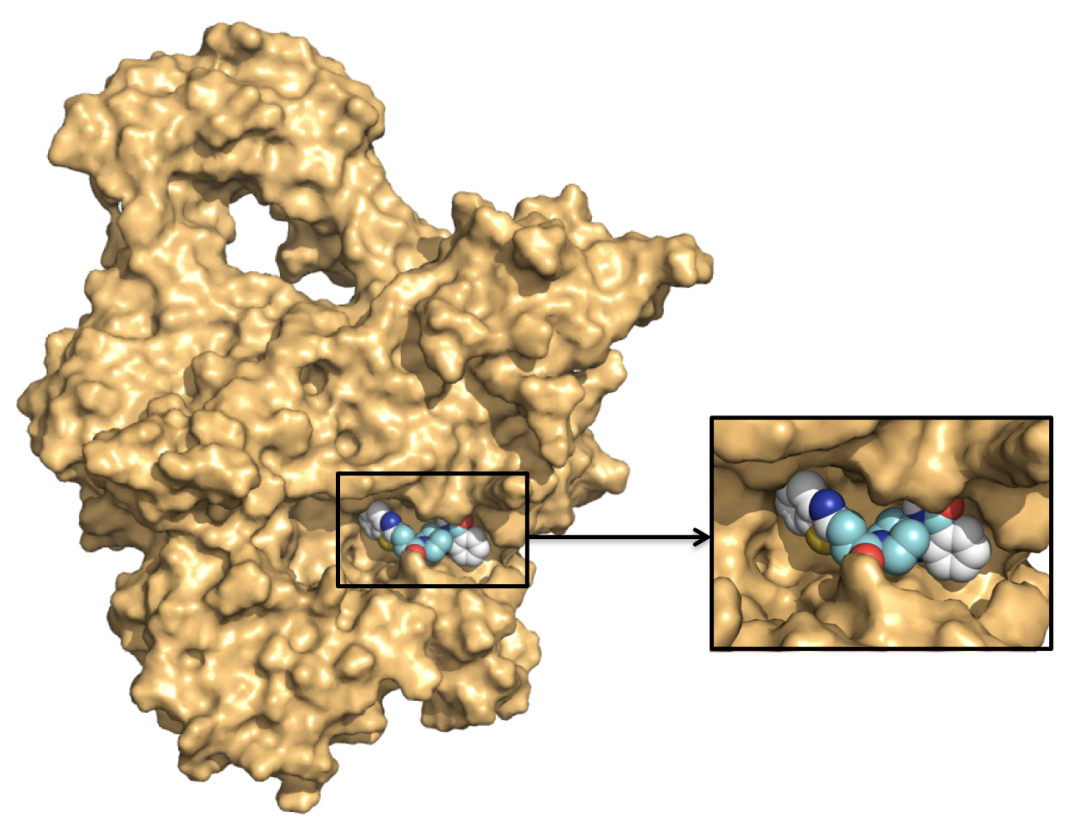

(b)

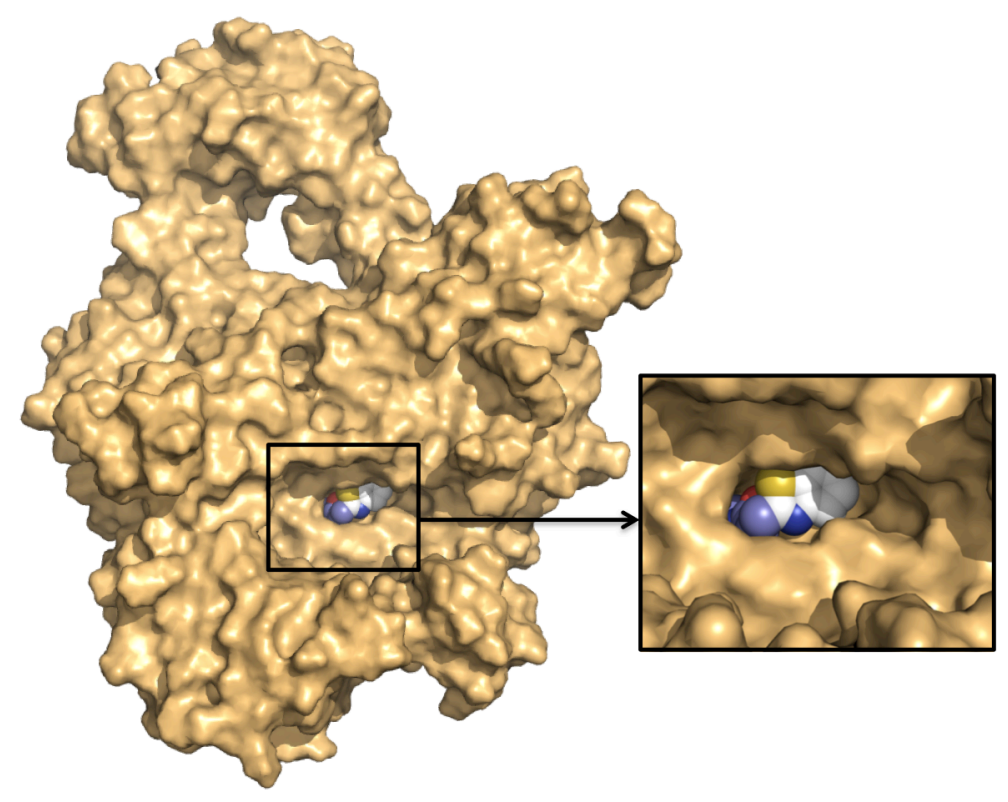

Figure 2.1. Molecular dynamics studies opened the DNA-binding pocket on MtbTopI: The Asinex compounds bind closer to the surface on the 5D5H crystal structure (a), while they can bind deeper inside the pocket on some of the MDgenerated structures (b). Shown is Compound 1. 


\section{Top candidates from screening of Asinex library}

The 82 purchased Asinex compounds were tested for inhibition of the relaxation activity of MtbTopI. Six compounds were found to inhibit MtbTopI with $\mathrm{IC}_{50} \leq 500 \mu \mathrm{M}$ (Table 2.1). Compound 1 (SYN 12502158), with an $\mathrm{IC}_{50}$ of $15.6 \mu \mathrm{M}$, was the most potent inhibitor against MtbTopI, with 4-fold or more selectivity for the type IA bacterial topoisomerase versus the type IB human topoisomerase I (HTOPI). Compounds $2-4$ had $\mathrm{IC}_{50}$ values ranging from $62.5 \mu \mathrm{M}$ to $125 \mu \mathrm{M}$, and did not inhibit human topoisomerase I when tested at $250 \mu \mathrm{M}$.

Table 2.1. IC $_{50}$ values of Asinex hit compounds against MtbTopI and HTOPI

\begin{tabular}{|c|c|c|c|}
\hline $\begin{array}{l}\text { Compound } \\
\text { Number }\end{array}$ & Asinex ID & $\begin{array}{c}\text { MtbTopI } \\
\text { Relaxation } \\
\text { Inhibition }\left(\mathrm{IC}_{\mathbf{5 0}},\right. \\
\mu \mathrm{M})\end{array}$ & $\begin{array}{c}\text { HTOPI Relaxation } \\
\text { Inhibition }\left(\text { IC }_{50}\right. \\
\mu \mathrm{M})\end{array}$ \\
\hline 1 & SYN 12502158 & 15.6 & 93.75 \\
\hline 2 & AOP 19767246 & 62.5 & $>250$ \\
\hline 3 & ADD 15417014 & 62.5 & $>250$ \\
\hline 4 & ADM 12439418 & 125 & $>250$ \\
\hline 5 & LEG 11118762 & 250 & n.d. \\
\hline 6 & AEM 11113320 & 500 & n.d. \\
\hline
\end{tabular}

n.d. - not determined

\section{Asinex hits share a common structural moiety}

Although the first screen was successful at finding some MtbTopI inhibitors, there is a need to improve the potency of inhibition. They were an interesting starting point for our first virtual screening against topoisomerase I done at FIU. Noticeably, the Asinex compounds identified contain a common structural motif - a piperidine amide located in the center of the molecule, with extremely varying R-groups 
attached to either side (Figure 2.2). After noting the similarity, the docking positions for these compounds were examined to determine the significance of the common moiety.

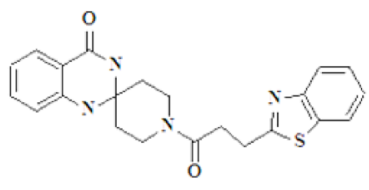

1

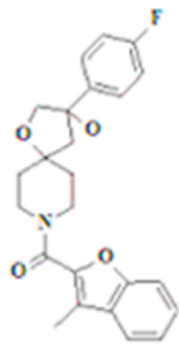

4

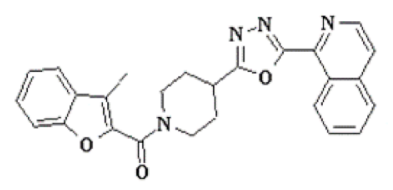

2

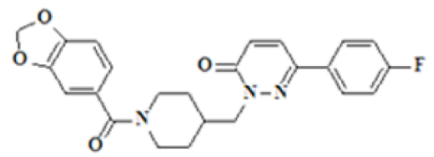

5

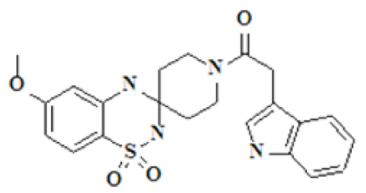

3

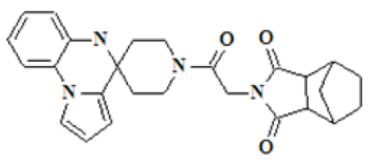

6

Figure 2.2. Structures of Asinex compounds identified from in silico screening and in vitro MtbTopI assay

In many of the top binding positions of these compounds in the MD-generated structures, the motif appears to be interacting with key residues in the DNA-binding pocket strictly conserved for catalysis. Specifically, the amide oxygen of the motif interacts with Arg167, while the amide nitrogen interacts with Glu115 (Figure 2.3). The corresponding residues in E. coli topoisomerase I can be seen to interact with the ribose ring on the DNA substrate in the covalent complex (Zhang et al., 2011). These residues are both conserved in the topoisomerase I DNA-binding region (Cheng et al., 2005). 
The common structural motif may serve as a lynchpin to hold the compound in place at the active site while the various R-group side chains interact with the protein in other ways. It may account for the enzyme inhibition observed in these compounds. However, the moiety is not by itself sufficient for enzyme inhibition, as many of the Asinex compounds contained the motif and did not show enzyme inhibition. Certain substitutions may prevent the compound from binding to the enzyme.
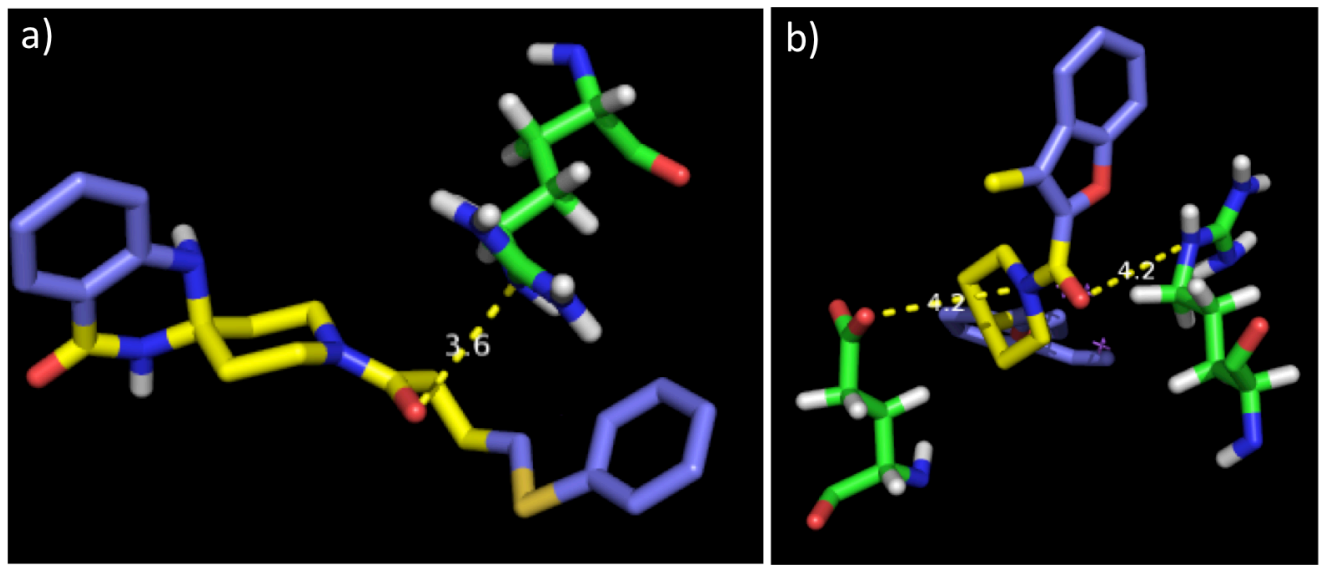

Figure 2.3. Tertiary amide moiety on Asinex hits interacts with key residues: The common piperidine amide moiety on the Asinex hits shows interactions with Arg167 and Glu115. Shown are (a) Compound 1 with Arg167, (b) Compound 2 with both Arg167 and Glu115.

\section{Chembridge virtual screen hits can inhibit bacterial topoisomerase I selectively}

After finding the common structural motif, a second virtual screen was conducted to further identify inhibitors of MtbTopI related to this cyclic tertiary amide motif. The screen was conducted on compounds from Chembridge that contained the similar moieties. Over 200 compounds were found that contained such 
cyclic tertiary amide substructures, and they were all docked using the same procedure as mentioned in the Asinex screen. Top compounds from the Chembridge library were found to exhibit the same interactions in the DNA-binding pocket as seen previously in the Asinex library. From the docking scores, the top binders were selected and 96 compounds were purchased for further testing.

First, the compounds were tested in vitro for inhibition of the purified MtbTopI to ascertain their ability to inhibit enzymatic activity. Eighteen compounds were found to have $\mathrm{IC}_{50} \leq 125 \mu \mathrm{M}$ (Table 2.2). Compound 7 (Chembridge ID 49981944) had an $\mathrm{IC}_{50}$ significantly lower than the other compounds tested $-2 \mu \mathrm{M}$ when compared with the next-lowest $\mathrm{IC}_{50}$ of $62.5 \mu \mathrm{M}$. The six compounds with $\mathrm{IC}_{50}$ $\leq 62.5 \mu \mathrm{M}$ (Compounds $7-12$, Figure 2.4) were screened against the human topoisomerase I, HTOPI, to determine whether they are selective for bacterial topoisomerase. None of the compounds inhibited the human enzyme below $250 \mu \mathrm{M}$, indicating that they are specific for the bacterial topoisomerase. The top hits were also tested against DNA gyrase, and no inhibition was seen up to $500 \mu \mathrm{M}$, indicating that the compounds are specific to the type I enzyme as well (Figure 2.5). 

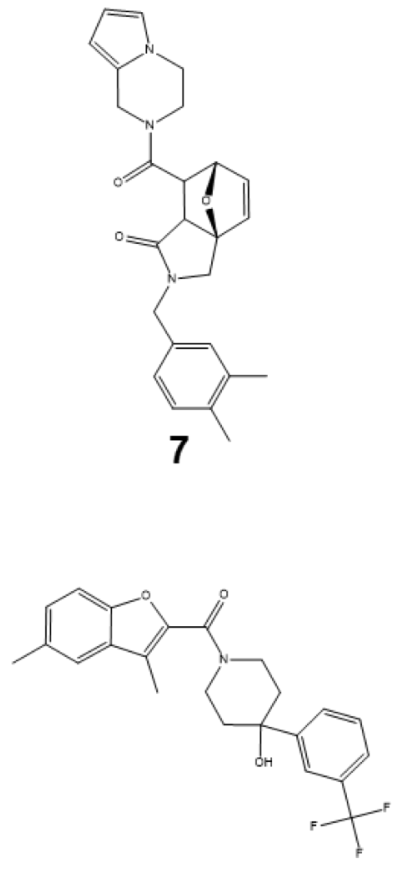

10

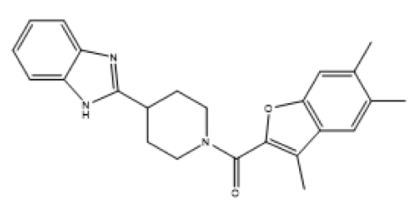

8

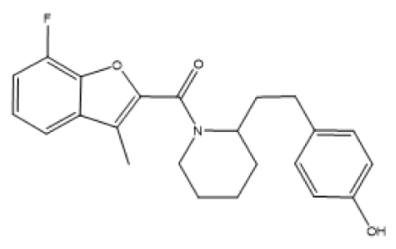

11

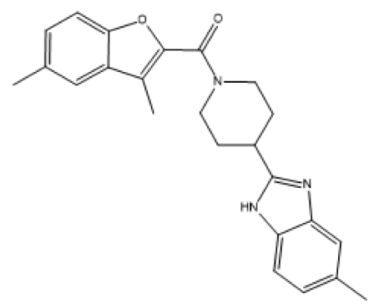

9

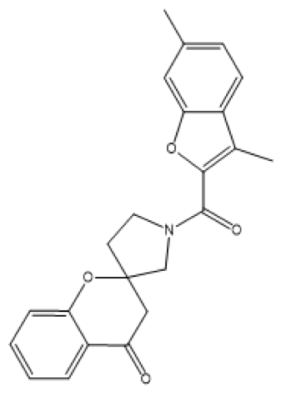

12

Figure 2.4. Structures of Chembridge compounds with $\mathrm{IC}_{50} \leq 62.5 \mu \mathrm{M}$ 
Table 2.2. IC $_{50}$ values of Chembridge hit compounds against MtbTopI, HTOPI, and $E$. coli DNA gyrase

\begin{tabular}{|c|c|c|c|c|}
\hline $\begin{array}{c}\text { Compound } \\
\text { Number }\end{array}$ & $\begin{array}{c}\text { Chembridge } \\
\text { ID }\end{array}$ & $\begin{array}{c}\text { MtbTopI } \\
\text { Relaxation } \\
\text { Inhibition } \\
\text { IC }_{\mathbf{5 0}, \boldsymbol{\mu M})}\end{array}$ & $\begin{array}{c}\text { HTOPI } \\
\text { Relaxation } \\
\text { Inhibition } \\
\text { (IC }_{\mathbf{5 0}, \boldsymbol{\mu M})}\end{array}$ & $\begin{array}{c}\text { E. coli DNA } \\
\text { Gyrase } \\
\text { Supercoiling } \\
\text { Inhibition } \\
\text { (IC }\end{array}$ \\
\hline $\mathbf{5 0}, \boldsymbol{\mu M})$ \\
\hline $\mathbf{8}$ & 49981944 & 2 & $>500$ & $>500$ \\
\hline $\mathbf{9}$ & 9302190 & 62.5 & $>500$ & $>500$ \\
\hline $\mathbf{1 0}$ & 88421238 & 62.5 & $>500$ & $>500$ \\
\hline $\mathbf{1 1}$ & 73600812 & 62.5 & $>500$ & $>500$ \\
\hline $\mathbf{1 2}$ & 80760557 & 62.5 & $>500$ & $>500$ \\
\hline $\mathbf{1 3}$ & 17951480 & $62.5-125$ & $>500$ & $>500$ \\
\hline $\mathbf{1 4}$ & 15044152 & $62.5-125$ & n.d. & n.d. \\
\hline $\mathbf{1 5}$ & 7931615 & $62.5-125$ & n.d. & n.d. \\
\hline $\mathbf{1 6}$ & 7875243 & 125 & n.d. & n.d. \\
\hline $\mathbf{1 7}$ & 19138872 & 125 & n.d. & n.d. \\
\hline $\mathbf{1 8}$ & 19046220 & 125 & n.d. & n.d. \\
\hline $\mathbf{1 9}$ & 67687224 & 125 & n.d. & n.d. \\
\hline $\mathbf{2 0}$ & 18538504 & 125 & n.d. & n.d. \\
\hline $\mathbf{2 1}$ & 68171804 & 125 & n.d. & n.d. \\
\hline $\mathbf{2 2}$ & 44982805 & 125 & n.d. & n.d. \\
\hline $\mathbf{2 3}$ & 67941389 & 125 & n.d. & n.d. \\
\hline $\mathbf{2 4}$ & 63920724 & 125 & n.d. & n.d. \\
\hline
\end{tabular}

n.d. - not determined 

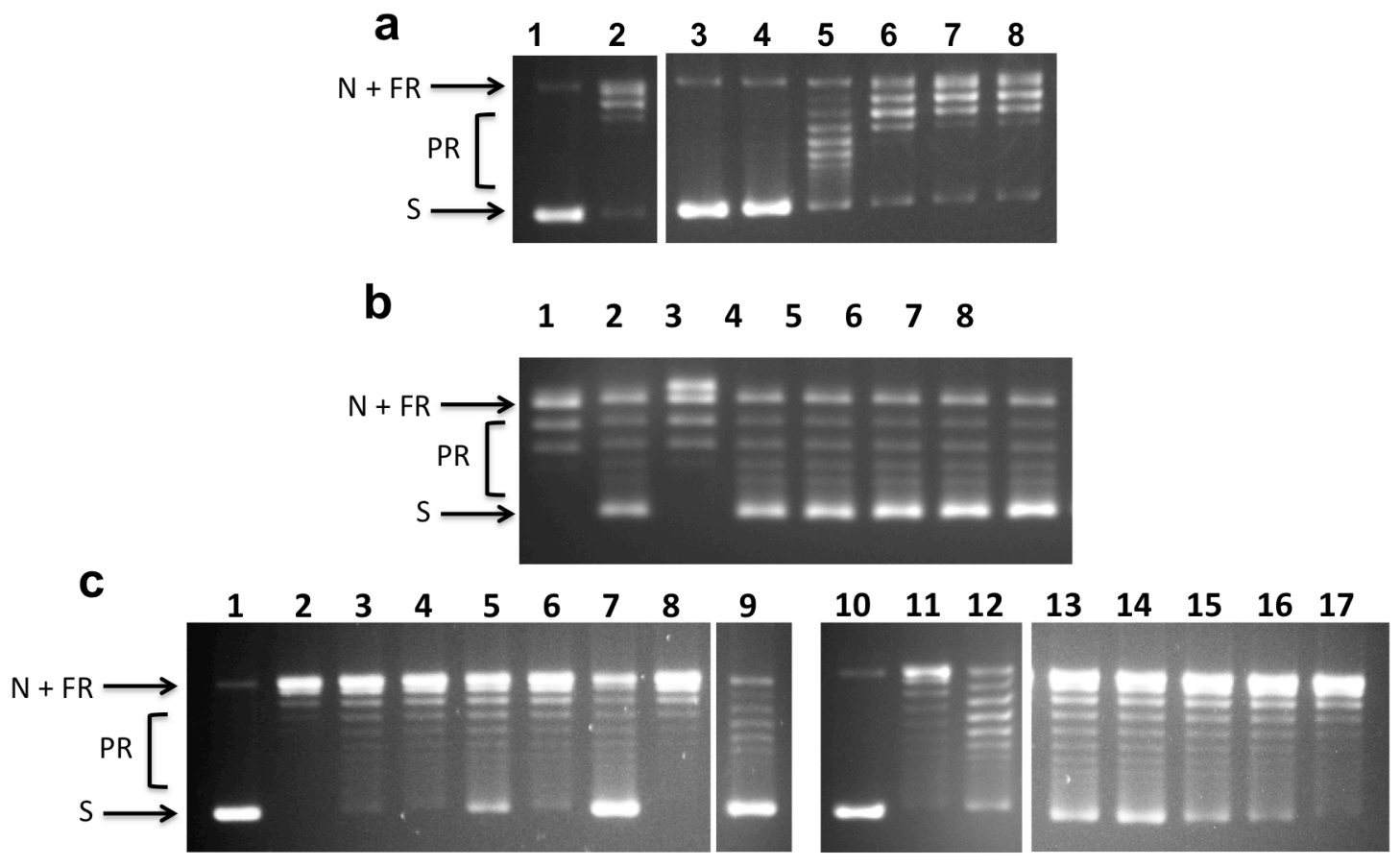

Figure 2.5. Selective inhibition of MtbTopI by Chembridge hit compounds: a) Inhibition of MtbTopI relaxation activity by Compound 7. Lane 1: negatively supercoiled pBAD/Thio plasmid DNA; Lane 2: DMSO as negative control; Lanes 3 8: $8,4,2,1,0.5$, and $0.25 \mu \mathrm{M}$ Compound 7. b) Compound 7 does not inhibit DNA gyrase supercoiling activity. Lane 1: relaxed covalently closed circular DNA; Lane 2: DMSO as negative control; Lane 3: $150 \mu \mathrm{M}$ ciprofloxacin; Lanes $4-8: 500,250,125$, 62.5, and $31.3 \mu \mathrm{M}$ Compound 7. c) Assay of Chembridge top hits for inhibition of human topoisomerase I relaxation activity. Lane 1: negatively supercoiled $\mathrm{pBAD} / \mathrm{Thio}$ plasmid DNA; Lane 2: DMSO as negative control; Lanes 3 - 8: Compounds 7, 8, 9, 10, 11, and 12, respectively, at $500 \mu \mathrm{M}$; Lane 9: $200 \mu \mathrm{M}$ camptothecin. The lanes shown here are from the same gel. S: supercoiled DNA, N: nicked DNA, FR: fully relaxed DNA, PR: partially relaxed DNA. 


\section{Top hits can prevent bacterial growth in the presence of efflux pump inhibitors}

The non-pathogenic M. smegmatis was used in antibacterial assays to assess whether the identified MtbTopI inhibitors can inhibit the growth of mycobacteria. If inhibition of topoisomerase I catalytic activity is part of the antibacterial mode of action, the MIC should increase if recombinant MtbTopI is overexpressed. Either weak or no antibacterial activity was observed in the initial antibacterial assays. Due to the weak antibacterial activity, the known efflux pump inhibitor thioridazine (TZ) was used in combination with the compounds. It has been shown that combining drugs with efflux pump inhibitors can have a synergistic effect, and can help in sensitizing the cells to antibiotics. Thioridazine can enhance cell killing by inhibiting the genetic expression and activity of efflux pumps that can extrude drugs before they are able to reach their intended target (Amaral and Viveiros, 2012; Coelho et al., 2015).

To study these interactions, assays combining thioridazine with several of the top hit compounds were employed to discern any synergistic effects. As predicted, the results (Table 2.3) indicate that the presence of thioridazine was able to lower the MIC values of the compounds, and more significantly, they are shifted higher with the overexpression of recombinant MtbTopI. The shift in MIC suggests that inhibition of MtbTopI activity contributes to the antibacterial activity. The difficulty with penetration of the mycobacterial cell wall may be the reason for lack of direct correlation between $\mathrm{MIC}$ and $\mathrm{IC}_{50}$ values. 
Table 2.3. MIC values for antibacterial activity of identified MtbTopI inhibitors against $M+$ and Mnol strains

\begin{tabular}{|c|c|c|c|c|}
\hline $\begin{array}{c}\text { Compound } \\
\text { Number }\end{array}$ & $\begin{array}{c}\text { Mnol } \\
\text { Growth } \\
\text { Inhibition } \\
(\mathbf{M I C}, \boldsymbol{\mu M})\end{array}$ & $\begin{array}{c}\text { M+ Growth } \\
\text { Inhibition } \\
\mathbf{( M I C ,} \boldsymbol{\mu M})\end{array}$ & $\begin{array}{c}\text { Mnol } \\
\text { Growth } \\
\text { Inhibition } \\
\text { with TZ } \\
\text { (MIC, } \boldsymbol{\mu M})\end{array}$ & $\begin{array}{c}\text { M+ Growth } \\
\text { Inhibition } \\
\text { with TZ } \\
(\mathbf{M I C}, \boldsymbol{\mu M})\end{array}$ \\
\hline $\mathbf{1}$ & $>500$ & $>500$ & $>500$ & $>500$ \\
\hline $\mathbf{2}$ & 187.5 & $>250$ & 31.3 & 62.5 \\
\hline $\mathbf{3}$ & 250 & $>250$ & 31.3 & 62.5 \\
\hline $\mathbf{7}$ & $>500$ & $>500$ & 500 & $>500$ \\
\hline $\mathbf{8}$ & $>500$ & $>500$ & 23.45 & 31.3 \\
\hline $\mathbf{9}$ & 125 & $>500$ & 23.45 & 31.3 \\
\hline $\mathbf{1 0}$ & 125 & $>500$ & 23.45 & 46.9 \\
\hline $\mathbf{1 1}$ & 500 & $>500$ & 46.9 & 125 \\
\hline $\mathbf{1 2}$ & $>500$ & $>500$ & 500 & $>500$ \\
\hline
\end{tabular}

MtbTopI inhibition occurs at a step following formation of the DNA-enzyme complex

The compounds did not affect the enzyme's ability to bind DNA. In the gel shift studies, the enzyme was titrated in the presence of $2 \mathrm{x} \mathrm{IC}_{50}$ of compounds 7 and 9. There was no observed decrease in DNA binding, indicating that the compounds may be inhibiting the enzyme's activity at a step following DNA binding (Figure 2.6). From their pattern of growth inhibition observed in $\mathrm{M}+$ and Mnol strains, it is likely they are acting as catalytic inhibitors. 

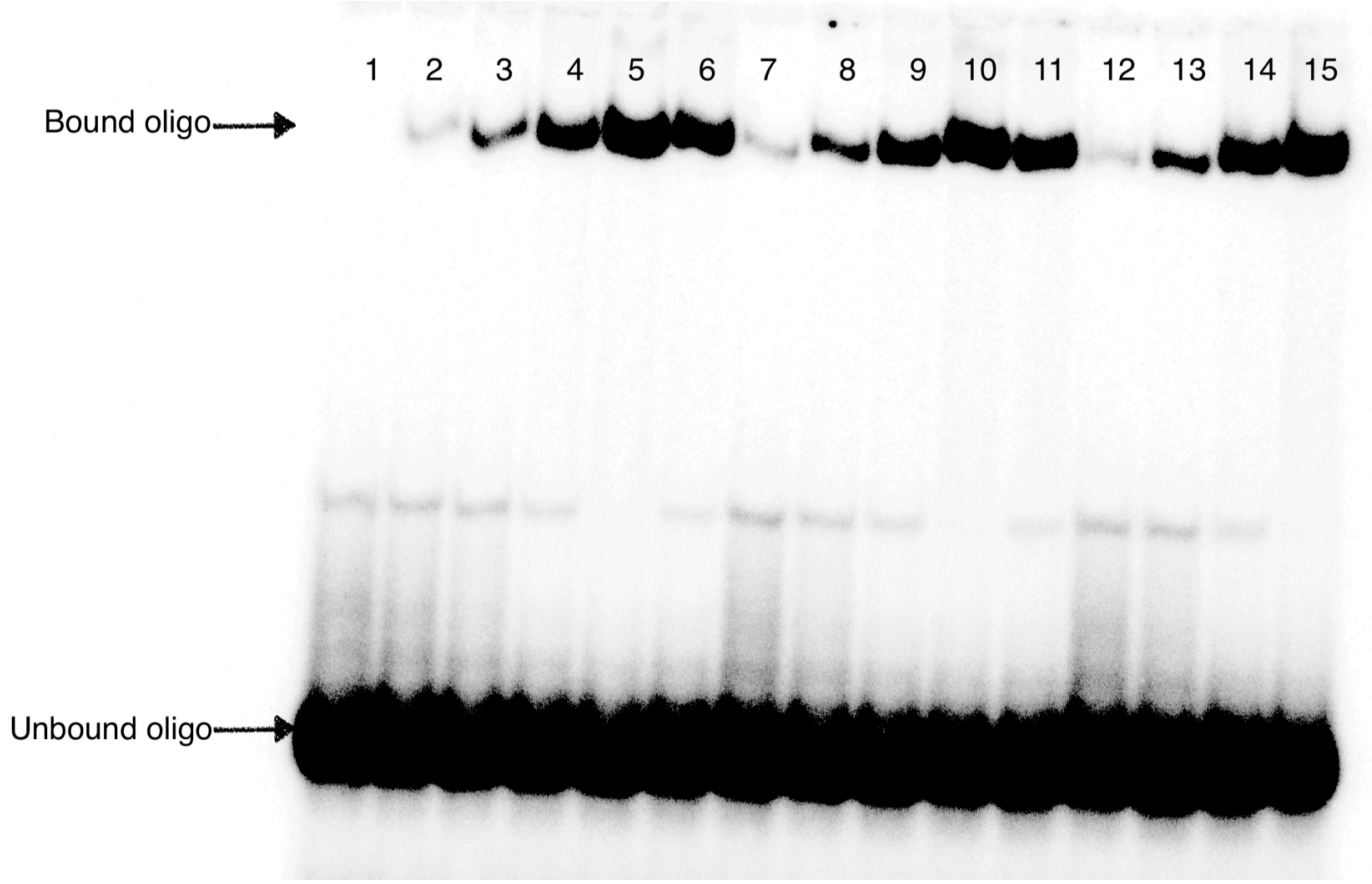

Figure 2.6. ChemBridge hits do not prevent MtbTopI from binding to DNA oligonucleotides: Lane 1: STS-32 oligo without enzyme; Lanes $2-6$ : MtbTopI at 0.1 pmole, 0.2 pmole, 0.5 pmole, 0.75 pmole, and 1 pmole; Lanes 7 - 11: MtbTopI at same amounts as mentioned, but in the presence of $2 \mathrm{x} \mathrm{IC}_{50}$ compound $7(4 \mu \mathrm{M})$; Lanes 12 - 15: same enzyme amounts (until 0.75 pmole) in the presence of $2 \mathrm{x} \mathrm{IC}_{50}$ compound $9(125 \mu \mathrm{M})$.

\section{Virtual screen of EcTopI-Specs compounds}

In a completely separate virtual screen, this time against EcTopI, the Specs compound library was screened. 205 of the top compounds were purchased. There were several that were found to display inhibition of bacterial type I topoisomerase, as well as antibacterial activity. Some of the compounds were strong topoisomerase inhibitors with weaker antibacterial activity, such as compound 168, which has an $\mathrm{IC}_{50}$ against $E$. coli and $M$. tuberculosis topoisomerase I between 15 and $30 \mu \mathrm{M}$ 
(Figure 2.7). The compound's antibacterial activity is moderate, with its lowest observed $\mathrm{MIC}_{90}$ being $200 \mu \mathrm{M}$ against wild type M. smegmatis.

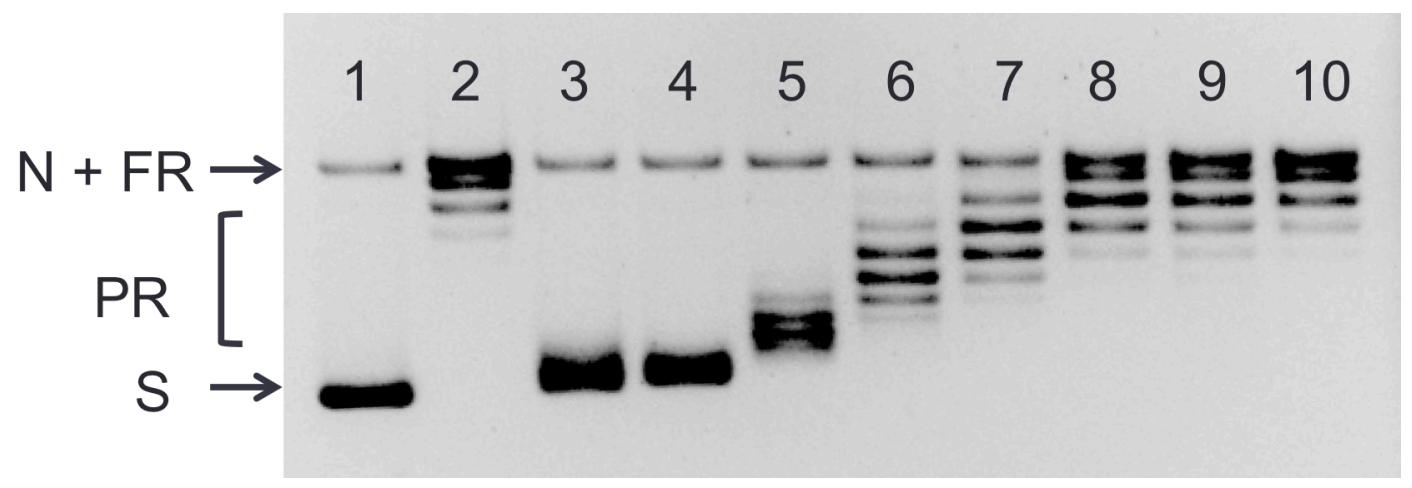

Figure 2.7. Inhibition of EcTopI relaxation activity by Specs compound 168: Lane 1: negatively supercoiled $\mathrm{pBAD} /$ Thio plasmid DNA; Lane 2: DMSO as negative control; Lanes 3 - 10: 250, 125, 62.5, 31.3, 15.6, 7.8, 3.9, and $1.9 \mu \mathrm{M}$ compound 168 . $\mathrm{N}$ : nicked, FR: fully relaxed, PR: partially relaxed, S: supercoiled.

Other compounds were found to have very good antibacterial activity, with weak inhibition of bacterial type I topoisomerase. These compounds may have other targets in the cell besides topoisomerase I. Two particular compounds, compounds $\mathbf{3 8}$ and 161, showed $\mathrm{IC}_{50}$ values against $E$. coli and $M$. tuberculosis topoisomerase I of $500 \mu \mathrm{M}$, but low MIC $(6.25-12.5 \mu \mathrm{M})$ values against the M. smegmatis strains. Significantly, compound 168, despite its high MIC values, showed a difference in growth inhibition between the $\mathrm{M}+$ strain and the Mnol strain. The compound shows a 2-fold difference in inhibition between the strains, with $\mathrm{M}+$ having a higher MIC. Overall, seven compounds showed some desirable activity (Table 2.4, Figure 2.8). The shift in MIC indicates catalytic inhibition of topoisomerase, either by preventing DNA binding or DNA cleavage. 
Table 2.4. MIC and $\mathrm{IC}_{50}$ values of top Specs compounds

\begin{tabular}{|c|c|c|c|c|c|}
\hline $\begin{array}{c}\text { Compound } \\
\text { number }\end{array}$ & SPECS ID\# & $\begin{array}{c}\text { EcTopI } \\
\text { Relaxation } \\
\text { Inhibition } \\
\left(\mathbf{I C}_{\mathbf{5 0}}, \boldsymbol{\mu M}\right)\end{array}$ & $\begin{array}{c}\text { MtbTopI } \\
\text { Relaxation } \\
\text { Inhibition } \\
\left.\mathbf{I}_{\mathbf{5 0}}, \boldsymbol{\mu M}\right)\end{array}$ & $\begin{array}{c}\text { M+ } \\
\text { Growth } \\
\text { Inhibition } \\
\mathbf{( M I C ,} \\
\boldsymbol{\mu M})\end{array}$ & $\begin{array}{c}\text { Mnol } \\
\text { Growth } \\
\text { Inhibition } \\
\text { (MIC, } \\
\boldsymbol{\mu M})\end{array}$ \\
\hline $\mathbf{3 2}$ & AP-970/42895169 & 500 & 500 & 50 & 50 \\
\hline $\mathbf{3 8}$ & AN-465/42889242 & 500 & 500 & 12.5 & 6.25 \\
\hline $\mathbf{9 1}$ & AL-182/11269031 & 62.5 & 62.5 & 400 & 400 \\
\hline $\mathbf{1 2 6}$ & AE-641/30177049 & 500 & n.d. & n.d. & n.d. \\
\hline $\mathbf{1 6 1}$ & AN-465/43411472 & 500 & 500 & 12.5 & 6.25 \\
\hline $\mathbf{1 6 4}$ & AN-465/43411478 & 500 & n.d. & n.d. & n.d. \\
\hline $\mathbf{1 6 8}$ & AH-262/08804012 & 31.3 & $15.7-31.3$ & 400 & 200 \\
\hline
\end{tabular}

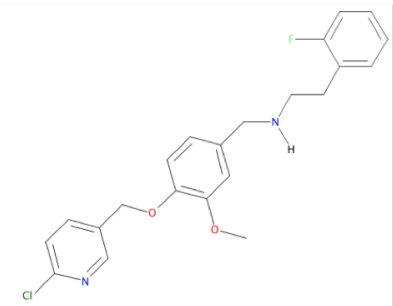

32

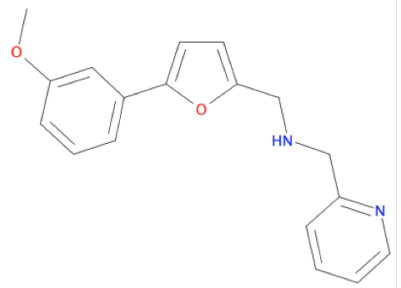

161

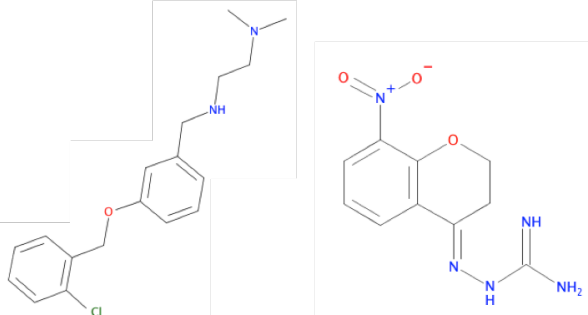

91

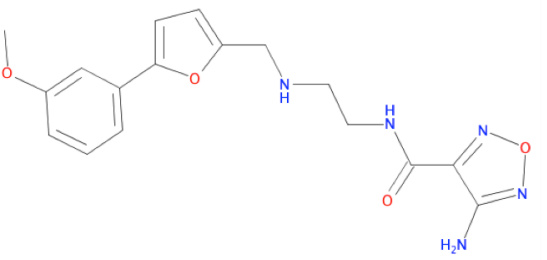

164

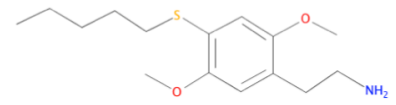

126

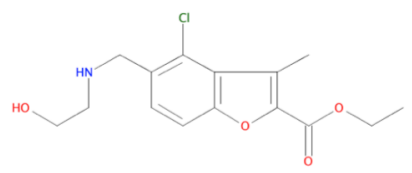

168

Figure 2.8. Structures of Specs compounds identified from in silico screening and in vitro MtbTopI assay

\section{CONCLUSION}

Virtual screening has been successfully used in the past to find novel inhibitors of various enzymes. Much work has been done with optimizing docking parameters, such that docking tools have become more reliable. To the best of my 
knowledge, this study of virtual screening against the crystal structure of MtbTopI is the first of its kind. Previously, homology models of MtbTopI have been used for virtual screening (Ekins et al., 2017). While homology models can be used as substitutes, there are differences when compared to the actual crystal structure. Here, the solved crystal structures for MtbTopI and EcTopI were used to conduct virtual screens.

In the main part of the study, an active site pocket in the DNA-binding region between domains D1 and D4 of MtTopI was targeted for in silico screening. The use of molecular dynamics further opened the DNA-binding pocket to allow compounds to bind much deeper inside the pocket. The initial docking study identified several Asinex compounds that all contained a common piperidine amide moiety that has not been seen previously in MtbTopI inhibitors. Examining the docking poses of these compounds showed that the sterically rigid amide motif may be interacting with key residues inside the pocket. These residues, specifically Arg167 and Glu115, are strictly conserved for catalysis in type IA topoisomerases, and they have been previously shown to interact with the DNA backbone. When the in silico screening was repeated on Chembridge compounds containing similar motifs, a high percentage of the compounds were found to inhibit MtbTopI relaxation activity. Selectivity was also maintained, as confirmed by the compounds' lack of inhibition of the human type IB topoisomerase.

The most potent enzyme inhibitor (compound 7) had an $\mathrm{IC}_{50}=2 \mu \mathrm{M}$. However, lack of potent whole-cell growth inhibition against M. smegmatis was an issue in many of the compounds. The antibacterial activity was improved in the 
presence of the efflux pump inhibitor thioridazine, and the observed MIC values were sensitive to the level of topoisomerase I present inside the cells. The shift in MIC indicates that topoisomerase I inhibition is at least partially responsible for the antibacterial activity.

In the screen against EcTopI, again, some enzyme inhibitors were discovered, however they were lacking in their antibacterial activity. Significantly, the compounds may have been able to inhibit EcTopI, but they were likely unable to penetrate the cell wall for an in vivo effect on E. coli. In both sets of virtual screens, the non-potent antibacterial activity must be improved. It is possible that future experiments may explore the piperidine amide motif found in the Asinex screen with improved side chains for better cellular penetration. Multiple studies have been published with various molecular characteristics thought to improve penetration, particularly in Gram-negative bacteria (Richter et al., 2017). Other pockets on the enzymes may be explored for virtual screening as well. 


\title{
IV. CHAPTER 3:
}

\section{SELECTIVITY OF ORGANOMETALLIC COMPLEXES AGAINST VARIOUS TOPOISOMERASE ENZYMES}

\begin{abstract}
Organometallic complexes have long been used as a source of antimicrobial and anticancer drugs. Many copper-containing complexes have been shown to target topoisomerases in human cancer cells as well. In the current chapter, several organometallic complexes were screened for inhibition of topoisomerases for use as anticancer and antimicrobial agents. Two copper complexes were found to inhibit human topoisomerases, specifically, they were found to be human topoisomerase II $\alpha$ poisons. The complexes trapped the topoisomerase on the DNA to prevent religation, causing an increase in the amount of cleavage product observed. They were specific inhibitors of the type II enzyme, as they were not potent inhibitors of the human type I topoisomerase. The complexes also had very potent anticancer properties, displaying cytotoxic effects on various colon and aggressive breast cancer cell lines. In addition to the copper complexes, several cobalt complexes were found to inhibit the bacterial type I topoisomerase more selectively than the human enzymes. All three of the cobalt complexes contained thiosemicarbazone ligands, and the most potent complex inhibited MtbTopI and EcTopI with an $\mathrm{IC}_{50}=0.8 \mu \mathrm{M}$. It was at least 4x more selective towards the bacterial enzyme than the human type I enzyme. The complex inhibited the enzyme by means of preventing DNA cleavage. It also was able to prevent the growth of various bacterial species. The present study indicates
\end{abstract}


that organometallic complexes can be a valuable tool when searching for novel topoisomerase inhibitors.

\section{INTRODUCTION}

Since the clinical success of cisplatin as an anticancer drug in the early $19^{\text {th }}$ century, there has been substantial effort to discover novel metal-based therapeutics. Cisplatin exerts its toxic effect by covalently binding to DNA, causing programmed cell death (Wong and Giandomenico, 1999). While binding to DNA is an effective way of killing cancer cells, it also leads to extensive unpleasant side effects for patients such as nausea, diarrhea, hair loss, and dehydration (Galanski et al., 2003). Resistance also decreases the usefulness of cisplatin and its derivatives. Ideally, novel metallo-drugs would interact with enzymes and protein targets, rather than DNA, as it is difficult to get much selectivity when the drug simply targets DNA. Metal complexes with labile ligands have been known to switch ligands, and can freely interact with protein residues (Che and Siu, 2010). Many transition metals such as gold, cobalt, iron, ruthenium, and copper have been studied for possible therapeutic effects, including anticancer and antimicrobial effects.

Several copper(II) complexes have been shown to inhibit human topoisomerase II $\alpha$ (Arjmand et al., 2011; Das et al., 2014; Duff et al., 2012). As human topoisomerase II $\alpha$ is overexpressed in many cancer cells, it is an attractive anticancer target, with existing drugs such as etoposide and doxorubicin (Jarvinen and Liu, 2006). However, many of these copper(II) complexes have not shown poison inhibition of human topoisomerase II $\alpha$, but rather catalytic inhibition, or else their 
mechanism of inhibition has not been mentioned at all. The discovery of a poison inhibitor is significant, because topoisomerase poisons are highly effective anticancer agents. Poison inhibitors cause the trapping of the covalent DNA-topoisomerase intermediate, and even just a small percentage of the trapped cleavage complex on chromosomal DNA is sufficient to initiate cancer cell death. In contrast, near complete inhibition of the catalytic activity of the target enzyme may be needed for a catalytic inhibitor of an essential enzyme to be effective in cancer cell growth inhibition (Nitiss, 2009).

While copper complexes have been studied before with regards to topoisomerases, less studied is the effect of cobalt(III) complexes on topoisomerases. There have been studies of cobalt complexes as antimicrobial agents, however, many of these studies do not identify a cellular target and rather simply state that the complexes are antimicrobial (Chai et al., 2017a; Chai et al., 2017b). Certainly, to the best of my knowledge, no cobalt(III) complexes have been used to target bacterial topoisomerases before.

In the current study, several copper and cobalt complexes were obtained from Dr. Alvin Holder at Old Dominion University. Many of the complexes contained thiosemicarbazones as ligands. Thiosemicarbazones have long been studied as anticancer ligands for transition metals, and they have been very successful in some cases (Zeglis et al., 2011). From the copper(II) complexes obtained from Dr. Holder, two were found to poison human topoisomerase II $\alpha$ and kill several types of cancer cells as well. Significantly, these complexes are the first to show measurable quantitative increases in the level of linear DNA cleavage product from trapped 
topoisomerase complexes, with specificity for the type II enzyme over type I. While the focus of the study is bacterial topoisomerase inhibitors, the discovery of novel human topoisomerase inhibitors is interesting as well, especially when compared to bacterial topoisomerase inhibition. More pertinent to the present study then is the comparison of several cobalt(III) complexes. Three cobalt(III) complex/ ligand pairs were studied and compared for their inhibitory effects on bacterial topoisomerase I. All three complexes are identical except for their modified versions of a thiosemicarbazone ligand. All of the complexes were more potent against the bacterial type I enzyme than against other topoisomerases.

The most potent complex showed an $\mathrm{IC}_{50}$ against MtbTopI and EcTopI of 0.8 $\mu \mathrm{M}$. The complexes were also able to prevent the growth of strains of M. smegmatis, as well as methicillin-resistant Staphylococcus aureus. In the strain of M. smegmatis overexpressing topoisomerase I, the MIC for two out of three complexes was raised. Overexpressing the target is expected to result in increased MIC values when the drug acts as a catalytic inhibitor, and indeed the most potent complex appears to exert its inhibitory effect by preventing DNA cleavage. These results indicate that cobalt complexes with thiosemicarbazone ligands may be an interesting new area in antimicrobial drug discovery.

\section{MATERIALS AND METHODS}

\section{Bacterial topoisomerase I relaxation inhibition assay}

The activity of bacterial topoisomerase I was assayed as described previously. Briefly, $10 \mathrm{ng}$ of the enzyme was combined with the compound of interest at varying 
concentrations in a buffer containing $10 \mathrm{mM}$ Tris ( $\mathrm{pH} 8.0), 50 \mathrm{mM} \mathrm{NaCl}, 0.1 \mathrm{mg} / \mathrm{mL}$ gelatin, and $0.5 \mathrm{mM} \mathrm{MgCl} 2.160 \mathrm{ng}$ of supercoiled $\mathrm{pBAD} /$ Thio plasmid DNA was added to the mixtures and the samples were then incubated for 30 minutes at $37^{\circ} \mathrm{C}$. After termination by the addition of an EDTA-stop buffer, the samples were loaded and run on a $1 \%$ agarose gel.

\section{DNA gyrase supercoiling inhibition assay}

The DNA gyrase inhibition assay was carried out as mentioned earlier. Briefly, $2 \mathrm{U}$ of the enzyme was mixed with $0.5 \mu \mathrm{L}$ of the compound dissolved in DMSO for the correct final concentration in a buffer provided by the manufacturer (35 mM Tris- $\mathrm{HCl}, 24 \mathrm{mM} \mathrm{KCl}, 4 \mathrm{mM} \mathrm{MgCl}$, 2 mM DTT, $1.75 \mathrm{mM}$ ATP, $5 \mathrm{mM}$ spermidine, $0.1 \mathrm{mg} / \mathrm{mL} \mathrm{BSA}$, and $6.5 \%$ glycerol). $300 \mathrm{ng}$ of relaxed covalently closed plasmid DNA was then added for a final volume of $20 \mu \mathrm{L}$. The samples were incubated for 30 minutes at $37^{\circ} \mathrm{C}$ before termination with an SDS stop buffer. The samples were loaded on a $1 \%$ agarose gel and analyzed.

\section{Human topoisomerase I relaxation inhibition assay}

The relaxation activity of human topoisomerase I (obtained from TopoGen) was assayed as described in previous chapters. Briefly, $160 \mathrm{ng}$ of supercoiled $\mathrm{pBAD} /$ Thio plasmid DNA was added to $0.5 \mathrm{U}$ of the enzyme containing the complexes at the desired concentrations dissolved in DMSO. The samples were suspended in a buffer containing $10 \mathrm{mM}$ Tris ( $\mathrm{pH} 8.0), 150 \mathrm{mM} \mathrm{NaCl}, 0.1 \%$ BSA, $0.1 \mathrm{mM}$ spermidine, and 5\% glycerol. The samples were then incubated for 30 
minutes at $37^{\circ} \mathrm{C}$ before being stopped by the addition of $4 \mu \mathrm{L}$ of a buffer containing $5 \%$ SDS, $0.25 \%$ bromophenol blue, and $25 \%$ glycerol. The samples were then loaded in a $1 \%$ agarose gel and run overnight at $25 \mathrm{~V}$. Upon completion, the gel was stained in ethidium bromide and photographed under UV light.

\section{Human topoisomerase II $\alpha$ relaxation inhibition assay}

The relaxation activity of human topoisomerase II $\alpha$ (obtained from TopoGen) was assayed by adding the indicated concentration of compound dissolved in DMSO to $160 \mathrm{ng}$ of purified supercoiled pBAD/Thio plasmid DNA. $2 \mathrm{U}$ of the enzyme was then added to the mixtures in an ATP-containing buffer provided by the manufacturer and the samples were incubated for 30 minutes at $37^{\circ} \mathrm{C}$. The reactions were stopped by the addition of $4 \mu \mathrm{L}$ of a buffer containing $5 \%$ SDS, $0.25 \%$ bromophenol blue, and $25 \%$ glycerol. The samples were then analyzed on $1 \%$ agarose gels and stained in ethidium bromide.

\section{Human topoisomerase II $\alpha$ religation inhibition assay}

The ability of the complexes to prevent human topoisomerase II $\alpha$ from religating the DNA (i.e., the ability to act as topoisomerase poisons) was assessed via agarose gel electrophoresis. $280 \mathrm{ng}$ of supercoiled pBAD/Thio plasmid DNA was used along with $5 \mathrm{U}$ of enzyme. The samples were incubated for 20 minutes at $37^{\circ} \mathrm{C}$ before adding $2 \mu \mathrm{L}$ of a stop solution containing $10 \%$ SDS and $20 \mathrm{mg} / \mathrm{mL}$ proteinase $\mathrm{K}$. The samples were then incubated further for 30 minutes at $37^{\circ} \mathrm{C}$. A loading buffer as described before was used. The samples were analyzed on a $1 \%$ agarose gel 
containing $0.5 \mu \mathrm{g} / \mathrm{mL}$ ethidium bromide, in a $1 \mathrm{x}$ TAE buffer containing ethidium bromide as well. The increased levels of cleavage products could be observed upon introduction to UV light (Sandhaus et al., 2016b).

\section{M. smegmatis growth inhibition assay}

Cultures were grown in Middlebrook $7 \mathrm{H} 9$ medium supplemented with $0.2 \%$ glycerol, $0.05 \%$ Tween 80 , and $10 \%$ ADN (albumin, dextrose, sodium chloride) for 1 day. $50 \mu / \mathrm{mL}$ hygromycin B was added to the overexpression strains. The cultures were then diluted 1:100 in the same medium without ADN and grown until the cells had reached the exponential phase $\left(\mathrm{OD}_{600}\right.$ between 0.6 and 0.8$)$. The cells were then adjusted to $\mathrm{OD}_{600}=0.5$ and diluted further $1: 10.50 \mu \mathrm{L}$ of the adjusted cells were added to clear-bottom 96-well plates containing $50 \mu \mathrm{L}$ of the compounds serially diluted in the same medium. The plates were grown at $37^{\circ} \mathrm{C}$ for 48 hours. Absorbance readings were taken every $\sim 4$ hours until the cells had grown to saturation $\left(\mathrm{OD}_{600}=\right.$ $1.5)$.

\section{S. aureus growth inhibition assay}

Single colonies were grown in lysogeny broth with $0.5 \mathrm{~g} / \mathrm{L} \mathrm{NaCl}$ (LBN) overnight until the cultures had reached saturation. The cells were adjusted to $\mathrm{OD}_{600}=$ 0.1 and then diluted 1:100. $50 \mu \mathrm{L}$ of the adjusted cells were then added to the clearbottom 96-well plates containing $50 \mu \mathrm{L}$ of the compounds serially diluted in the same medium. The plates were incubated for 24 hours at $37^{\circ} \mathrm{C}$ before the addition of $10 \mu \mathrm{L}$ of $0.02 \%$ resazurin (final concentration $=0.002 \%$ ) and further incubation for $4-6$ 
hours. The fluorescence was then measured with $\mathrm{Ex}=540 \mathrm{~nm}$ and $\mathrm{Em}=590 \mathrm{~nm}$. The MIC is recorded as the minimum compound concentration that can prevent $90 \%$ cell growth.

\section{MtbTopI-DNA binding gel shift assay}

The topoisomerase-DNA binding was studied in the presence of inhibiting compounds. The enzyme concentrations range from 0.1 pmole $(10 \mathrm{ng})$ to 1 pmole $(100 \mathrm{ng})$. The compound was added to the enzyme before 0.5 pmole of the labeled oligonucleotide STS-32 was added. The samples were incubated and loaded as mentioned earlier in previous chapters. The gels were dried and analyzed via Phosphor-Image analysis.

\section{MtbTopI-DNA cleavage inhibition assay}

The cleavage inhibition was assayed with ethidium bromide gels. The enzyme was added to a reaction buffer containing $10 \mathrm{mM}$ Tris (pH 8), $50 \mathrm{mM} \mathrm{NaCl}$, and 0.1 $\mathrm{mg} / \mathrm{mL}$ gelatin for a final enzyme concentration of $50 \mathrm{ng} /$ reaction. The compounds were then added to the enzyme mixture before the addition of $160 \mathrm{ng}$ of supercoiled $\mathrm{pBAD} /$ Thio plasmid DNA. The samples were incubated for 30 minutes at $37^{\circ} \mathrm{C}$ before the addition of $2.5 \mu \mathrm{L}$ of $10 \%$ SDS and $0.625 \mu \mathrm{L}$ of $20 \mathrm{mg} / \mathrm{mL}$ proteinase $\mathrm{K}$. The samples were further incubated for 1 hour. The samples were then loaded into a $1 \%$ agarose gel containing $0.5 \mu \mathrm{g} / \mathrm{mL}$ ethidium bromide. The gels were photographed under UV light. 


\section{RESULTS AND DISCUSSION}

\section{Copper complexes are potent and selective human topoisomerase II $\alpha$ poisons}
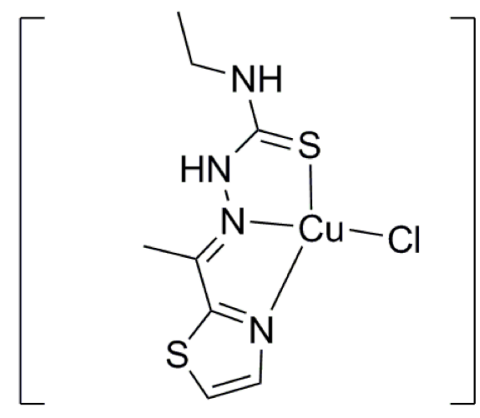

1
Cl $0.25 \mathrm{C}_{2} \mathrm{H}_{5} \mathrm{OH}$<smiles></smiles>

2

Figure 3.1. Structures of copper complexes: (left) [Cu(acetylethTSC)Cl] $\cdot 0.25 \mathrm{C}_{2} \mathrm{H}_{5} \mathrm{OH}$ (complex 1), (right) $\left[\mathrm{Cu}\left(\right.\right.$ quin) $\left.\mathrm{Cl}_{2}\right]$ (complex 2).

Two copper complexes were tested, [Cu(acetylethTSC)Cl] $0.25 \mathrm{C}_{2} \mathrm{H}_{5} \mathrm{OH}$ (where acetylethTSC $=$

(E)- $N$-ethyl-2-[1-(thiazol-2yl)ethylidene]hydrazinecarbothioamide), and $\left[\mathrm{Cu}(\right.$ quin $\left.) \mathrm{Cl}_{2}\right]$ (where quin $=$ trans-2(2'-quiolyl)methylene-3-quinuclidione). The complexes, 1 and 2 (Figure 3.1), respectively, were both found to inhibit the relaxation activity of human topoisomerase II $\alpha$ (Figure 3.2). Significantly, the ligands alone do not inhibit the enzyme's activity up to $100 \mu \mathrm{M}$, rather, it is the complete metal-ligand complex that is able to inhibit the enzyme. Inhibition of the relaxation activity of human topoisomerase I was not observed for complex 1, and complex $\mathbf{2}$ showed only very minor inhibition at $100 \mu \mathrm{M}$. The results indicate that the copper complexes are selective toward the type II enzyme. 
(A)

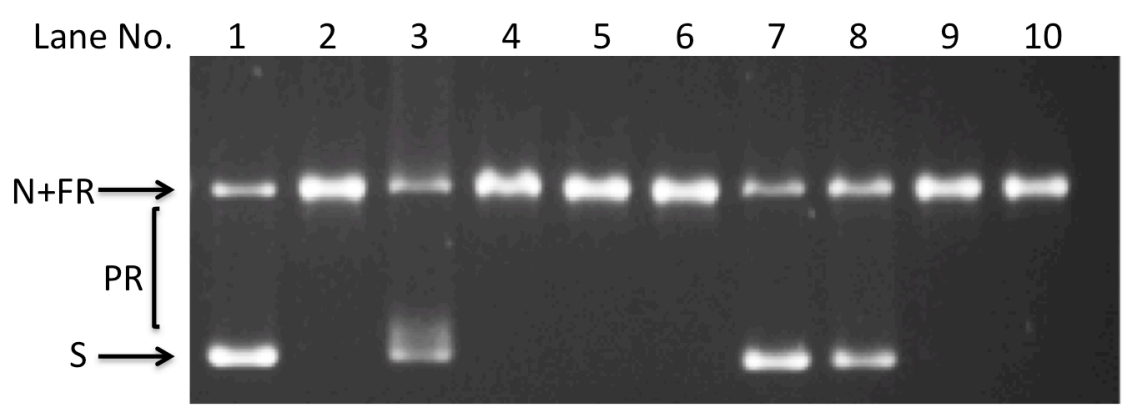

(B)

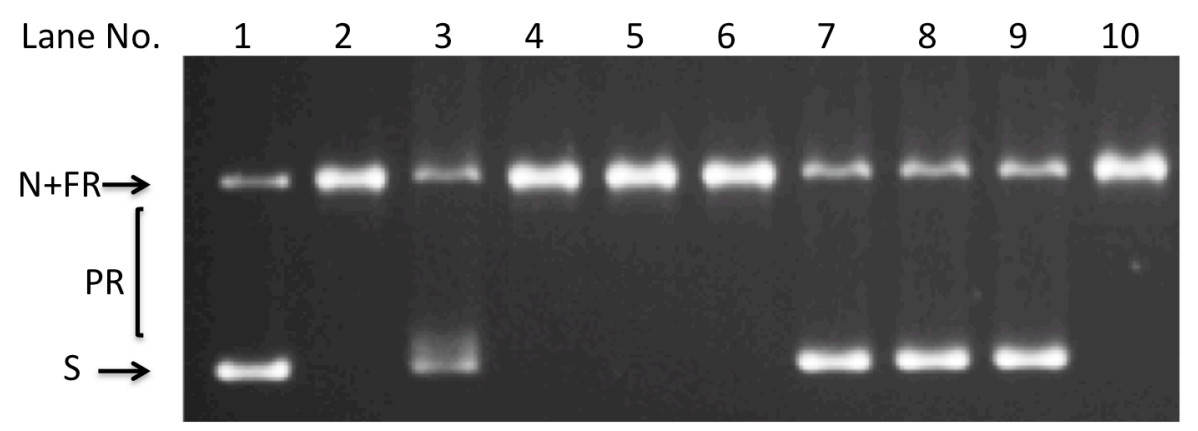

Figure 3.2. Inhibition of human topoisomerase II $\alpha$ relaxation activity by copper complexes: (A) Lane 1: negatively supercoiled $\mathrm{pBAD} /$ Thio plasmid DNA; Lane 2: DMSO as negative control; Lane 3: positive control $m$ AMSA at $75 \mu \mathrm{M}$; Lanes $4-6$ : 100,50 , and $25 \mu \mathrm{M}$ quin; Lanes $7-10: 100,50,25$, and $12.5 \mu \mathrm{M}$ [Cu(quin) $\left.\mathrm{Cl}_{2}\right]$. (B) Lane 1: negatively supercoiled pBAD/Thio plasmid DNA; Lane 2: DMSO as negative control; Lane 3: positive control mAMSA at $75 \mu \mathrm{M}$; Lanes 4-6: 100, 50, and $25 \mu \mathrm{M}$ acetylethTSC; Lanes $7-10: \quad 100, \quad 50, \quad 25, \quad$ and $12.5 \mu \mathrm{M}$ $\left[\mathrm{Cu}(\right.$ acetylethTSC) $\mathrm{Cl}] \mathrm{Cl} \cdot 0.25 \mathrm{C}_{2} \mathrm{H}_{5} \mathrm{OH}$. N: nicked, FR: fully relaxed, PR: partially relaxed, S: supercoiled.

In addition to inhibiting the relaxation activity of human topoisomerase II $\alpha$, complexes 1 and 2 also produced an increase in the linear DNA cleavage product (Figure 3.3) (Sandhaus et al., 2016b). The presence of linear DNA product indicates that the complex can act as a poison inhibitor. As mentioned earlier, poison inhibitors prevent DNA religation following cleavage by the topoisomerase enzyme. The DNAenzyme covalent intermediate persists, and as human topoisomerase II $\alpha$ is a type II 
enzyme that cleaves both strands, the DNA is trapped with a double-stranded break. Free copper, in the form of the copper(II) salt, $\mathrm{CuCl}_{2} \cdot 2 \mathrm{H}_{2} \mathrm{O}$, did not result in any significant increase in topoisomerase cleavage product. Likewise, the ligand alone had no effect on the level of cleavage product. Only the presence of the copper complexes increased the linear DNA product, and the levels for complex 1 were increased by 3- to 4-fold over the DMSO control lane. Complex 2 was less effective than complex 1 at accumulating linear DNA. 
(A)

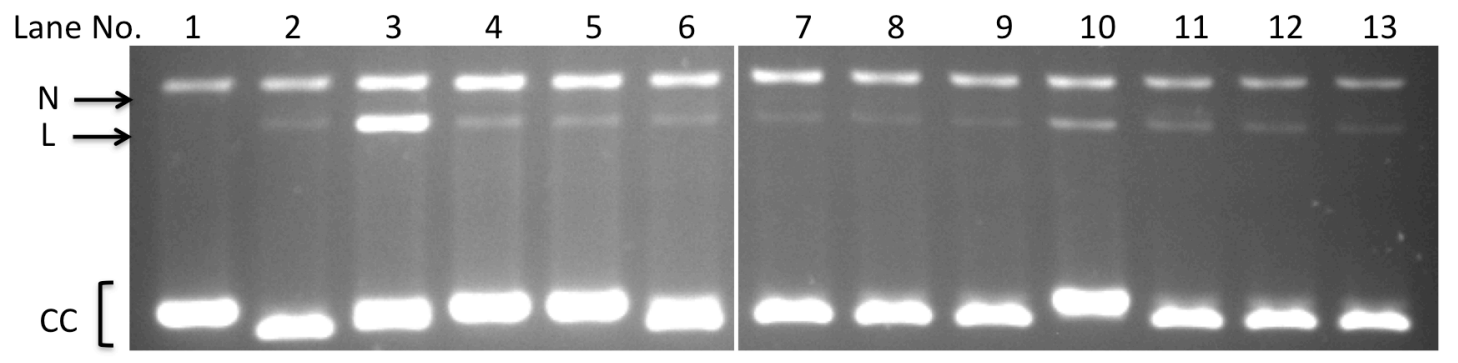

(B)

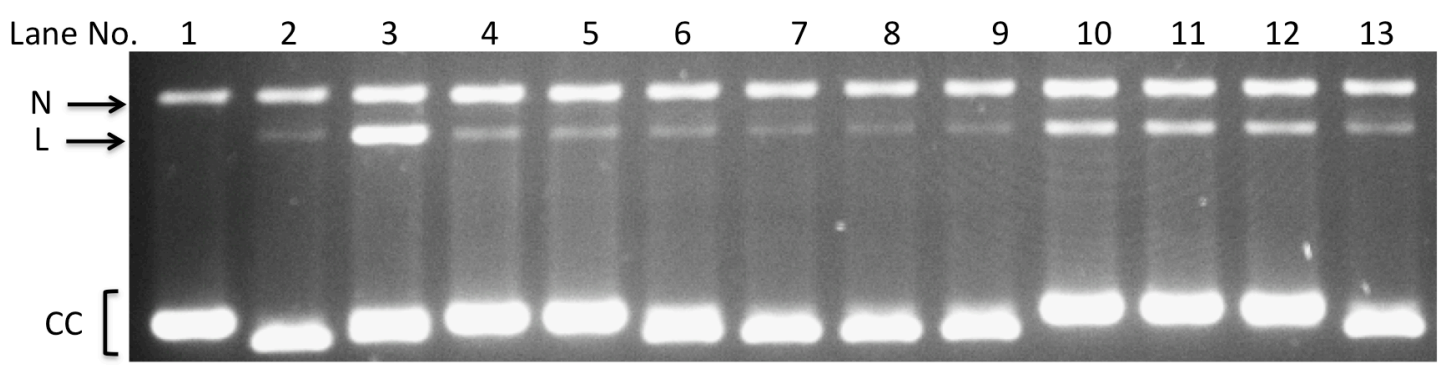

Figure 3.3. Increase in plasmid DNA cleavage by human topoisomerase II $\alpha$ in the presence of copper complexes: (A) Lane 1: negatively supercoiled pBAD/Thio plasmid DNA; Lane 2: DMSO as negative control; Lane 3: positive control $m$ AMSA at $25 \mu \mathrm{M}$; Lanes $4-6: 200,100$, and $50 \mu \mathrm{M} \mathrm{CuCl}_{2} \cdot 2 \mathrm{H}_{2} \mathrm{O}$; Lanes $7-9: 100,50$, and 25 $\mu \mathrm{M}$ quin; Lanes $10-13: 100,50,25$, and $12.5 \mu \mathrm{M}$ [Cu(quin) $\left.\mathrm{Cl}_{2}\right]$. The lanes shown here are from the same gel. (B) Lane 1: negatively supercoiled $\mathrm{pBAD} /$ Thio plasmid DNA; Lane 2: DMSO as negative control; Lane 3: positive control $m A M S A$ at $25 \mu \mathrm{M}$; Lanes $4-6: 200,100$, and $50 \mu \mathrm{M} \mathrm{CuCl}_{2} \cdot 2 \mathrm{H}_{2} \mathrm{O}$; Lanes $7-9: 100,50$, and $25 \mu \mathrm{M}$ acetylethTSC; Lanes $10-13: 100, \quad 50, \quad 25$, and $12.5 \mu \mathrm{M}$ $\left[\mathrm{Cu}(\right.$ acetylethTSC)Cl$] \mathrm{Cl} \cdot 0.25 \mathrm{C}_{2} \mathrm{H}_{5} \mathrm{OH}$. Electrophoresis buffer contained $0.5 \mu \mathrm{g} / \mathrm{mL}$ ethidium bromide. N: nicked, L: linear, CC: covalently closed. 
The novel effect is significant, since the accumulation of topoisomerase cleavage intermediates would be an important mode of action for anticancer activity. The copper(II) complex is the first of its kind to show measurable quantitative increases in the linear DNA cleavage product from human topoisomerase II $\alpha$. The quantitative increase is indicative of a poison mechanism of inhibition, as human topoisomerase II $\alpha$ poisons would cause an increase in double-stranded DNA breaks. The poison mechanism of action is particularly lethal, and may account for the antiproliferative effects exerted on various cancer cell lines. Dr. Holder's lab determined that complex 1 was more effective than etoposide against various colon cancer cell lines, and could even kill aggressive forms of breast cancer at concentrations ranging from 1 to $20 \mu \mathrm{M}$. Only a few stabilized covalent cleavage complexes could be enough to trigger the apoptosis pathway, and at $12.5 \mu \mathrm{M}$ complex 1 increased linear DNA by $30 \%$ over the DMSO control. 


\section{Comparison of cobalt(III) complexes as bacterial topoisomerase I inhibitors}
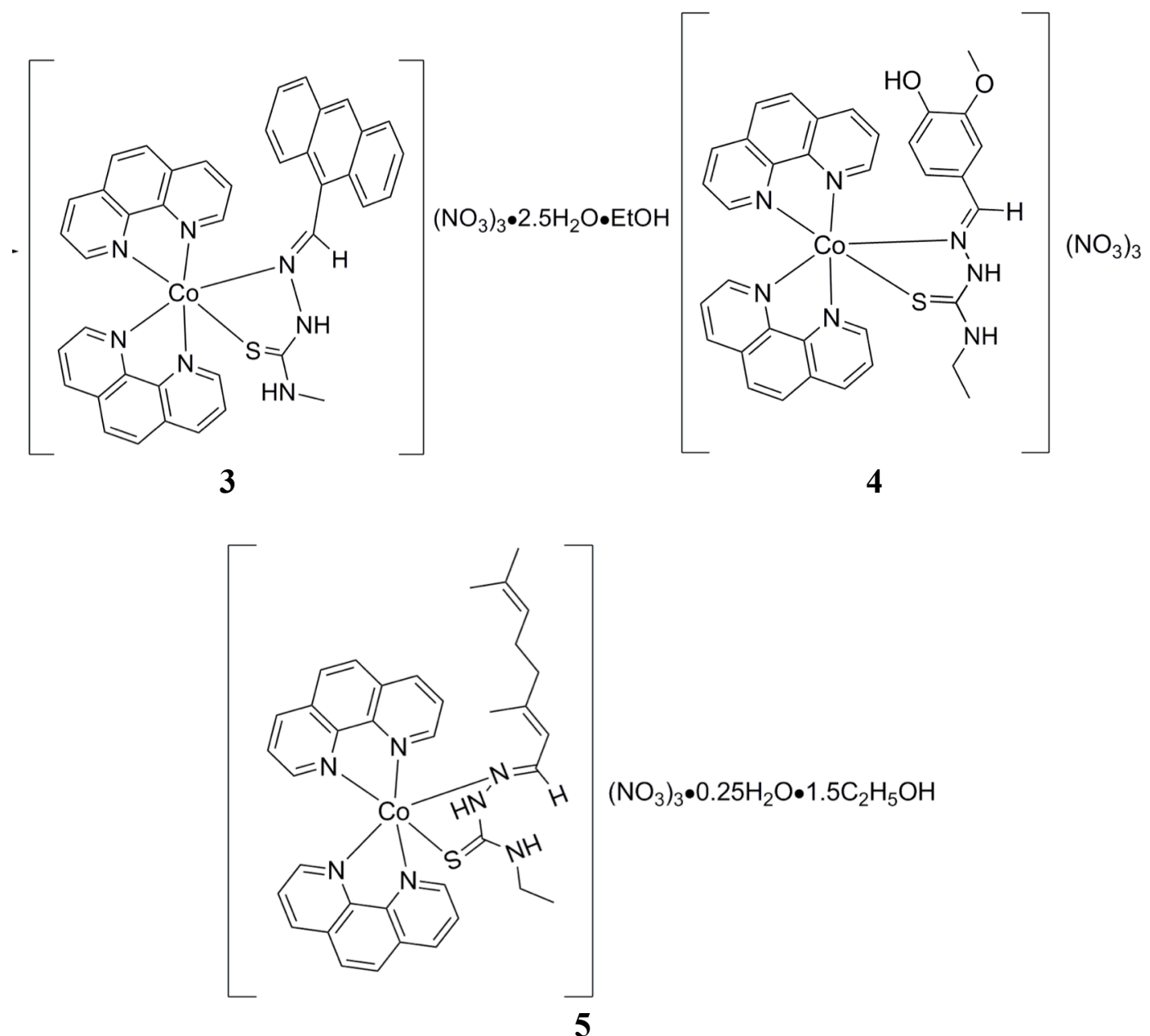

Figure 3.4. Structures of cobalt complexes: (top left) $\left[\mathrm{Co}(\text { phen })_{2}(\mathrm{MeATSC})\right]\left(\mathrm{NO}_{3}\right)_{3} \cdot 2.5 \mathrm{H}_{2} \mathrm{O} \cdot \mathrm{C}_{2} \mathrm{H}_{5} \mathrm{OH} \quad$ (complex 3), (top right) $\left[\mathrm{Co}(\text { phen })_{2}(\right.$ vanillinTSC $\left.)\right]\left(\mathrm{NO}_{3}\right)_{3} \quad$ (complex 4$), \quad$ (bottom) $\left[\mathrm{Co}(\text { phen })_{2}\left(\right.\right.$ citralEtTSC) $\left(\mathrm{NO}_{3}\right)_{3} \cdot 0.25 \mathrm{H}_{2} \mathrm{O} \cdot 1.5 \mathrm{C}_{2} \mathrm{H}_{5} \mathrm{OH}$ (complex 5).

As the aim of the current body of research was to discover novel inhibitors of bacterial topoisomerase I, the organometallic complexes were all tested for inhibition against the enzyme. Both the E. coli and M. tuberculosis topoisomerase I enzymes were tested against three complex/ ligand pairs containing $\mathrm{Co}(\mathrm{III})$ as their metal center (Figure 3.4). When the cobalt(III) complex, 
$\left[\mathrm{Co}(\text { phen })_{2}(\mathrm{MeATSC})\right]\left(\mathrm{NO}_{3}\right)_{3} \cdot 2.5 \mathrm{H}_{2} \mathrm{O} \cdot \mathrm{C}_{2} \mathrm{H}_{5} \mathrm{OH}$ (where phen $=1,10$ phenanthroline and MeATSC $=9$-anthraldehyde- N(4)-methylthiosemicarbazone), was tested against MtbTopI and EcTopI, it was found to be a very potent inhibitor of the bacterial enzyme relaxation activity. The complex (3) was able to inhibit both the enzymes' activity with an $\mathrm{IC}_{50}$ of $0.8 \mu \mathrm{M}$ (Figure 3.5). The MeATSC ligand alone had an $\mathrm{IC}_{50}=$ $25 \mu \mathrm{M}$ for both enzymes, indicating that it is not the ligand, but rather the complex, that exerts the potent inhibitory activity on the enzyme.

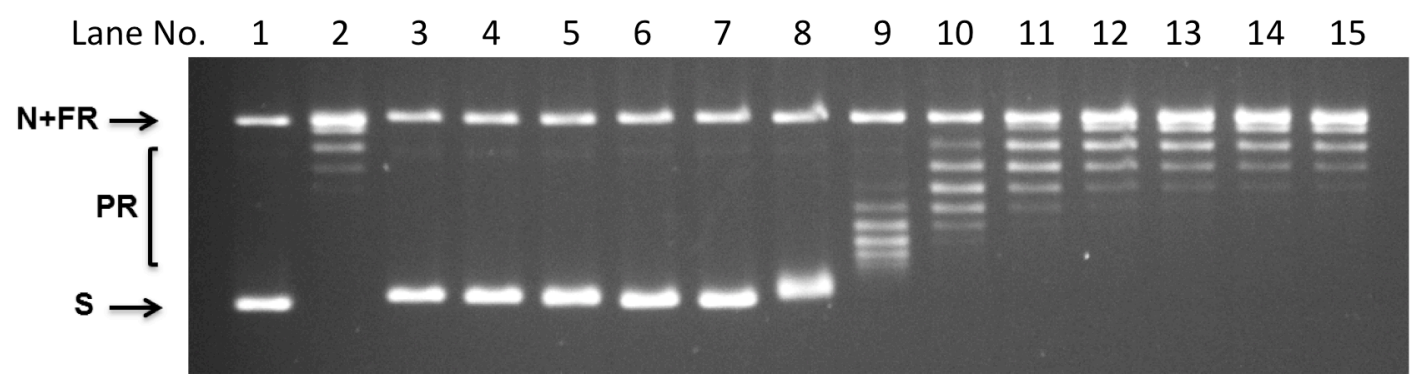

Figure 3.5. Cobalt(III) complex can inhibit EcTopI at low concentrations: Lane 1: negatively supercoiled $\mathrm{pBAD} /$ Thio plasmid DNA; Lane 2: DMSO as negative control; Lanes 3 - 15: 100, 50, 25, 12.5, 6.25, 3.13, 1.56, 0.8, 0.4, 0.2, 0.1, 0.05, and $0.025 \mu \mathrm{M}$ $\left[\mathrm{Co}(\text { phen })_{2}(\mathrm{MeATSC})\right]\left(\mathrm{NO}_{3}\right)_{3} \cdot 2.5 \mathrm{H}_{2} \mathrm{O} \cdot \mathrm{C}_{2} \mathrm{H}_{5} \mathrm{OH}$. N: nicked, FR: fully relaxed, PR: partially relaxed, S: supercoiled.

The complex 3 also inhibited human topoisomerase I at $6.25 \mu \mathrm{M}$, a 7.8-fold difference from the bacterial enzymes. Some inhibition was also seen against human topoisomerase II $\alpha$ at $25 \mu \mathrm{M}$, more than a 30-fold difference from the bacterial enzyme. The complex did not inhibit the activity of DNA gyrase up to $100 \mu \mathrm{M}$. These results indicate that the cobalt complex may be a powerful and selective inhibitor of bacterial type I topoisomerase.

Two other cobalt(III) complex/ ligand pairs were tested as well. The other cobalt complexes also contained the same phenanthroline and thiosemicarbazone 
ligands, but the thiosemicarbazones were modified. In the case of complex $\mathbf{3}$, anthracene was attached to the ligand. The other complexes included the attachment of o-vanillin (2-hydroxy-3-methoxybenzaldehyde) and citral (3,7-dimethyl-2,6octadienal) to the thiosemicarbazones. The activity of these complexes is not nearly as potent when compared to complex 3 (Table 3.1). [Co(phen $)_{2}\left(\right.$ vanillinTSC)] $\left(\mathrm{NO}_{3}\right)_{3}$ (complex 4) has an $\mathrm{IC}_{50}=50 \mu \mathrm{M}$ against the bacterial topoisomerase I, while $\left[\mathrm{Co}(\text { phen })_{2}(\right.$ citralEtTSC) $]\left(\mathrm{NO}_{3}\right)_{3} \cdot 0.25 \mathrm{H}_{2} \mathrm{O} \cdot 1.5 \mathrm{C}_{2} \mathrm{H}_{5} \mathrm{OH}\left(\right.$ complex 5) has an $\mathrm{IC}_{50}=25$ $\mu \mathrm{M}$. They are still more selective for the bacterial type I enzyme, with 2- to 4-fold differences in $\mathrm{IC}_{50}$ when compared to human topoisomerase I, human topoisomerase II $\alpha$, and DNA gyrase. The thiosemicarbazone ligands alone do not inhibit the enzymes up to $100 \mu \mathrm{M}$. As was seen with some of the Torrey Pines compounds from chapter 1, the large aromatic group increased the potency of the complex against bacterial type I topoisomerase.

All three cobalt complexes had comparable antibacterial activity against strains of M. smegmatis, with MIC values ranging from $4.7-18.8 \mu \mathrm{M}$. Complex 3 showed a 3-fold increase in MIC value when topoisomerase I is overexpressed in the $\mathrm{M}+$ strain, indicating that the topoisomerase I is a cellular target. Complexes $\mathbf{3}$ and $\mathbf{5}$ also showed growth inhibition of S. aureus, both of the wild-type (SA-14775) and methicillin-resistant strain MRSA (SA-BAA-44). 
Table 3.1. MIC and $\mathrm{IC}_{50}$ values of cobalt-thiosemicarbazone complexes

\begin{tabular}{|c|c|c|c|c|c|c|c|c|c|c|}
\hline Number & Formula & $\begin{array}{c}\text { EcTopI } \\
\text { Relaxation } \\
\text { Inhibition } \\
\left(\mathrm{IC}_{50}, \mu \mathrm{M}\right)\end{array}$ & $\begin{array}{c}\text { MtbTopI } \\
\text { Relaxation } \\
\text { Inhibition } \\
\left(\mathrm{IC}_{50}, \mu \mathrm{M}\right)\end{array}$ & $\begin{array}{c}\text { HTOPI } \\
\text { Relaxation } \\
\text { Inhibition } \\
\left(\mathrm{IC}_{50}, \mu \mathrm{M}\right)\end{array}$ & $\begin{array}{l}\text { HTOPII } \alpha \\
\text { Relaxation } \\
\text { Inhibition } \\
\left(\mathbf{I C}_{50}, \mu \mathrm{M}\right)\end{array}$ & $\begin{array}{c}\text { DNA Gyrase } \\
\text { Supercoiling } \\
\text { Inhibition } \\
\left(\mathrm{IC}_{\mathbf{5 0}}, \boldsymbol{\mu} \mathrm{M}\right)\end{array}$ & $\begin{array}{l}\text { M+ Growth } \\
\text { Inhibition } \\
(\mathrm{MIC}, \mu \mathrm{M})\end{array}$ & $\begin{array}{c}\text { Mnol } \\
\text { Growth } \\
\text { Inhibition } \\
(\mathrm{MIC}, \mu \mathrm{M})\end{array}$ & $\begin{array}{l}\text { SA-14775 } \\
\text { Growth } \\
\text { Inhibition } \\
(\mathrm{MIC}, \mu \mathrm{M})\end{array}$ & $\begin{array}{l}\text { SA-BAA-44 } \\
\text { Growth } \\
\text { Inhibition } \\
(\mathrm{MIC}, \mu \mathrm{M})\end{array}$ \\
\hline \multirow[t]{2}{*}{3} & {$\left[\mathrm{Co}(\text { phen })_{2}(\mathrm{MeATSC})\right]\left(\mathrm{NO}_{3}\right)_{3}$} & 0.8 & 0.8 & 6.25 & 25 & $>100$ & 18.75 & 6.25 & 25 & 50 \\
\hline & MeATSC & 25 & 25 & 50 & $>100$ & $>100$ & $>100$ & $>100$ & $>100$ & $>100$ \\
\hline \multirow[t]{2}{*}{4} & {$\left[\mathrm{Co}(\text { phen })_{2}(\right.$ vanillinTSC $\left.)\right]\left(\mathrm{NO}_{3}\right)_{3}$} & 50 & 50 & $>100$ & 100 & 100 & 6.25 & 6.25 & $>100$ & $>100$ \\
\hline & vanillinTSC & $>100$ & $>100$ & $>100$ & $>100$ & $>100$ & $>100$ & $>100$ & $>100$ & $>100$ \\
\hline \multirow[t]{2}{*}{5} & {$\left[\mathrm{Co}(\text { phen })_{2}(\right.$ citralEtTSC $\left.)\right]\left(\mathrm{NO}_{3}\right)_{3}$} & 25 & 25 & 100 & 100 & 100 & 9.38 & 4.69 & 25 & 50 \\
\hline & citralEtTSC & $>100$ & $>100$ & $>100$ & $>100$ & $>100$ & $>100$ & $>100$ & $>100$ & $>100$ \\
\hline
\end{tabular}




\section{Cobalt(III) complexes act as catalytic inhibitors to prevent DNA cleavage}

The mechanism of inhibition was further studied by gel shift and cleavage inhibition assays. Gel shift data indicates that complex 3 does not prevent the topoisomerase enzyme from binding to DNA. Rather, the complexes all appear to prevent DNA cleavage. At the $\mathrm{IC}_{50}$ of complex $\mathbf{3}$, the complex inhibits approximately 50\% DNA cleavage. Complex 5 appears to be a potent cleavage inhibitor as well-it inhibits $80 \%$ DNA cleavage at $2 \mathrm{x} \mathrm{IC}_{50}$. The complexes all had better cleavage inhibition than their ligands alone (Figure 3.6). These data support the assertion that these complexes act as catalytic inhibitors of bacterial topoisomerase I. 
a)

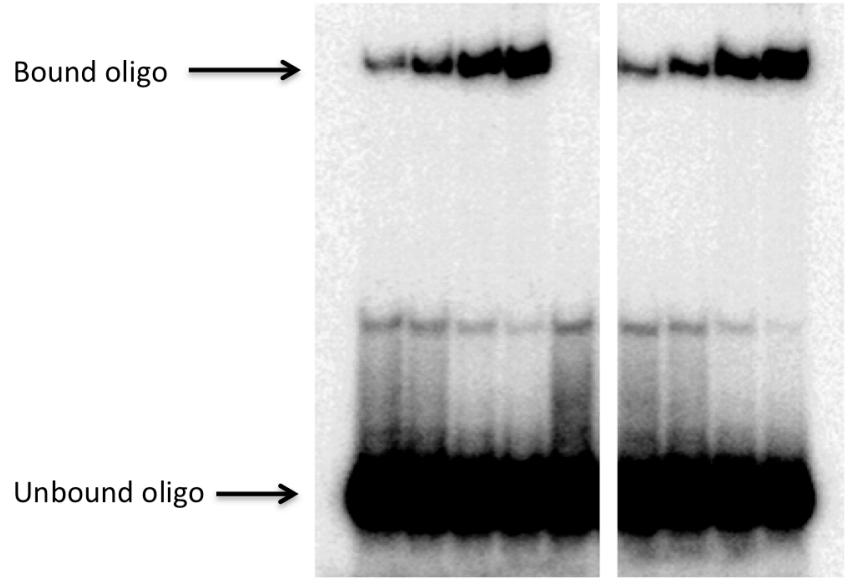

b)

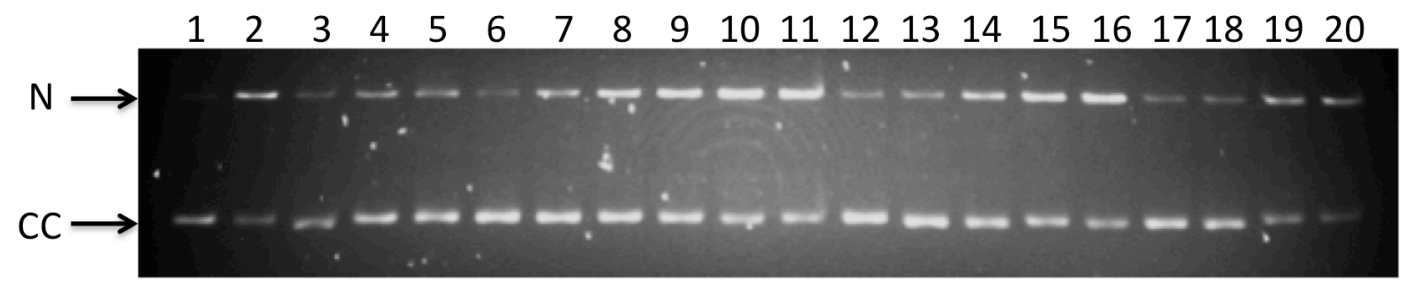

Figure 3.6. DNA cleavage by MtbTopI decreases in the presence of cobalt complexes: a) DNA binding is not affected by the presence of cobalt complexes. Lanes 1 - 4: MtbTopI at 0.1 pmole, 0.2 pmole, 0.5 pmole, and 0.75 pmole; Lane 5: STS-32 oligo without enzyme; Lanes 6-9: MtbTopI at same amounts as mentioned, but in the presence of $2 \mathrm{x} \mathrm{IC}_{50}\left[\mathrm{Co}(\mathrm{phen})_{2}(\mathrm{MeATSC})\right]\left(\mathrm{NO}_{3}\right)_{3} \cdot 2.5 \mathrm{H}_{2} \mathrm{O} \cdot \mathrm{C}_{2} \mathrm{H}_{5} \mathrm{OH}(1.6$ $\mu \mathrm{M})$. b) DNA cleavage is reduced in the presence of cobalt complexes. Lane 1: negatively supercoiled pBAD/Thio plasmid DNA; Lane 2: DMSO as negative control; Lane 3: addition of $0.5 \mathrm{mM} \mathrm{MgCl}_{2}$; Lanes 4 - 5: 100 and $50 \mu \mathrm{M}$ MeATSC; Lanes $6-$ 9: $6.3,3.1,1.6$, and $0.8 \mu \mathrm{M}\left[\mathrm{Co}(\text { phen })_{2}(\mathrm{MeATSC})\right]\left(\mathrm{NO}_{3}\right)_{3} \cdot 2.5 \mathrm{H}_{2} \mathrm{O} \cdot \mathrm{C}_{2} \mathrm{H}_{5} \mathrm{OH}$; Lanes 10 - 11: 100 and $50 \mu \mathrm{M}$ citralEtTSC; Lanes $12-14: 100,50$, and $25 \mu \mathrm{M}$ $\left[\mathrm{Co}(\text { phen })_{2}(\right.$ citralEtTSC)$)\left(\mathrm{NO}_{3}\right)_{3} \cdot 0.25 \mathrm{H}_{2} \mathrm{O} \cdot 1.5 \mathrm{C}_{2} \mathrm{H}_{5} \mathrm{OH}$; Lanes $15-16: 100$ and $50 \mu \mathrm{M}$ vanillinTSC; Lanes $17-20: 100, \quad 50, \quad 25, \quad$ and $12.5 \mu \mathrm{M}$ $\left[\mathrm{Co}(\text { phen })_{2}\right.$ (vanillinTSC) $]\left(\mathrm{NO}_{3}\right)_{3}$. Electrophoresis buffer contained $0.5 \mu \mathrm{g} / \mathrm{mL}$ ethidium bromide. $\mathrm{N}$ : nicked, $\mathrm{CC}$ : covalently closed.

\section{CONCLUSION}

Organometallic complexes have long been studied for their anticancer and antimicrobial properties. The popularity of cisplatin, a platinum-based anticancer 
drug, led to the desire for new organometallic drugs. Previously, many studies were carried out with copper, ruthenium, gold, and others. It was found that many copper complexes were targeting topoisomerases in human cancer cells, and were effective anticancer agents. In the present study, two copper complexes were found to inhibit the activity of human topoisomerase II $\alpha$. Not only were they effective at inhibiting the relaxation activity, but they also acted by preventing DNA religation. They were acting as topoisomerase poisons, and they increased the amount of linear DNA cleavage product. Topoisomerase poisons are very effective anticancer agents, as only a small number of trapped covalent DNA-enzyme intermediates is sufficient to initiate cell death. As such, these copper complexes were very potent anticancer agents. Complex 1 was even able to kill resistant strains of breast cancer.

Other than the copper complexes, there were three cobalt complexes as well. The cobalt complexes, when tested against bacterial topoisomerase I, were found to be extremely selective for the bacterial type I enzyme over any other type of topoisomerase. One complex, $\mathbf{3}$, was very potent as well, with an $\mathrm{IC}_{50}=0.8 \mu \mathrm{M}$. When complex 3 was tested against strains of M. smegmatis, it was found to be effective at preventing bacterial cell growth. Also, when topoisomerase I was overexpressed, the MIC increased 3-fold. The results indicate that complex 3 is targeting the bacterial topoisomerase, and the cellular mechanism of action is likely to be topoisomerase inhibition. The complex acted as a catalytic inhibitor, with decreased cleavage levels observed. Significantly for all three cobalt complexes, the ligands alone were not sufficient to prevent topoisomerase activity or bacterial cell growth. Rather, the complete complex was required for inhibition. 
All three cobalt complexes, as well as the more potent copper complex $\mathbf{1}$, contained a thiosemicarbazone ligand. Thiosemicarbazones are popular ligands because of their reported anticancer, antimicrobial, antimalarial, and antiviral properties. As was seen in the current study, the thiosemicarbazone ligands complexed with the transition metals made effective topoisomerase inhibitors. While poison inhibition was seen for human topoisomerase II $\alpha$, we have yet to observe poisoning of the bacterial topoisomerase I. The cobalt complexes were not acting as poisons, but rather as catalytic inhibitors. As was seen in both the first chapters, we were not successful in finding bacterial topoisomerase I poisons.

Further studies could be carried out on more cobalt(III)-thiosemicarbazone complexes. As we know these kinds of complexes can inhibit bacterial topoisomerase I, new ligands may be even more potent. The importance of the ligand could be studied as well by possibly obtaining a co-crystal, or by attempting to dock the complexes on the enzyme crystal structure. If we understood where the complex was interacting with the enzyme, we would be better able to determine how it exerts its inhibitory effect. Importantly, the cytotoxicity of these complexes should be determined as well. They may act as selective inhibitors of the bacterial enzyme, but whether they kill human cells must be determined. Good antibacterial candidates obviously must kill bacteria selectively over human cells. The discovery of cobalt complexes inhibiting bacterial topoisomerase I is novel, and may open the door for many new potential antibiotic treatments. 


\section{SUMMARY}

The present body of research was devoted to discovering novel inhibitors of bacterial topoisomerase I. Topoisomerase I is a valuable drug target for antibiotics, as there are no existing clinical drugs that specifically inhibit it. As drug resistance is a major global health problem, there has been a push to discover new antibiotics. Current antibiotics are no longer effective against many bacterial pathogens. Tuberculosis, staph infections, and even urinary tract infections are becoming more difficult to treat. The population most at risk is immunocompromised patients, like AIDS and cancer patients, but antimicrobial resistance affects everyone. Childbirth, surgery, and common infections would become life threatening. The use of a novel drug target, like topoisomerase I, is helpful, as there would not be resistance at the start of clinical use. Responsible use and prescription of new antibiotics would help keep resistance to a minimum as well.

Bacterial topoisomerase $\mathrm{I}$ is an enzyme which is responsible for relaxing supercoiled DNA inside the cell. The enzyme works by first binding a single strand of DNA, then creating a nick on the DNA and passing a separate strand through the nick to relax it, and then finally religating the DNA. Inhibitors may act by preventing any of the three steps: DNA binding, DNA cleavage, or DNA religation. Inhibition of either of the first two steps causes catalytic inhibition - the enzyme cannot perform any part of its function. Without a backup enzyme, the cell dies because functions such as DNA replication and transcription cannot proceed. Inhibition of the last step, DNA religation, is called topoisomerase poisoning - the enzyme cleaves the DNA, 
but cannot put it back together. The DNA is then trapped with breaks, causing apoptosis. There is only one type IA topoisomerase in mycobacteria, thus the enzyme is essential. Catalytic inhibition of the enzyme is sufficient to kill the cell. In Escherichia coli, catalytic inhibition is not sufficient, as there is another type IA topoisomerase that can take over for part of the lost activity. In E. coli then, poison inhibition of the enzyme may be necessary to initiate cell death.

Throughout the body of work, various techniques and approaches were utilized in order to find inhibitors of bacterial topoisomerase I. In chapter 1, mixturebased screening was used to go from a weak topoisomerase I inhibiting mixture to multiple potent inhibitors. In chapter 2, virtual screening was used to screen hundreds of thousands of compounds in compound libraries in order to find novel topoisomerase inhibitors. In chapter 3, novel organometallic complexes were tested to find metal-ligand complexes that inhibited bacterial topoisomerase I selectively. All three chapters yielded novel, potent, and selective inhibitors of bacterial topoisomerase I.

In chapter 1, we discovered a scaffold backbone that was able to inhibit bacterial topoisomerase I selectively over DNA gyrase. The scaffold was a polyamine backbone with three varying R-groups, containing thousands of individual compounds. Positional-scanning was then used to narrow down R-groups with the best tendency to promote potency and selectivity. It was discovered that large aromatic groups tended to yield low $\mathrm{IC}_{50}$ values against Escherichia coli topoisomerase I (EcTopI) and Mycobacterium tuberculosis topoisomerase I (MtbTopI). The individual compounds that were generated were selective and very 
potent, with a minimum $\mathrm{IC}_{50}=0.7 \mu \mathrm{M}$ against $\mathrm{MtbTopI}$. The compounds were also bactericidal against Mycobacterium smegmatis, with increased MIC values when the topoisomerase I was overexpressed. Further studies confirmed that the compounds were acting as catalytic inhibitors by preventing the topoisomerase from cleaving DNA. Significantly, the bactericidal activity was conserved in M. tuberculosis, and the compounds were not cytotoxic against human cells.

Improvements could be made in future mixture-based studies by beginning the screening with cell-based assays using strains expressing topoisomerase I at different levels alongside the enzyme-based assays. Using bacterial strains with various levels of topoisomerase I, selections could be made early on for poisoning activity and the ability to penetrate Gram-negatives, among others.

In chapter 2, we discovered a novel structural motif that aided in topoisomerase binding in silico and in vitro. Through virtual docking, we were able to screen hundreds of thousands of compounds against the bacterial topoisomerase I crystal structure. The most potent inhibitors, when tested in vitro, all contained a piperidine amide that appeared to aid in binding to the enzyme. The motif was interacting with residues that are highly conserved for catalysis, indicating that it may act as a lynchpin to hold the molecule in place. The side chains attached to the central motif varied. When the motif was used to carry out another round of virtual screens, the most potent inhibitor had an $\mathrm{IC}_{50}=2 \mu \mathrm{M}$ against MtbTopI. In the presence of an efflux pump inhibitor, the compounds also displayed increased MIC values when the topoisomerase I was overexpressed in M. smegmatis. The compounds were found to 
inhibit the enzyme's activity at a step following DNA binding, and their in vivo activity suggests they act as catalytic inhibitors.

Future virtual screens against bacterial topoisomerase I may attempt docking in other pockets not tried here. Modifications on the piperidine amide motif side chains may also improve the compounds' penetration ability for more potent antibacterial activity.

In chapter 3 , we discovered that new organometallic complexes containing copper and cobalt bound to thiosemicarbazone ligands were able to inhibit topoisomerase enzymes. The copper complexes acted as poisons for human topoisomerase II $\alpha$, and were effective anticancer agents. The cobalt complexes each contained a $\mathrm{Co}(\mathrm{III})$ center bound to a slightly-modified thiosemicarbazone ligand. When these complexes were tested against various topoisomerases, it was discovered that they were more selective for the type I bacterial enzyme, making them interesting potential antibacterial agents. The most potent complex had an $\mathrm{IC}_{50}=0.8 \mu \mathrm{M}$ against MtbTopI. Significantly, the ligands alone were unable to prevent relaxation, only the complex of metal and ligand could. Cell-based studies and enzyme-based studies indicated that the complexes were likely acting as catalytic inhibitors of the enzyme, preventing DNA cleavage.

Altering the thiosemicarbazone ligands to generate more diverse cobalt complexes would help with determining structure-activity relationships. If one of the complexes was so significantly more potent than the other two with only a small change to the overall complex, perhaps we could find others that are even more potent. Studies to determine where the complex interacts with the enzyme, such as 
virtual docking, co-crystallization, etc. would greatly help, as they could guide the synthesis of ligands more optimally shaped for binding the topoisomerase.

While the current body of work was successful in many ways, it was unable to find bacterial topoisomerase poisons. The lack of poisoning activity may be responsible for another deficiency, namely, the absence of broad-spectrum utility for most of the compounds. As mentioned, E. coli possesses a second type IA topoisomerase that can take on part of the role of EcTopI in the case of catalytic inhibition. Gram-negative bacteria are also famously difficult to penetrate because of their cell wall. Compounds with very potent inhibitory activity against purified EcTopI were ineffective against whole-cell E. coli, and that was likely the result of one of the above reasons. Going forward, screens could be conducted in ways to promote the discovery of topoisomerase poisons, such as beginning screens with cellbased assays against strains expressing different levels of topoisomerase I. If the presence of high levels of topoisomerase I causes more cell death, that is a strong indication that the compound may be acting as a topoisomerase poison. There are also many studies devoted to formulating predictive compound accumulation rules, to better allow compounds to penetrate and accumulate inside Gram-negative bacteria (Brown et al., 2014; O'Shea and Moser, 2008; Richter et al., 2017). Existing hits could possibly be modified to allow for broad-spectrum antibacterial activity.

Overall, the present work sought to discover novel inhibitors of bacterial topoisomerase I for potential antibiotic use, and I believe that goal has been met. Multiple potent and selective compounds were found using different approaches, and all of the structures are novel. They are widely varied, from polyamines to 
organometallics, and they are all effective at inhibiting the relaxation activity of bacterial topoisomerase I. Further effort is necessary for optimization and fine-tuning, but the results displayed in this body of work are a solid foundation for the targeting of bacterial topoisomerase I enzymes for novel antibiotic leads. 


\section{LIST OF REFERENCES}

Alanis, A. J. Resistance to Antibiotics: Are We in the Post-Antibiotic Era? Archives of Medical Research 2005, 36, 697-705.

Amaral, L.; Viveiros, M. Why thioridazine in combination with antibiotics cures extensively drug-resistant Mycobacterium tuberculosis infections. International Journal of Antimicrobial Agents 2012, 39, 376-380.

Aravind, L.; Leipe, D. D.; Koonin, E. V. Toprim--a conserved catalytic domain in type IA and II topoisomerases, DnaG-type primases, OLD family nucleases and RecR proteins. Nucleic Acids Research 1998, 26, 4205-4213.

Arjmand, F.; Sharma, G. C.; Muddassir, M.; Tabassum, S. Synthesis and enantiopreferential DNA-binding profile of late $3 \mathrm{~d}$ transition metal $\mathrm{R}$ - and $\mathrm{S}$ enantiomeric complexes derived from N,N-bis-(1-benzyl-2-ethoxyethane): Validation of R-enantiomer of copper(II) complex as a human topoisomerase II inhibitor. Chirality 2011, 23, 557-567.

Baell, J.; Walters, M. A. Chemistry: Chemical con artists foil drug discovery. Nature 2014, 513, 481-482, 483.

Baell, J. B.; Holloway, G. A. New Substructure Filters for Removal of Pan Assay Interference Compounds (PAINS) from Screening Libraries and for Their Exclusion in Bioassays. Journal of Medicinal Chemistry 2010, 53, 2719-2740.

Bajorath, J.; Decornez, H.; Furr, J. R.; Kitchen, D. B. Docking and scoring in virtual screening for drug discovery: methods and applications. Nature Reviews Drug Discovery 2004, 3, 935+.

Banda, S.; Tiwari, P. B.; Darici, Y.; Tse-Dinh, Y. Investigating direct interaction between Escherichia coli topoisomerase I and RecA. Gene 2016, 585, 65-70.

Bowling, J. J.; Shadrick, W. R.; Griffith, E. C.; Lee, R. E. In Going Small: Using Biophysical Screening to Implement Fragment Based Drug Discovery; Chen, T., Chai, S. C., Eds.; Special Topics in Drug Discovery; InTech: Rijeka, 2016; pp Ch. 02.

Branzei, D.; Foiani, M. Maintaining genome stability at the replication fork. Nature Reviews Molecular Cell Biology 2010, 11, 208-219.

Brown, D. G.; May-Dracka, T. L.; Gagnon, M. M.; Tommasi, R. Trends and exceptions of physical properties on antibacterial activity for Gram-positive and Gram-negative pathogens. Journal of Medicinal Chemistry 2014, 57, 10144-10161. 
Brown, E. D.; Wright, G. D. Antibacterial drug discovery in the resistance era. Nature 2016, 529, 336-343.

Carlet, J.; Jarlier, V.; Harbarth, S.; Voss, A.; Goossens, H.; Pittet, D. Ready for a world without antibiotics? The Pensieres Antibiotic Resistance Call to Action. Antimicrobial Resistance and Infection Control 2012, 1, 11-11.

Chai, L.; Mao, K.; Zhang, J.; Zhang, K.; Zhang, H. Synthesis, X-ray crystal structure, spectroscopic, electrochemical and antimicrobial studies of a new dinuclear cobalt(III) complex. Inorganica Chimica Acta 2017a, 457, 34-40.

Chai, L.; Tang, L.; Zhang, K.; Zhang, J.; Zhang, H. Two two-dimensional supramolecular copper(II) and cobalt(III) complexes derived from a new quinazolinetype ligand: Syntheses, structures, and spectral, thermal, electrochemical and antimicrobial activity studies. Applied Organometallic Chemistry 2017b, e3786-n/a.

Champoux, J. J. DNA Topoisomerases: Structure, Function, and Mechanism. Annual Review of Biochemistry 2001, 70, 369-413.

Che, C.; Siu, F. Metal complexes in medicine with a focus on enzyme inhibition. Current Opinions in Chemical Biology 2010, 14, 255-261.

Chen, S.; Wang, J. C. Identification of Active Site Residues in Escherichia coli DNA Topoisomerase I. Journal of Biological Chemistry 1998, 273, 6050-6056.

Cheng, B.; Cao, S.; Vasquez, V.; Annamalai, T.; Tamayo-Castillo, G.; Clardy, J.; Tse-Dinh, Y. Identification of Anziaic Acid, a Lichen Depside from Hypotrachyna sp., as a New Topoisomerase Poison Inhibitor. PLoS ONE 2013, 8, e60770.

Cheng, B.; Shukla, S.; Vasunilashorn, S.; Mukhopadhyay, S.; Tse-Dinh, Y. Bacterial Cell Killing Mediated by Topoisomerase I DNA Cleavage Activity. Journal of Biological Chemistry 2005, 280, 38489-38495.

Clatworthy, A. E.; Pierson, E.; Hung, D. T. Targeting virulence: a new paradigm for antimicrobial therapy. Nature Chemical Biology 2007, 3, 541-548.

Coelho, T.; Machado, D.; Couto, I.; Maschmann, R.; Ramos, D.; von Groll, A.; Rossetti, M. L.; Silva, P. A.; Viveiros, M. Enhancement of antibiotic activity by efflux inhibitors against multidrug resistant Mycobacterium tuberculosis clinical isolates from Brazil. Frontiers in Microbiology 2015, 6, 330.

Collignon, P.; Athukorala, P.; Senanayake, S.; Khan, F. Antimicrobial Resistance: The Major Contribution of Poor Governance and Corruption to This Growing Problem. PLoS ONE 2015, 10, e0116746. 
Cross, J. B.; Thompson, D. C.; Rai, B. K.; Baber, J. C.; Fan, K. Y.; Hu, Y.; Humblet, C. Comparison of Several Molecular Docking Programs: Pose Prediction and Virtual Screening Accuracy. Journal of Chemical Information and Modeling 2009, 49, 14551474.

Das, P.; Jain, C. K.; Dey, S. K.; Saha, R.; Chowdhury, A. D.; Roychoudhury, S.; Kumar, S.; Majumder, H. K.; Das, S. Synthesis, crystal structure, DNA interaction and in vitro anticancer activity of a $\mathrm{Cu}$ (ii) complex of purpurin: dual poison for human DNA topoisomerase I and II. RSC Advances 2014, 4, 59344-59357.

Drwal, M. N.; Griffith, R. Combination of ligand- and structure-based methods in virtual screening. Drug Discovery Today: Technologies 2013, 10, e395-e401.

Drwal, M. N.; Marinello, J.; Manzo, S. G.; Wakelin, L. P. G.; Capranico, G.; Griffith, R. Novel DNA Topoisomerase IIa Inhibitors from Combined Ligand- and StructureBased Virtual Screening. PLoS ONE 2014, 9, e114904.

Duff, B.; Reddy Thangella, V.; Creaven, B. S.; Walsh, M.; Egan, D. A. Anti-cancer activity and mutagenic potential of novel copper(II) quinolinone Schiff base complexes in hepatocarcinoma cells. European Journal of Pharmacology 2012, 689, 45-55.

Ekins, S.; Godbole, A. A.; Kéri, G.; Orfi, L.; Pato, J.; Bhat, R. S.; Verma, R.; Bradley, E. K.; Nagaraja, V. Machine learning and docking models for Mycobacterium tuberculosis topoisomerase I. Tuberculosis. 2017, 103, Supplement C, 52-60.

Fleming-Dutra, K. E.; Hersh, A. L.; Shapiro, D. J.; et al. Prevalence of inappropriate antibiotic prescriptions among us ambulatory care visits, 2010-2011. JAMA. 2016, 315(17), 1864-1873.

Friedman, N. D.; Temkin, E.; Carmeli, Y. The negative impact of antibiotic resistance. Clinical microbiology and infection 2016, 22(5), 416-422.

Galal, S. A.; Hegab, K. H.; Hashem, A. M.; Youssef, N. S. Synthesis and antitumor activity of novel benzimidazole-5-carboxylic acid derivatives and their transition metal complexes as topoisomerease II inhibitors. European Journal of Medicinal Chemistry 2010, 45, 5685-5691.

Galanski, M.; Arion, V. B.; Keppler, M. A. J. a. B. K. Recent Developments in the Field of Tumor-Inhibiting Metal Complexes. Current Pharmaceutical Design 2003, 9, 2078-2089.

Godbole, A. A.; Ahmed, W.; Bhat, R. S.; Bradley, E. K.; Ekins, S.; Nagaraja, V. Inhibition of Mycobacterium tuberculosis topoisomerase I by m-AMSA, a eukaryotic 
type II topoisomerase poison. Biochemical and Biophysical Research Communications 2014a, 446, 916-920.

Godbole, A. A.; Ahmed, W.; Bhat, R. S.; Bradley, E. K.; Ekins, S.; Nagaraja, V. Targeting Mycobacterium tuberculosis Topoisomerase I by Small-Molecule Inhibitors. Antimicrobial Agents and Chemotherapy 2014b, 59, 1549-1557.

Goossens, H.; Ferech, M.; Coenen, S.; Stephens, P.; European Surveillance of Antimicrobial Consumption Project Group Comparison of Outpatient Systemic Antibacterial Use in 2004 in the United States and 27 European Countries. Clinical Infectious Diseases 2007, 44(8), 1091-1095.

Hooper, D. C. Emerging Mechanisms of Fluoroquinolone Resistance. Emerging Infectious Diseases 2001, 7, 337-341.

Houghten, R. A.; Pinilla, C.; Giulianotti, M. A.; Appel, J. R.; Dooley, C. T.; Nefzi, A.; Ostresh, J. M.; Yu, Y.; Maggiora, G. M.; Medina-Franco, J.; Brunner, D.; Schneider, J. Strategies for the Use of Mixture-Based Synthetic Combinatorial Libraries: Scaffold Ranking, Direct Testing In Vivo, and Enhanced Deconvolution by Computational Methods. Journal of Combinatorial Chemistry 2008, 10, 3-19.

Hsiang, Y. H.; Hertzberg, R.; Hecht, S.; Liu, L. F. Camptothecin induces proteinlinked DNA breaks via mammalian DNA topoisomerase I. Journal of Biological Chemistry 1985, 260, 14873-14878.

Humnabadkar, V.; Madhavapeddi, P.; Basavarajappa, H.; Sheikh, M. G.; Rane, R.; Basu, R.; Verma, P.; Sundaram, A.; Mukherjee, K.; de Sousa, S. M. Assays, Surrogates, and Alternative Technologies for a TB Lead Identification Program Targeting DNA Gyrase ATPase. Journal of Biomolecular Screening 2015, 20, 265274.

Jarvinen, T. A. H.; Liu, E. T. Simultaneous amplification of HER-2 (ERBB2) and topoisomerase IIalpha (TOP2A) genes--molecular basis for combination chemotherapy in cancer. Current Cancer Drug Targets 2006, 6, 579-602.

Lagorce, D.; Sperandio, O.; Galons, H.; Miteva, M. A.; Villoutreix, B. O. FAFDrugs2: Free ADME/tox filtering tool to assist drug discovery and chemical biology projects. BMC Bioinformatics 2008, 9, 396.

Li, F.; Collins, J. G.; Keene, F. R. Ruthenium complexes as antimicrobial agents. Chemical Society Reviews 2015, 44, 2529-2542.

Liu, Y. Y.; Wang, Y.; Walsh, T. R.; Yi, L. X.; Zhang, R.; Spencer, J.; Doi, Y.; Tian, G.; Dong, B.; Huang, X.; Yu, L. F.; Gu, D.; Ren, H.; Chen, X.; Lv, L.; He, D.; Zhou, H.; Liang, Z.; Liu, J. H.; Shen, J. Emergence of plasmid-mediated colistin resistance 
mechanism MCR-1 in animals and human beings in China: a microbiological and molecular biological study. The Lancet Infectious Diseases 2016, 16(2), 161-168.

Morris, G. M.; Huey, R.; Lindstrom, W.; Sanner, M. F.; Belew, R. K.; Goodsell, D. S.; Olson, A. J. AutoDock4 and AutoDockTools4: Automated Docking with Selective Receptor Flexibility. Journal of computational chemistry 2009, 30, 2785-2791.

Nature Editorial The Antibiotic Alarm. Nature 2013, 495(141).

Nitiss, J. L. Targeting DNA topoisomerase II in cancer chemotherapy. Nature reviews Cancer 2009, 9, 338-350.

O'Shea, R.; Moser, H. E. Physicochemical properties of antibacterial compounds: implications for drug discovery. Journal of Medicinal Chemistry 2008, 51, 28712878.

Ott, I.; Gust, R. Non Platinum Metal Complexes as Anti-cancer Drugs. Archiv der Pharmazie (Weinheim) 2007, 340, 117-126.

Pinilla, C.; Appel, J. R.; Blanc P; Houghten, R. A. Rapid identification of high affinity peptide ligands using positional scanning synthetic peptide combinatorial libraries. Biotechniques 1992, 13(6), 901-905.

Pinilla, C.; Appel, J. R.; Borras, E.; Houghten, R. A. Advances in the use of synthetic combinatorial chemistry: Mixture-based libraries. Nature Medicine 2003, 9, 118-122.

Poirel, L.; Kieffer, N.; Liassine, N.; Thanh, D.; Nordmann, P. Plasmid-mediated carbapenem and colistin resistance in a clinical isolate of Escherichia coli. The Lancet Infectious Diseases 2016, 16, 281.

Pommier, Y. Drugging Topoisomerases: Lessons and Challenges. ACS chemical biology 2013, 8, 82-95.

Pommier, Y.; Huang, S. N.; Gao, R.; Das, B. B.; Murai, J.; Marchand, C. TyrosylDNA-phosphodiesterases (TDP1 and TDP2). DNA repair 2014, 19, 114-129.

Pommier, Y.; Leo, E.; Zhang, H.; Marchand, C. DNA Topoisomerases and Their Poisoning by Anticancer and Antibacterial Drugs. Chemical Biology 2010, 17, 421433.

Prutz, W. A. Reduction of resazurin by glutathione activated by sulfanes and selenite. Journal of the Chemical Society, Chemical Communications 1994, 1639-1640.

Ravishankar, S.; Ambady, A.; Awasthy, D.; Mudugal, N. V.; Menasinakai, S.; Jatheendranath, S.; Guptha, S.; Sharma, S.; Balakrishnan, G.; Nandishaiah, R.; 
Ramachandran, V.; Eyermann, C. J.; Reck, F.; Rudrapatna, S.; Sambandamurthy, V. K.; Sharma, U. K. Genetic and chemical validation identifies Mycobacterium tuberculosis topoisomerase I as an attractive anti-tubercular target. Tuberculosis. 2015, 95(5), 589-598.

Richter, M. F.; Drown, B. S.; Riley, A. P.; Garcia, A.; Shirai, T.; Svec, R. L.; Hergenrother, P. J. Predictive compound accumulation rules yield a broad-spectrum antibiotic. Nature. 2017, 545, 299-304.

Rideout, M. C.; Boldt, J. L.; Vahi-Ferguson, G.; Salamon, P.; Nefzi, A.; Ostresh, J. M.; Giulianotti, M.; Pinilla, C.; Segall, A. M. Potent antimicrobial small molecules screened as inhibitors of tyrosine recombinases and Holliday junction-resolving enzymes. Molecular Diversity 2011, 15, 989.

Sandhaus, S.; Annamalai, T.; Welmaker, G.; Houghten, R. A.; Paz, C.; Garcia, P. K.; Andres, A.; Narula, G.; Rodrigues Felix, C.; Geden, S.; Netherton, M.; Gupta, R.; Rohde, K. H.; Giulianotti, M. A.; Tse-Dinh, Y. Small-Molecule Inhibitors Targeting Topoisomerase I as Novel Antituberculosis Agents. Antimicrobial Agents and Chemotherapy 2016a, 60, 4028-4036.

Sandhaus, S.; Taylor, R.; Edwards, T.; Huddleston, A.; Wooten, Y.; Venkatraman, R.; Weber, R. T.; González-Sarrías, A.; Martin, P. M.; Cagle, P.; Tse-Dinh, Y.; Beebe, S. J.; Seeram, N.; Holder, A. A. A novel copper(II) complex identified as a potent drug against colorectal and breast cancer cells and as a poison inhibitor for human topoisomerase II $\alpha$. Inorganic Chemistry Communications 2016b, 64, 45-49.

Sawyer, J. S.; Anderson, B. D.; Beight, D. W.; Campbell, R. M.; Jones, M. L.; Herron, D. K.; Lampe, J. W.; McCowan, J. R.; McMillen, W. T.; Mort, N.; Parsons, S.; Smith, E. C. R.; Vieth, M.; Weir, L. C.; Yan, L.; Zhang, F.; Yingling, J. M. Synthesis and Activity of New Aryl- and Heteroaryl-Substituted Pyrazole Inhibitors of the Transforming Growth Factor- $\hat{I}^{2}$ Type I Receptor Kinase Domain. Journal of Medicinal Chemistry 2003, 46, 3953-3956.

Schames, J. R.; Henchman, R. H.; Siegel, J. S.; Sotriffer, C. A.; Ni, H.; McCammon, J. A. Discovery of a Novel Binding Trench in HIV Integrase. Journal of Medicinal Chemistry 2004, 47, 1879-1881.

Shiloh, M. U.; DiGiuseppe Champion, P. A. To catch a killer. What can mycobacterial models teach us about Mycobacterium tuberculosis pathogenesis? Current Opinion in Microbiology 2010, 13, 86-92.

Singh, J.; Chuaqui, C. E.; Boriack-Sjodin, P. A.; Lee, W.; Pontz, T.; Corbley, M. J.; Cheung, H. -.; Arduini, R. M.; Mead, J. N.; Newman, M. N.; Papadatos, J. L.; Bowes, S.; Josiah, S.; Ling, L. E. Successful shape-Based virtual screening: The discovery of 
a potent inhibitor of the type I TGF $\beta$ receptor kinase (T $\beta$ RI). Bioorganic \& Medicinal Chemistry Letters 2003, 13, 4355-4359.

Sliwoski, G.; Kothiwale, S.; Meiler, J.; Lowe, E. W. Computational Methods in Drug Discovery. Pharmacology Review 2013, 66, 334.

Stupina, V. A.; Wang, J. C. Viability of Escherichia coli topA Mutants Lacking DNA Topoisomerase I. Journal of Biological Chemistry 2005, 280, 355-360.

Tabassum, S.; Afzal, M.; Arjmand, F. New modulated design, docking and synthesis of carbohydrate-conjugate heterobimetallic $\mathrm{Cu}(\mathrm{II}) / \mathrm{Sn}(\mathrm{IV})$ complex as potential topoisomerase II inhibitor: In vitro DNA binding, cleavage and cytotoxicity against human cancer cell lines. European Journal of Medicinal Chemistry 2014a, 74, 694702.

Tabassum, S.; Zaki, M.; Afzal, M.; Arjmand, F. Synthesis and characterization of $\mathrm{Cu}(\mathrm{II})$-based anticancer chemotherapeutic agent targeting topoisomerase IIa: In vitro DNA binding, pBR322 cleavage, molecular docking studies and cytotoxicity against human cancer cell lines. European Journal of Medicinal Chemistry 2014b, 74, 509523.

Tan, K.; Cao, N.; Cheng, B.; Joachimiak, A.; Tse-Dinh, Y. Insights from the Structure of Mycobacterium tuberculosis Topoisomerase I with a Novel Protein Fold. Journal of Molecular Biology 2016, 428, 182-193.

Tan, K.; Zhou, Q.; Cheng, B.; Zhang, Z.; Joachimiak, A.; Tse-Dinh, Y. Structural basis for suppression of hypernegative DNA supercoiling by E. coli topoisomerase I. Nucleic Acids Res. 2015, 43(22), 11031-11046.

Tse-Dinh, Y. Targeting bacterial topoisomerase I to meet the challenge of finding new antibiotics. Future medicinal chemistry 2015, 7, 459-471.

Tse-Dinh, Y. Bacterial topoisomerase I as a target for discovery of antibacterial compounds. Nucleic Acids Research 2008, 37, 731-737.

Tse-Dinh, Y. C. Zinc (II) coordination in Escherichia coli DNA topoisomerase I is required for cleavable complex formation with DNA. Journal of Biological Chemistry 1991, 266, 14317-14320.

Van Drie, J. H. Computer-aided drug design: the next 20 years. Journal of ComputerAided Molecular Design 2007, 21, 591-601.

Ventola, C. L. The Antibiotic Resistance Crisis: Part 1: Causes and Threats. Pharmacology and Therapeutics 2015, 40, 277-283. 
Viard, T.; de la Tour, C. B. Type IA topoisomerases: A simple puzzle? Biochimie 2007, 89, 456-467.

Vos, S. M.; Tretter, E. M.; Schmidt, B. H.; Berger, J. M. All tangled up: how cells direct, manage and exploit topoisomerase function. Nature Reviews Molecular Cell Biology 2011, 12, 827-841.

Wang, J. C. Cellular roles of DNA topoisomerases: a molecular perspective. Nature Reviews Molecular Cell Biology 2002, 3, 430+.

Wang, J. C. DNA Topoisomerases. Annual Review of Biochemistry 1996, 65, 635692.

Wang, J. C. Interaction between DNA and an Escherichia coli protein $\omega$. Journal of Molecular Biology 1971, 55, 523-IN16.

Wong, E.; Giandomenico, C. M. Current Status of Platinum-Based Antitumor Drugs. Chemical Reviews 1999, 99, 2451-2466.

World Health Organization Antimicrobial Resistance: Fact Sheet. http://www.who.int/mediacentre/factsheets/antibiotic-resistance/en/ (accessed July 11, 2017).

World Health Organization Global Tuberculosis Report. http://www.who.int/tb/publications/global_report/en/(accessed July 11, 2017).

World Health Organization Antimicrobial Resistance: United Nations high-level meeting on antimicrobial resistance. http://www.who.int/antimicrobialresistance/events/UNGA-meeting-amr-sept2016/en/ (accessed September 25, 2017).

Zeglis, B. M.; Divilov, V.; Lewis, J. S. Role of Metalation in the Topoisomerase IIa Inhibition and Antiproliferation Activity of a Series of a-Heterocyclic-N4-Substituted Thiosemicarbazones and Their $\mathrm{Cu}(\mathrm{II})$ Complexes. Journal of Medicinal Chemistry 2011, 54, 2391-2398.

Zhang, Z.; Cheng, B.; Tse-Dinh, Y. Crystal structure of a covalent intermediate in DNA cleavage and rejoining by Escherichia coli DNA topoisomerase I. Proceedings of the National Academy of Sciences 2011, 108, 6939-6944.

Zhu, C.; Qi, H.; Tse-Dinh, Y. Mutation in Cys662 of Escherichia coli DNA Topoisomerase I Confers Temperature Sensitivity and Change in DNA Cleavage Selectivity. Journal of Molecular Biology 1995, 250, 609-616. 
Zhu, C.; Roche, C. J.; Tse-Dinh, Y. Effect of Mg(II) Binding on the Structure and Activity of Escherichia coli DNA Topoisomerase I. Journal of Biological Chemistry 1997, 272, 16206-16210.

Zhu, C.; Roche, C. J.; Papanicolaou, N.; DiPietrantonio, A.; Tse-Dinh, Y. Sitedirected mutagenesis of conserved aspartates, glutamates, and arginines in the active site region of Escherichia coli DNA topoisomerase I. Journal of Biological Chemistry 1998, 273, 8783-8789.

Zhu, C.; Tse-Dinh, Y. Overexpression and purification of bacterial DNA topoisomerase I. DNA topoisomerase protocols. Methods in molecular biology ${ }^{\mathrm{TM}}$ 1999, vol 94, Humana Press. 
VITA

\section{SHAYNA SANDHAUS}

2013

B.A. Chemistry

Summa Cum Laude and Phi Beta Kappa

Florida International University

Miami, Florida

2015

Biomedical Research Initiative Summer Research

Award

Florida International University

Miami, Florida

2016

M.S. Chemistry

Florida International University

Miami, Florida

2017

Doctoral Candidate and FIU RISE Research Fellow

Florida International University

Miami, Florida

\section{PUBLICATIONS \& PRESENTATIONS}

Cheng B, Annamalai T, Sandhaus S, Bansod P, Tse-Dinh YC. Inhibition of Zn(II) Binding Type IA Topoisomerases by Organomercury Compounds and $\mathrm{Hg}(\mathrm{II})$. PLoS ONE 2015, 10, e0120022.

Feng L, Maddox MM, Alam MZ, Tsutsumi LS, Narula G, Bruhn DF, Wu X, Sandhaus S, Lee RB, Simmons CJ, Tse-Dinh YC, Hurdle JG, Lee RE, Sun D. Synthesis, Structure-Activity Relationship Studies, and Antibacterial Evaluation of 4Chromanones and Chalcones, as Well as Olympicin A and Derivatives. J. Med. Chem. 2014, 57, 8398-8420.

Sandhaus S, Annamalai T, Welmaker G, Houghten RA, Paz C, Garcia PK, Andres A, Narula G, Felix CR, Geden S, Netherton M, Gupta R, Rohde KH, Giulianotti MA, Tse-Dinh Y-C. Small-molecule inhibitors targeting topoisomerase I as novel antituberculosis agents. Antimicrob Agents Chemother 2016, 60:4028-4036.

Sandhaus S, Taylor R, Edwards T, Huddleston A, Wooten Y, Venkatraman R, Weber RT, González-Sarrías A, Martin PM, Cagle P, Tse-Dinh, YC, Beebe SJ, Seeram N, Holder AA. A novel copper(II) complex identified as a potent drug against colorectal and breast cancer cells and as a poison inhibitor for human topoisomerase II $\alpha$. Inorganic Chemistry Communications 2016, 64, 45-49. 
Sandhaus S, Tse-Dinh YC. Mixture-based Drug Discovery and Targeting Bacterial Topoisomerase I Enzymes for Novel Antibiotics. Oral presentation: 92nd Florida Annual Meeting and Exposition 2017.

*Sandhaus S, Tse-Dinh YC. Drug Candidate Discovery: Targeting Bacterial Topoisomerase I Enzymes for Novel Antibiotic Leads. Oral presentation: Graduate Student Appreciation Week, FIU 2017.

Sandhaus S, Tse-Dinh YC. Drug Candidate Discovery: Targeting Bacterial Topoisomerase I Enzymes for Novel Antibiotic Leads. Poster: ASM Microbe 2016.

*Sandhaus S, Tse-Dinh YC. In silico Docking and Targeting Bacterial Topoisomerase I Enzymes for New Antibiotic Leads. Oral presentation: $18^{\text {th }}$ Annual Biomedical \& Comparative Immunology Symposium, FIU 2016.

$* 1^{\text {st }}$ place Oral Presentation Award 